\title{
DARHT 2 kA Cathode Development
}

\author{
F. M. Bieniosek1, E. Henestroza1, T. Houck2, J.W. Kwan1, \\ M. Leitner1, G. Miram4, \\ B. Prichard3, P.K. Roy1, W. Waldron1, G. Westenskow2, S. \\ $\mathrm{Yu} 4$
}

1LBNL, 2 LLNL, 3SAIC, 4Retired

Accelerator Fusion Research Division

Ernest Orlando Lawrence Berkeley National Laboratory

University of California

Berkeley, California 94720

March 2009

This work was supported by the Director, Office of Science, Office of Fusion Energy Sciences, of the U.S. Department of Energy under Contract No. DE-AC0205CH11231. 


\section{DARHT 2 kA Cathode Development}

F. M. Bieniosek ${ }^{1}$, E. Henestroza ${ }^{1}$, T. Houck ${ }^{2}$, J.W. Kwan', M. Leitner ${ }^{1}$, G. Miram B. Prichard ${ }^{3}$, P.K. Roy ${ }^{1}$, W. Waldron ${ }^{1}$, G. Westenskow ${ }^{2}$, S. Y $\mathbf{u}^{4}$

${ }^{1}$ LBNL, ${ }^{2}$ LLNL, ${ }^{3}$ SAIC, ${ }^{4}$ Retired

March 9, 2009 
This document was prepared as an account of work sponsored by the United States Government. While this document is believed to contain correct information, neither the United States Government nor any agency thereof, nor The Regents of the University of California, nor any of their employees, makes any warranty, express or implied, or assumes any legal responsibility for the accuracy, completeness, or usefulness of any information, apparatus, product, or process disclosed, or represents that its use would not infringe privately owned rights. Reference herein to any specific commercial product, process, or service by its trade name, trademark, manufacturer, or otherwise, does not necessarily constitute or imply its endorsement, recommendation, or favoring by the United States Government or any agency thereof, or The Regents of the University of California. The views and opinions of authors expressed herein do not necessarily state or reflect those of the United States Government or any agency thereof or The Regents of the University of California.

\section{$\underline{\text { Acknowledgement }}$}

This work has been performed under the auspices of the US DOE by UC-LBNL under contract DE-AC03-76SF00098 and by UC-LLNL under contract W-7405-ENG-48. 
1. EXECUTIVE SUMMARY 2

2. THE DARHT INJECTOR DESIGN 4

3. RECENT ENGINEERING CHANGES

4. COMPUTER SIMULATION OF BEAM OPTICS 28

5. DISPENSER CATHODES 31

6. TESTING OF THE 6.5" CATHODE AT LBNL 36

7. TESTING OF THE QUARTER-INCH CATHODE AT LBNL 44

8. ACTIVATION \& TESTING OF THE DARHT-II CATHODE AT LANL 59

9. DISCUSSION AND RECOMMENDATIONS

10. ATTACHMENTS

$\begin{array}{ll}\text { APPENDIX A } & 79\end{array}$

$\begin{array}{ll}\text { APPENDIX B } & 90\end{array}$

$\begin{array}{ll}\text { APPENDIX C } & 107\end{array}$

$\begin{array}{ll}\text { APPENDIX D } & 109\end{array}$

$\begin{array}{ll}\text { APPENDIX E } & 111\end{array}$ 


\section{EXECUTIVE SUMMARY}

In the campaign to achieve $2 \mathrm{kA}$ of electron beam current, we have made several changes to the DARHT-II injector during 2006-2007. These changes resulted in a significant increase in the beam current, achieving the $2 \mathrm{kA}$ milestone. Until recently (before 2007), the maximum beam current that was produced from the 6.5" diameter (612M) cathode was about $1300 \mathrm{~A}$ when the cathode was operating at a maximum temperature of 1140 degree $\mathrm{C}$. At this temperature level, the heat loss was dominated by radiation which is proportional to temperature to the fourth power. The maximum operating temperature was limited by the damage threshold of the potted filament and the capacity of the filament heater power supply, as well as the shortening of the cathode life time. There were also signs of overheating at other components in the cathode assembly. Thus it was clear that our approach to increase beam current could not be simply trying to run at a higher temperature and the preferred way was to operate with a cathode that has a lower work function.

The dispenser cathode initially used was the type 612M made by SpectraMat. According to the manufacturer's bulletin, this cathode should be able to produce more than $10 \mathrm{~A} / \mathrm{cm}^{2}$ of current density (corresponding to $2 \mathrm{kA}$ of total beam current) at our operating conditions. Instead the measured emission (space charge limited) was 6 $\mathrm{A} / \mathrm{cm}^{2}$. The result was similar even after we had revised the activation and handling procedures to adhere more closely to the recommend steps (taking longer time and nonstop to do the out-gassing).

Vacuum was a major concern in considering the cathode's performance.

Although the vacuum gauges at the injector vessel indicated $10^{-8}$ Torr, the actual vacuum condition near the cathode in the central region of the vessel, where there might be significant out-gassing from the heater region, was never determined. Poor vacuum at the surface of the cathode degraded the emission (by raising the work function value). We reexamined all the components in the cathode region and eliminated those parts that were suspected to be potential sources of contamination, e.g., feed-throughs with zinc coating. 
Finally, we considered a change in the cathode type, by using a different combination of impregnation and coating. Since the ETA-II accelerator at LLNL used a $12.5 \mathrm{~cm}$ diameter 311XW (barium oxide doped with scandium and coated with a osmium-tungsten thin film) cathode and emitted 2200A of beam current (i.e. $18 \mathrm{~A} / \mathrm{cm}^{2}$ ), it was reasonable to assume that DARHT can adopt this type of cathode to produce $2 \mathrm{kA}$ (i.e., $10 \mathrm{~A} / \mathrm{cm}^{2}$ ). However, it was later found that the $311 \mathrm{XW}$ has a higher radiation heat loss than the $612 \mathrm{M}$ and therefore resulted in a maximum operating temperature (as limited by filament damage) below that required to produce the high current. With the evidence provided by systematic emission tests using quarter-inch size cathodes, we confirmed that the 311XM (doped with scandium and has a osmium-ruthenium (M) coating) had the best combination of low work function and low radiation heat loss. Subsequently a 6.5 " diameter 311XM cathode was installed in DARHT and $2 \mathrm{kA}$ beam current was obtained on June 14, 2007.

In testing the quarter-inch size cathode, we found that the beam current was sensitive to the partial pressure of various gases in the vacuum chamber. Furthermore, there was a hysteresis effect on the emission as a function of temperature. The phenomenon suggested that the work function of the cathode was dependent on the dynamic equilibrium between the diffusion of the impregnated material to the surface and the contamination rate from the surrounding gas. Water vapor was found to be the worst contaminant amongst the various gases that we have tested. Our data showed that the required vacuum for emitting at $10 \mathrm{~A} / \mathrm{cm}^{2}$ is in the low $10^{-8}$ Torr range. 


\section{The DARHT-II Injector Design.}

The DARHT-II Injector (Fig. 1) is designed to deliver a $2 \mathrm{kA}$ electron beam at 2.5 MV from a thermionic cathode of diameter $6.5 "=16.5 \mathrm{~cm}$ for injection into the DARHTII accelerator. A description of issues relevant to the DARHT-II Injector previous to this work is presented in a number of documents.

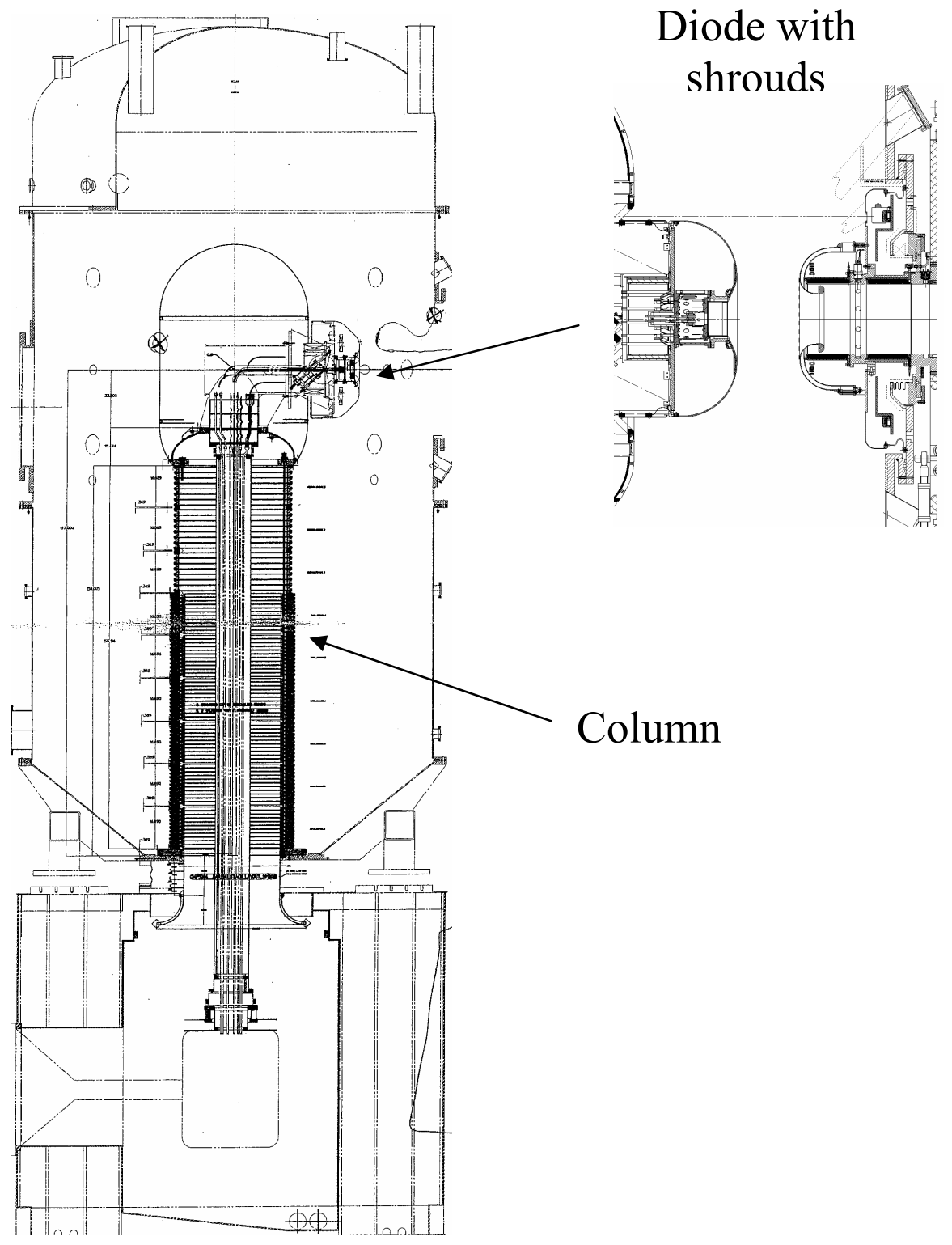

Figure 1. Schematic of DARHT-II Injector. 
Column high voltage design, modeling, and measurement are summarized in Appendix A. Issues and general information related to injected beam production are summarized in Appendix B. Detailed information on cathode activation, heating and diagnostics is included in Refs 1-3.

A spectrum of injector oscillations especially at $7.8 \mathrm{MHz}$ was excited by the diode voltage and stalk current rise time and by the crowbar to decrease the voltage fall time. Extensive work on mitigating injector transients by use of the ferrite damper is described in Ref. 4. The design was completed and the ferrite damper was installed in the DARHTII Injector in February 2006. Testing of the ferrite damper showed that it was very effective in damping the rise-time-excited 7.8 MHz oscillations, and the $\sim 3 \mathrm{x}$ faster damping rate turned out to be in good accord with the simulation circuit in Ref. 4.

\section{References}

1. Timothy Houck, Cathode heating and related diagnostic testing in support of the DARHT-II Injector commissioning, DARHT-II Note 258, 19-Aug-2002.

2. Timothy Houck (ed.), Synopsis of cathode \#4 activation, LBNL HIFAR Note xxxx, 15-May-2006.

3. Timothy Houck, Cathode Heating and Related Diagnostic Testing in support of the DARHT-II Injector Commissioning, DARHT 258, 19-Aug-2002.

4. Richard Briggs, Will Waldron, Lou Reginato, Ken Chow, Tim Houck, Enrique Henestroza, Simon Yu, Michael Kang, DARHT-II Injector Transients and the Ferrite Damper, LBNL HIFAN 1605, 4-Aug-2006. 


\section{Recent Engineering Changes (this section is partially completed)}

\subsection{General Issues}

Changes were made in the cathode design to improve thermal handling and vacuum pumping capabilities. The filament design was one of the areas of concern since "burning up" a filament is usually how a cathode ended its life (besides accidental exposure to air due to vacuum failure in the system). Another issue is the heat conduction from the cathode to the support structure through the thin sheet of Re stand off.

\subsection{Heater Filament Design}

There was evidence for a cold spot appearing on the cathode surface. However it has never been confirmed if the cold spot coincided with the filament lead location where there was a "missing turn". Another possible explanation was the shorting of a filament turn, randomly occurring along the filament winding.

One way to prevent the occurrence of turn-to-turn shorts is to reduce the number of turns, allowing more space between turns. The proposal was to reduce the number of turns from 97 to 91 . The consequence was that the filament must now run hotter in order to deliver the same radiation power for heating the cathode to the same temperature. Likewise, there is a change in the total resistance of the heater (shorter length but higher resistivity) affecting the power supply requirement. In order to make sure that the existing filament power supply was adequate to heat up the shortened filament, we calculated the resistance using the test data provided by Spectra-Mat.

Table 3.1, Spectra-Mat Factory Test Data on First Production Run DARHT Cathodes.

Filament has 97 turns

\begin{tabular}{|c|c|c|c|c|c|}
\hline $\begin{array}{c}\text { Filament } \\
\text { Current }(\mathrm{A})\end{array}$ & $\begin{array}{c}\text { Heater } \\
\text { Voltage }(\mathrm{V})\end{array}$ & $\begin{array}{c}\text { Power } \\
(\mathrm{W})\end{array}$ & $\begin{array}{c}\text { Filament } \\
\text { Resistance }(\Omega)\end{array}$ & $\begin{array}{c}\text { Estimated Heater } \\
\text { Temp }\left({ }^{\circ} \mathrm{C}\right)\end{array}$ & $\begin{array}{c}\text { Cathode } \\
\text { Temp }\left({ }^{\circ} \mathrm{C}_{\mathrm{b}}\right)\end{array}$ \\
\hline 0.0 & 0.0 & 0 & & & \\
\hline 13.4 & 3.0 & 40 & 0.224 & 303 & \\
\hline 19.5 & 5.3 & 103 & 0.272 & 389 & \\
\hline 19.6 & 6.3 & 123 & 0.321 & 483 & \\
\hline 25.8 & 9.9 & 255 & 0.384 & 604 & \\
\hline 28.2 & 12.3 & 346 & 0.436 & 701 & \\
\hline
\end{tabular}




\begin{tabular}{|c|c|c|c|c|c|}
\hline 31.7 & 14.9 & 473 & 0.470 & 768 & \\
\hline 34.4 & 18.0 & 619 & 0.523 & 867 & \\
\hline 37.0 & 20.6 & 763 & 0.557 & 931 & \\
\hline 40.0 & 25.0 & 999 & 0.625 & 1057 & 845 \\
\hline 41.3 & 26.0 & 1074 & 0.630 & 1067 & 857 \\
\hline 45.2 & 30.0 & 1356 & 0.664 & 1131 & 913 \\
\hline 47.6 & 34.5 & 1641 & 0.725 & 1245 & 953 \\
\hline 50.4 & 37.8 & 1905 & 0.750 & 1294 & 998 \\
\hline 53.6 & 41.9 & 2247 & 0.782 & 1354 & 1040 \\
\hline
\end{tabular}

In reducing the number of turns from 97 to 91 (which is now the nominal design), the filament length was reduced by a factor of $91 / 97$. Since the radiation is proportional to the fourth power of absolute temperature, and that we have the same radiation power for the two cases, we find:

$$
\begin{aligned}
& \mathrm{L}_{1} / \mathrm{L}_{0}=91 / 97=0.938 \\
& \mathrm{~T}_{1} / \mathrm{T}_{0}=(97 / 91)^{0.25}=1.016
\end{aligned}
$$

So if the cathode temperature is at $1040{ }^{\circ} \mathrm{C}$ and filament $\mathrm{T}_{0}=1354{ }^{\circ} \mathrm{C}=1627^{\circ} \mathrm{K}$, then $\mathrm{T}_{1}$ increases to $\mathrm{T}_{1}=1653{ }^{\circ} \mathrm{K}=1380^{\circ} \mathrm{C}$. According to the table, the filament resistance was linear to the temperature, thus at $1380^{\circ} \mathrm{C}$, the resistance of a 97-turn heater would become $0.796 \mathrm{ohm}$. If reduced to 91 turns, and at $1380{ }^{\circ} \mathrm{C}$, the resistance will be 0.747 $\mathrm{ohm}$. Of course, it is necessary to deliver the same power of $2247 \mathrm{~W}$ from the heater power supply with this load of $0.747 \mathrm{ohm}$. This corresponds to $40.96 \mathrm{~V}$ and $54.85 \mathrm{~A}$ of power supply voltage and current.

There are two possible heater filament winding styles: the center-return and the bifilar types. The disadvantage in the bifilar style is that a single electrical short between neighboring turns stops power flow to the remaining part of the filament and therefore renders the cathode useless. On the other hand, a single short between neighboring turns in the center-return style will only eliminate the heat from that one turn (resulting in a cold spot) thus the cathode can still be used, but it may have non-uniform emission. Other advantages in using the bifilar style include: (1) the magnetic field generated by the heater current can be minimized, (2) according to Spectra-Mat, the center-return type winding is harder to make because they had difficulty in making sure that the return lead stays on center, and (3) the center return lead part is at a much higher temperature than 
the rest of the winding. Thus when operating at high power, the center lead may exceed the temperature limit and starts to decompose the potting material. The bifilar heater filament was tested in the two $311 \mathrm{XW}$ cathodes. However as noted below both of these filaments failed in test. For comparison, the HT molybdenum filament melts at $2610 \mathrm{C}$, but the potting material breaks down at $1800 \mathrm{C}$.

As a result all subsequent DARHT-II cathodes filaments have been of the centerreturn type. Heating of the filament in the DARHT cathode will be powered by an ac power supply. AC power supply is preferred over a DC power supply (see Spectra-Mat bulletin TB-200 --A8/04).

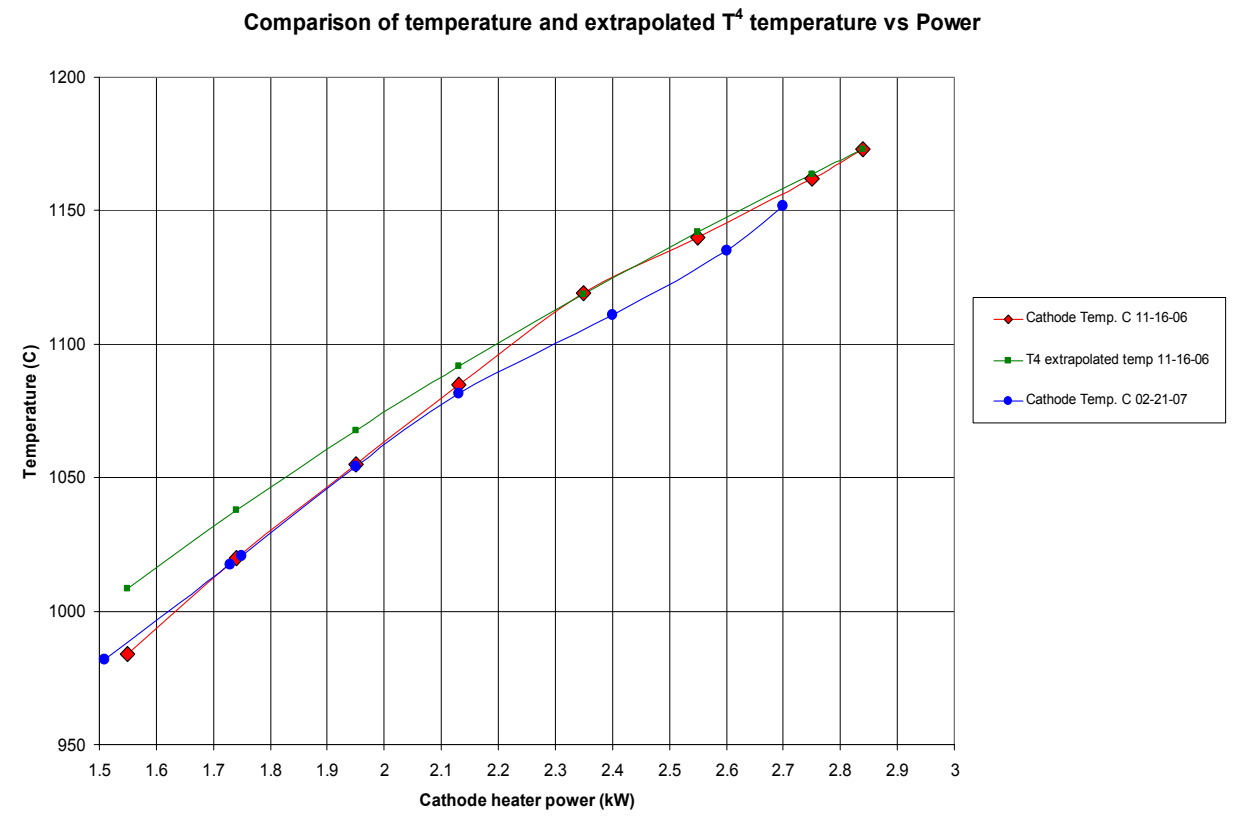

Figure. Due to radiation dominated heat loss, the heating power is proportional to the fourth power of the cathode temperature. (data from LANL) 


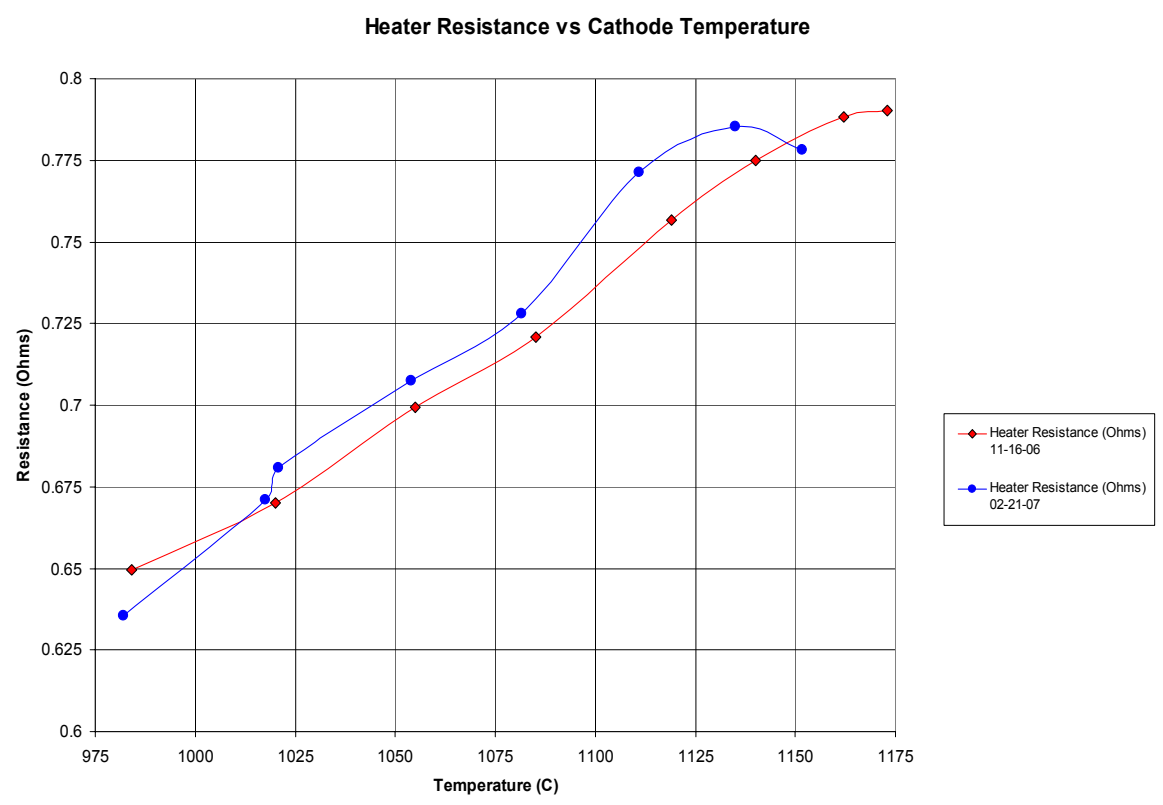

Figure. Cathode heater resistance vs. temperature (data from LANL, presented 070227)

Some pictures of the emitter surface prior to M-coat, for the 311-XM are shown below (from Spectramat).

The pictures show "at the center", "at the edge", and at a point about $80 \%$ along the radius. The pictures were taken after final machining of the surface. Magnification was about $\sim 960 X$. Porosity goes throughout the matrix. It is independent of cathode size. 


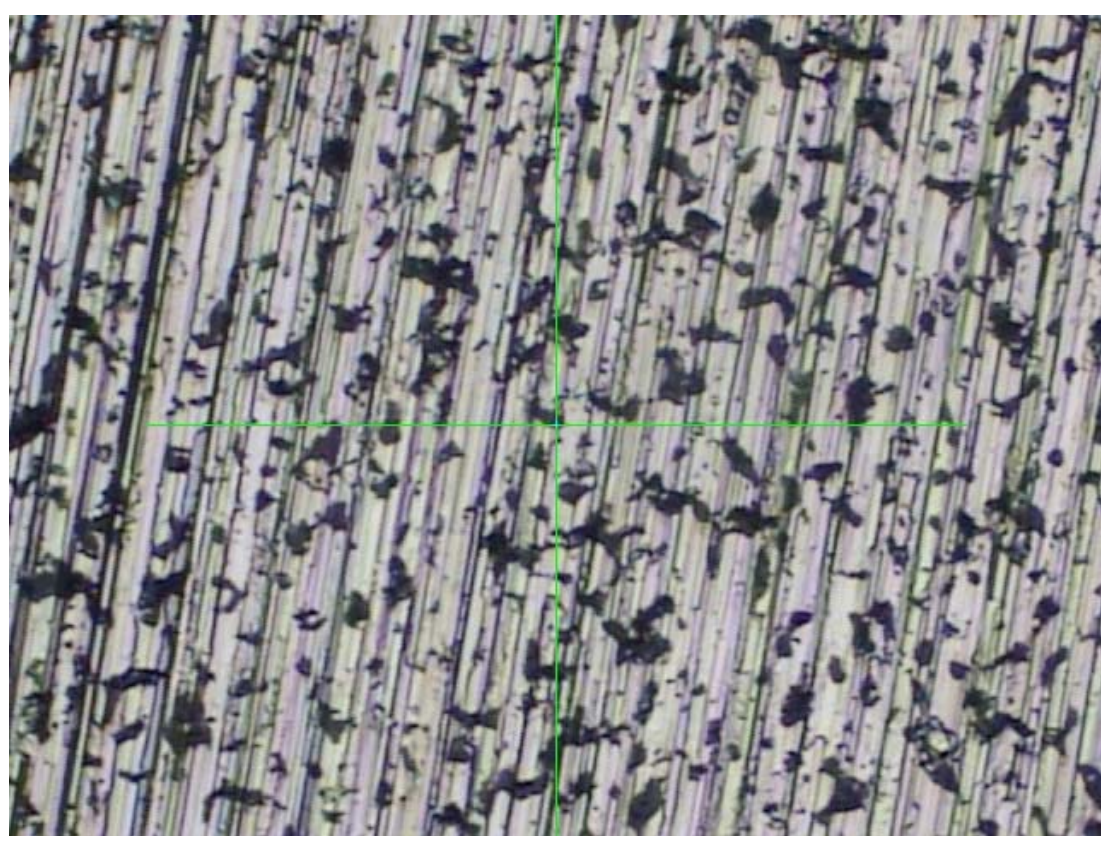

Near center

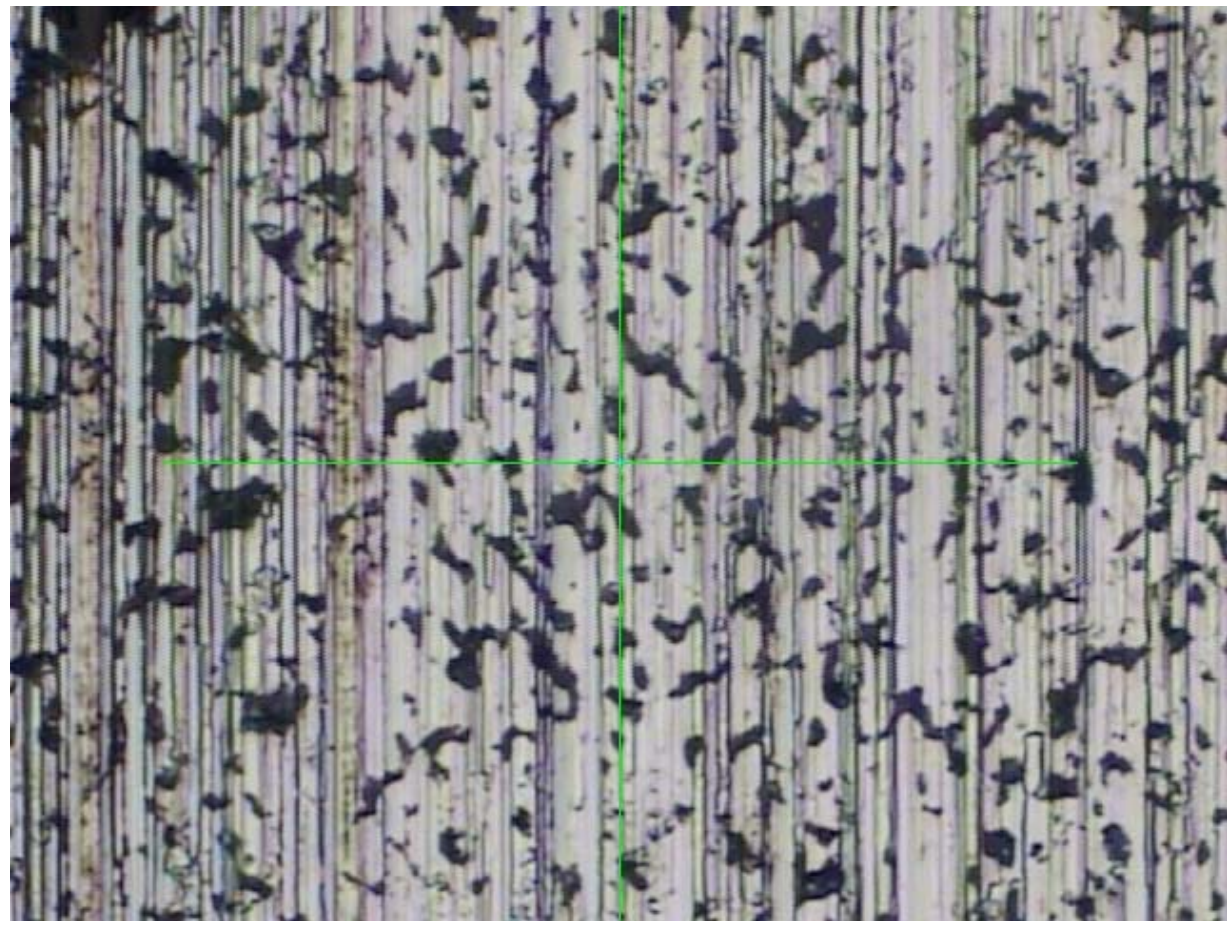

At $80 \%$ from center 


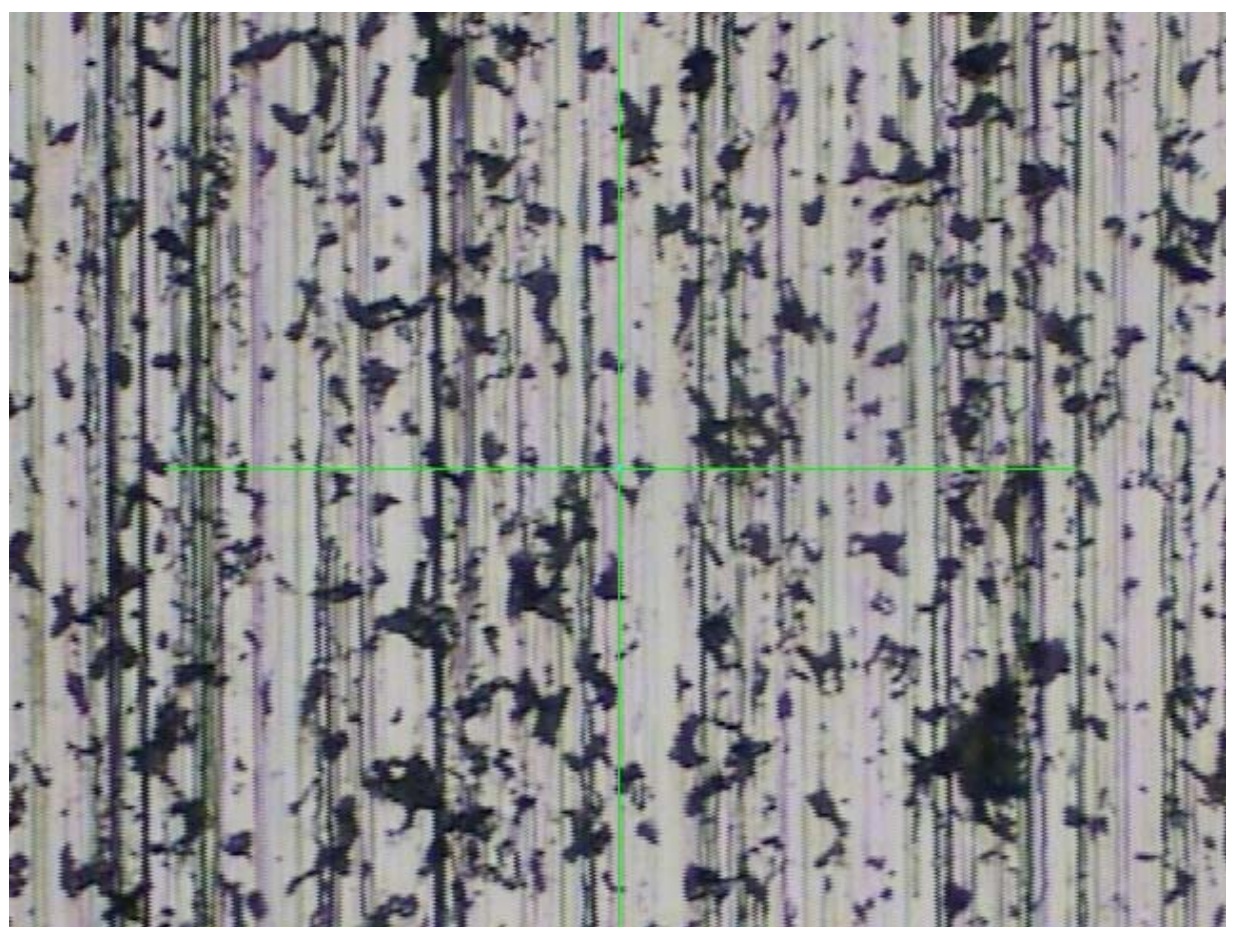

At the edge 


\section{Cathode Heat Management}

\section{(1) Layout}
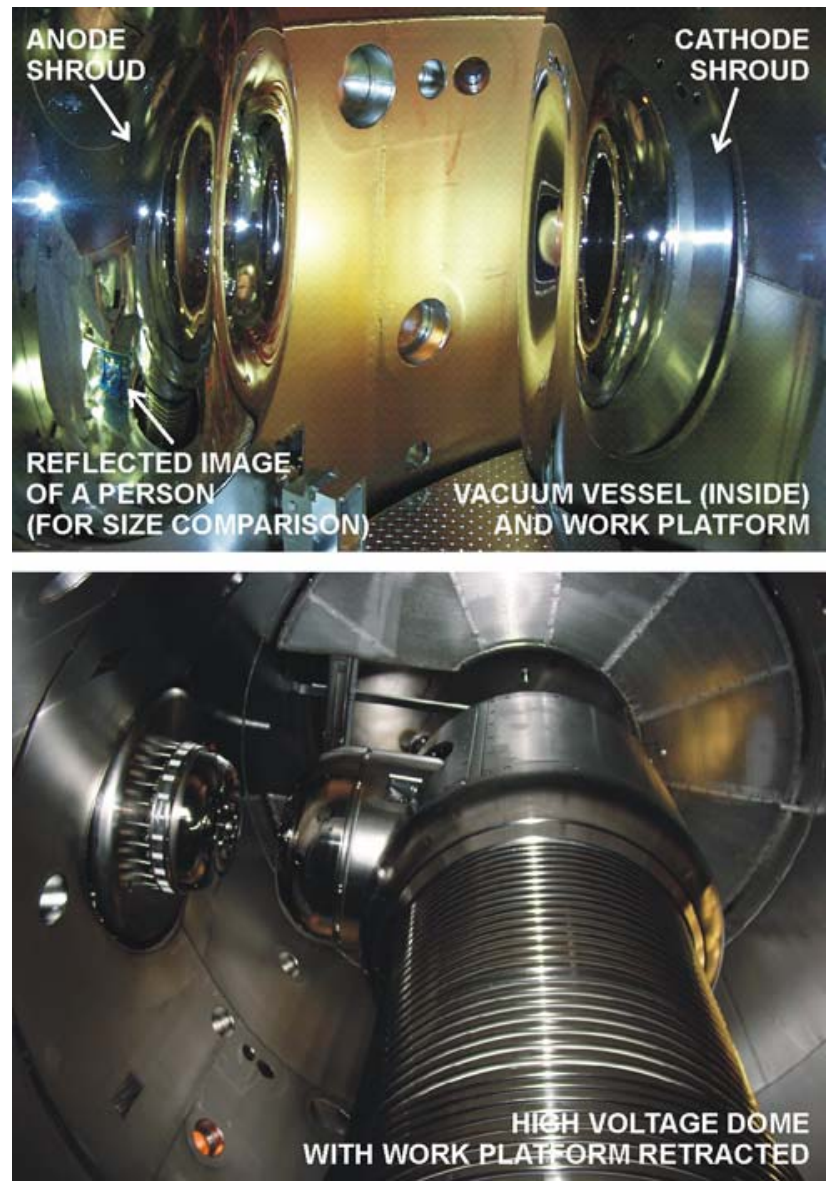

FIGURE 1

View of DARHT injector

high-voltage dome and vacuum vessel. 


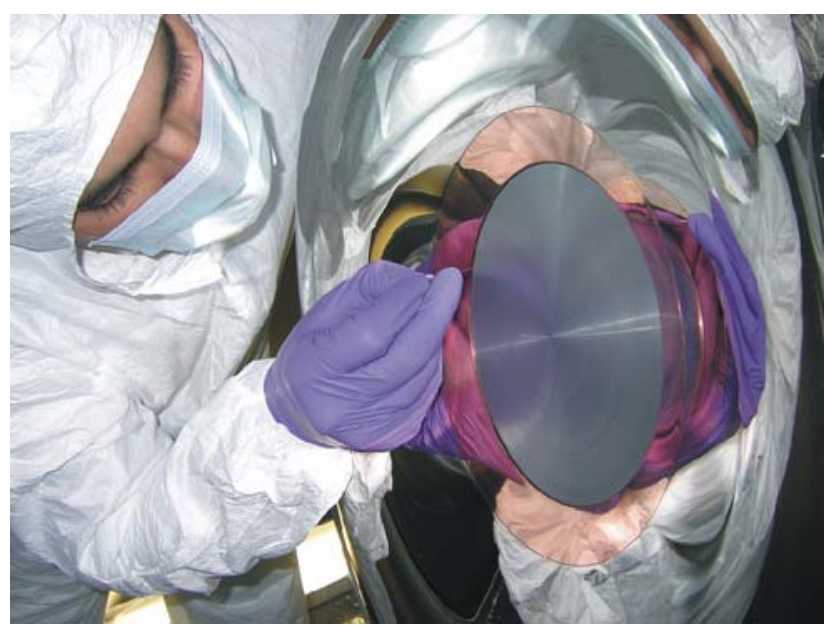

FIGURE 2

View of DARHT dispenser cathode (dark) installed inside high-voltage dome and surrounded by cathode shroud, which is highly polished for high voltage standoff reasons. 


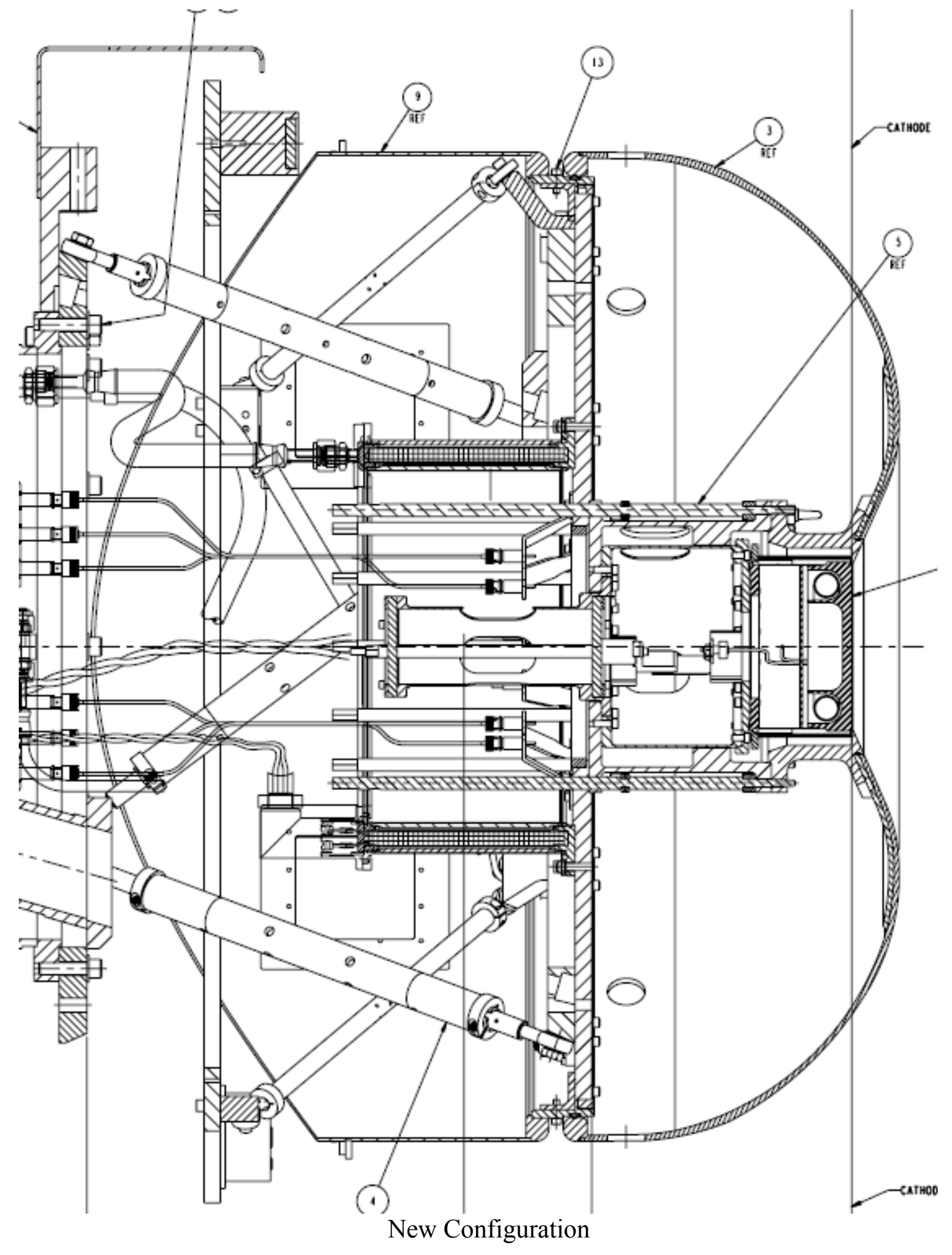




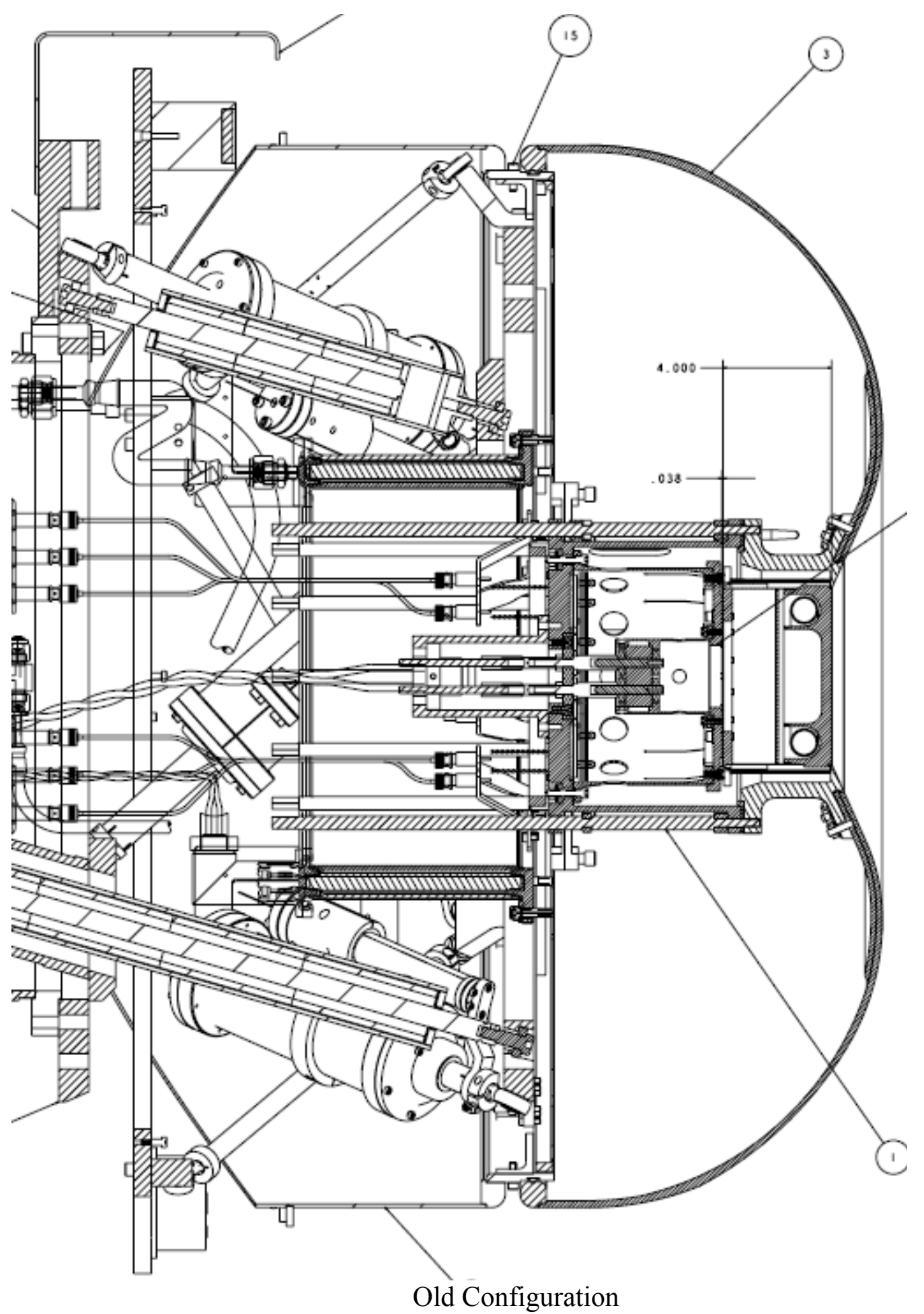



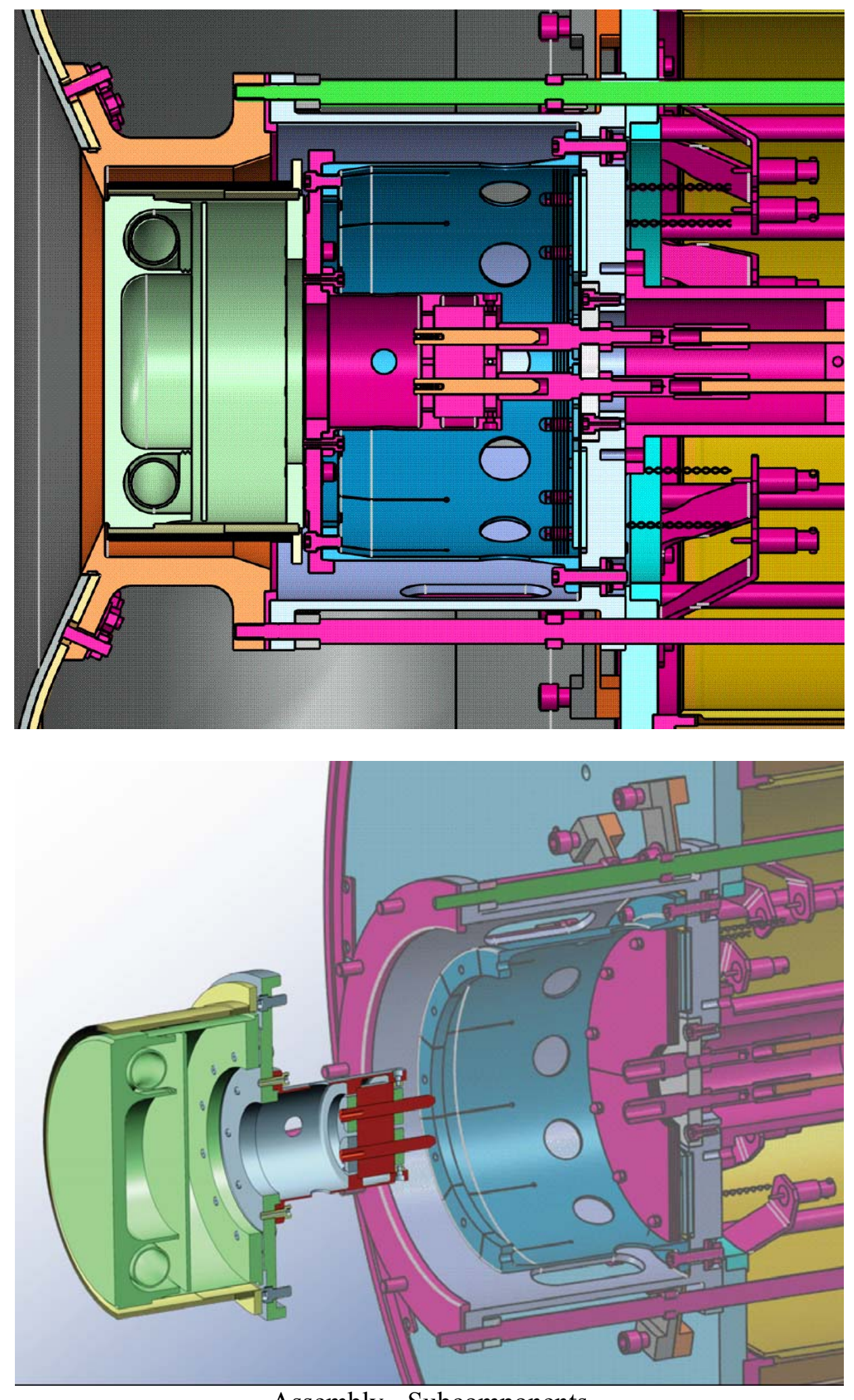

Assembly - Subcomponents 


\section{(2) CATHODE SIMULATION}

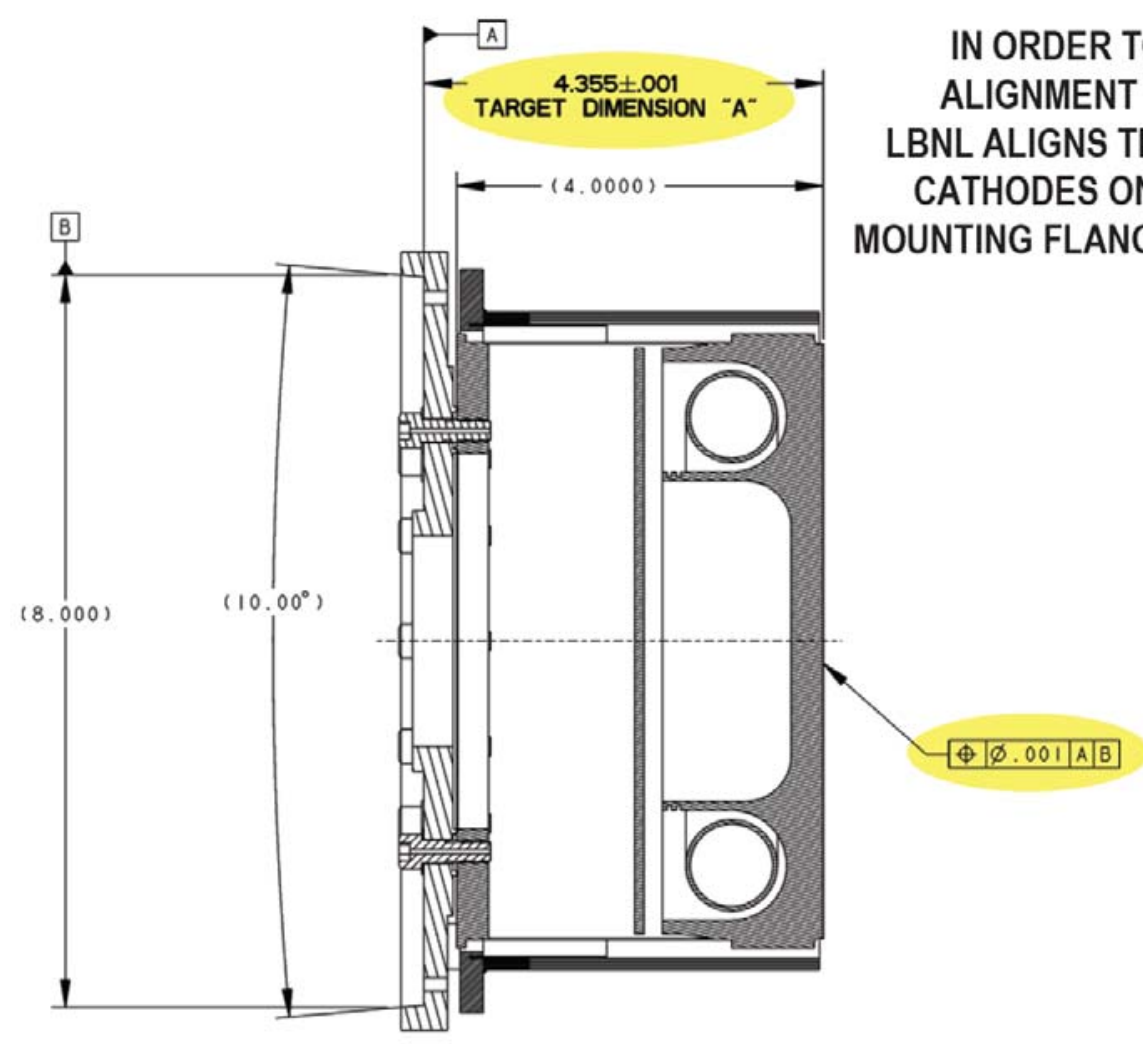

Cathode Specification

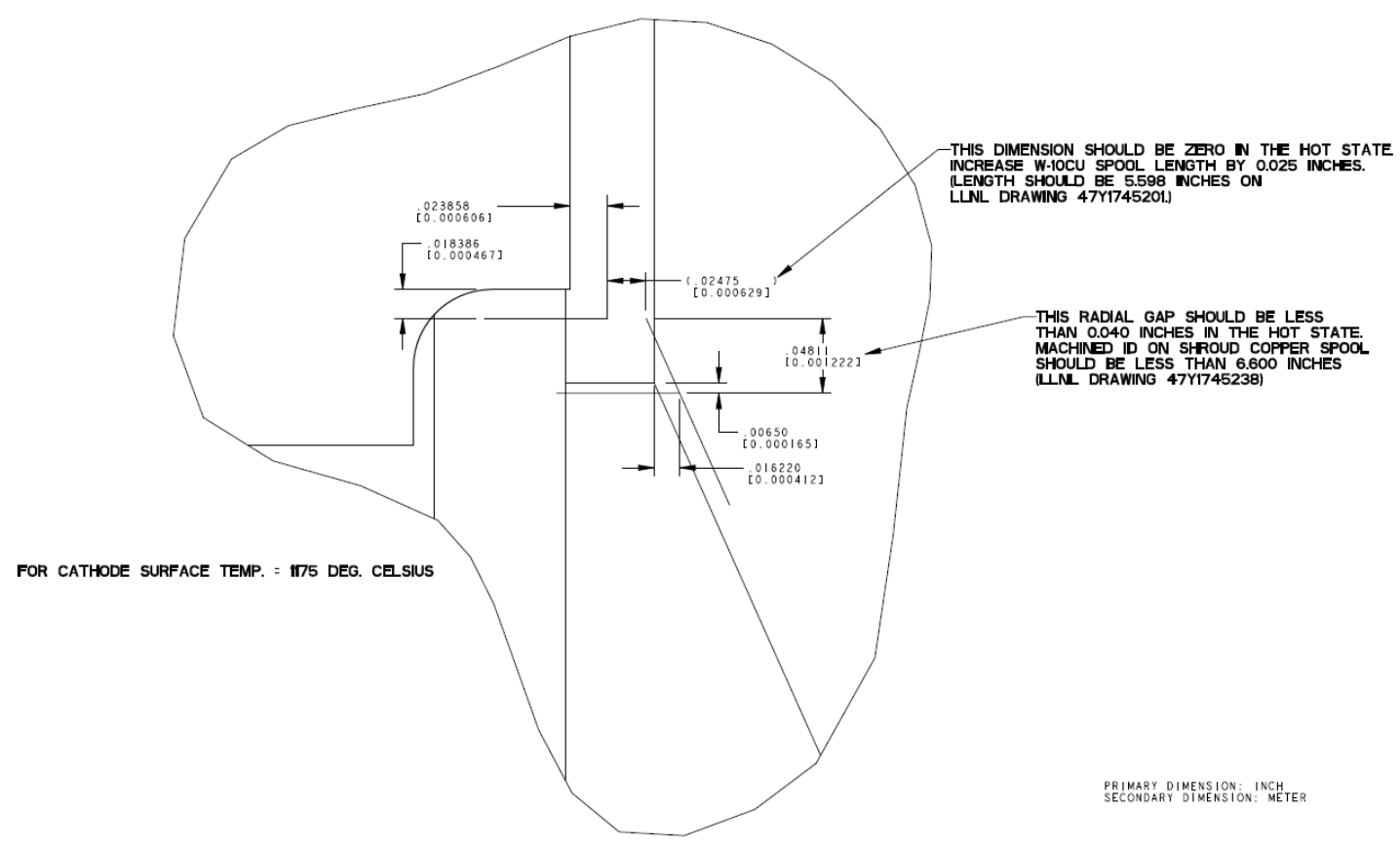


HIGHEST TEMP. ON

CATHODE FRONT SURFACE $1063^{\circ} \mathrm{C}$

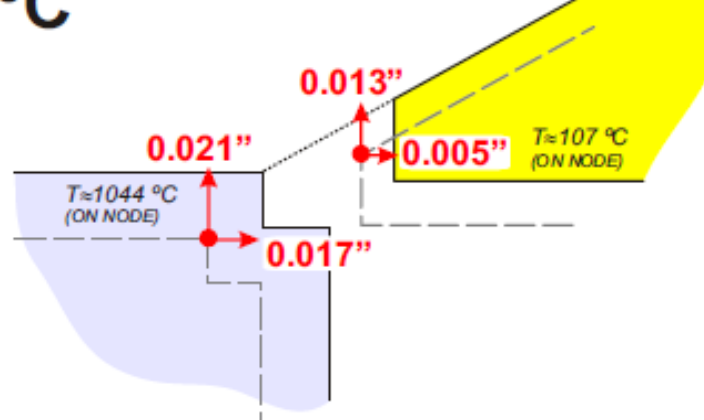

HIGHEST TEMP. ON

CATHODE FRONT SURFACE

$1154{ }^{\circ} \mathrm{C}$

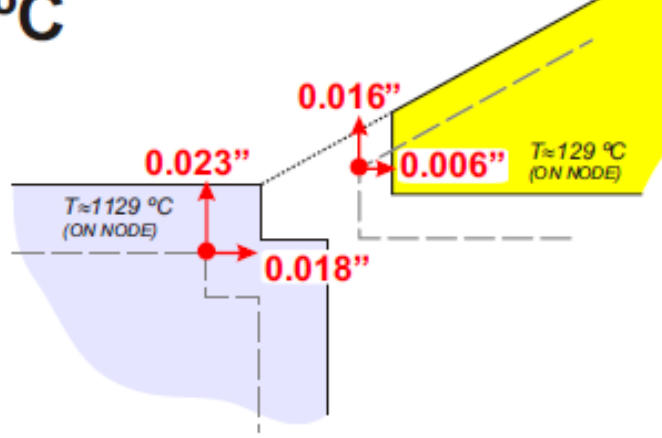

HIGHEST TEMP. ON

CATHODE FRONT SURFACE

$1175^{\circ} \mathrm{C}$

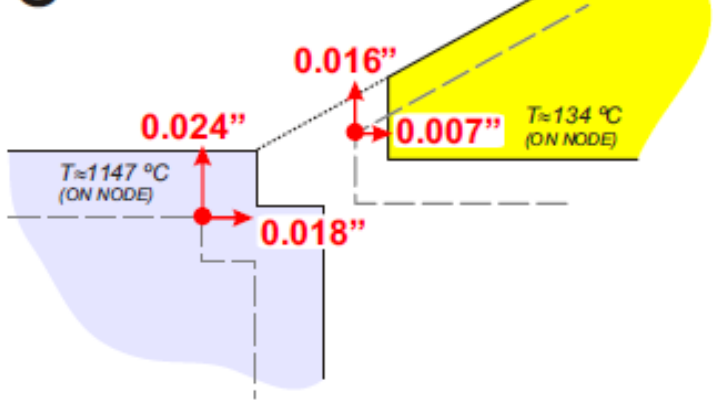

Cathode Thermal Movement 


\section{(3) MATERIAL DATA}

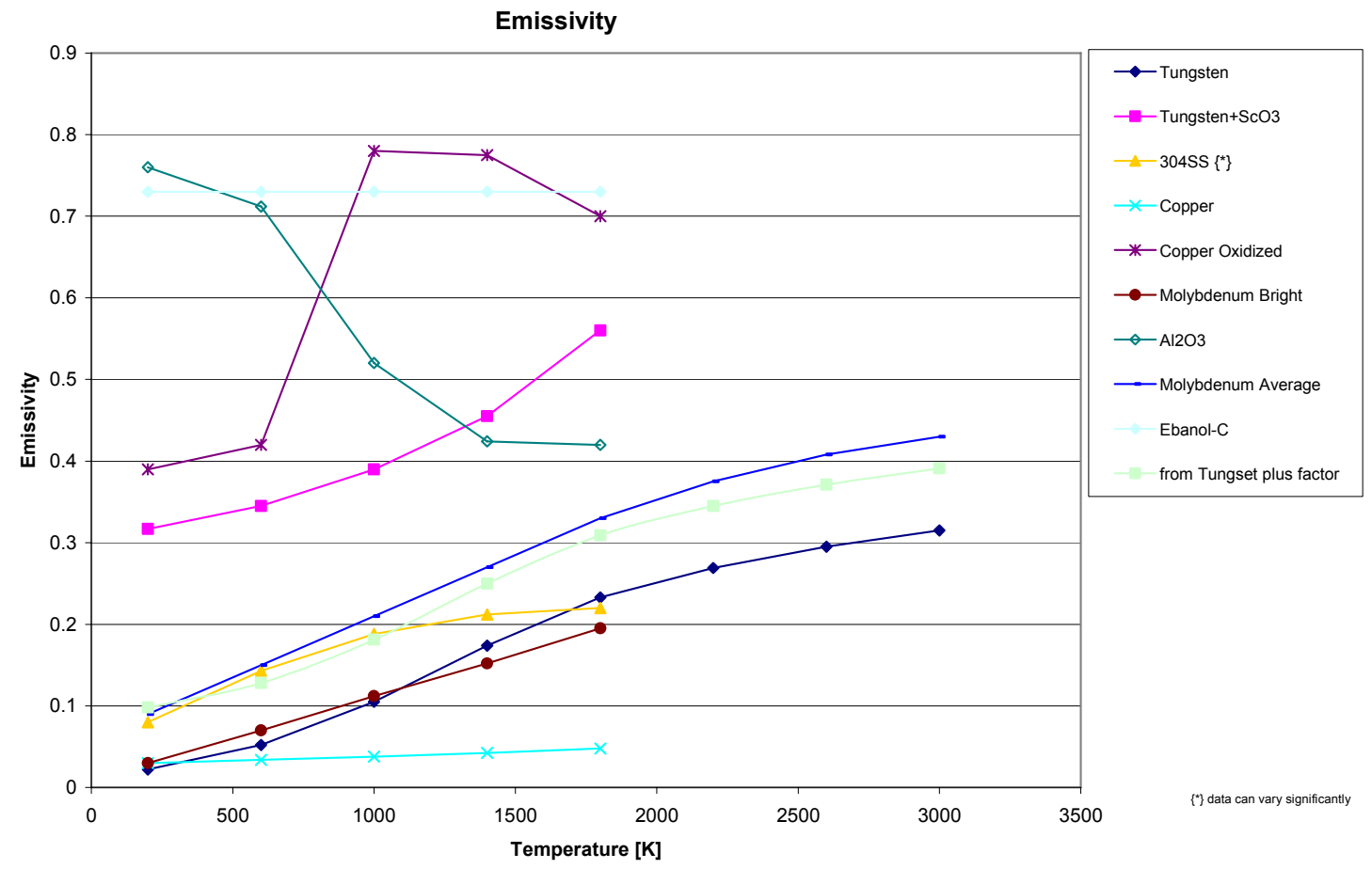

Thermal Expansion [dI/l]

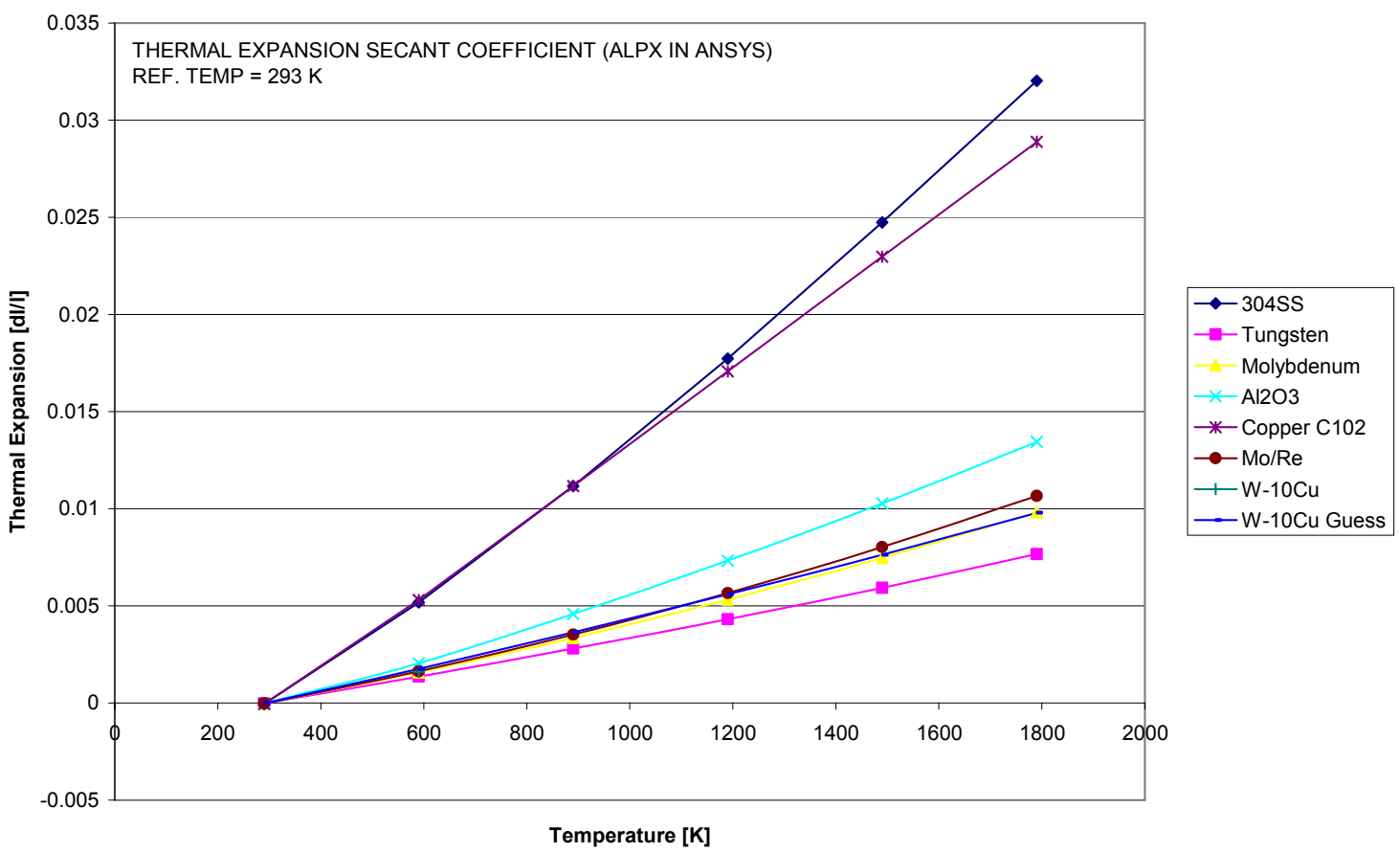


Thermal Conductivity [W/(m-K)]

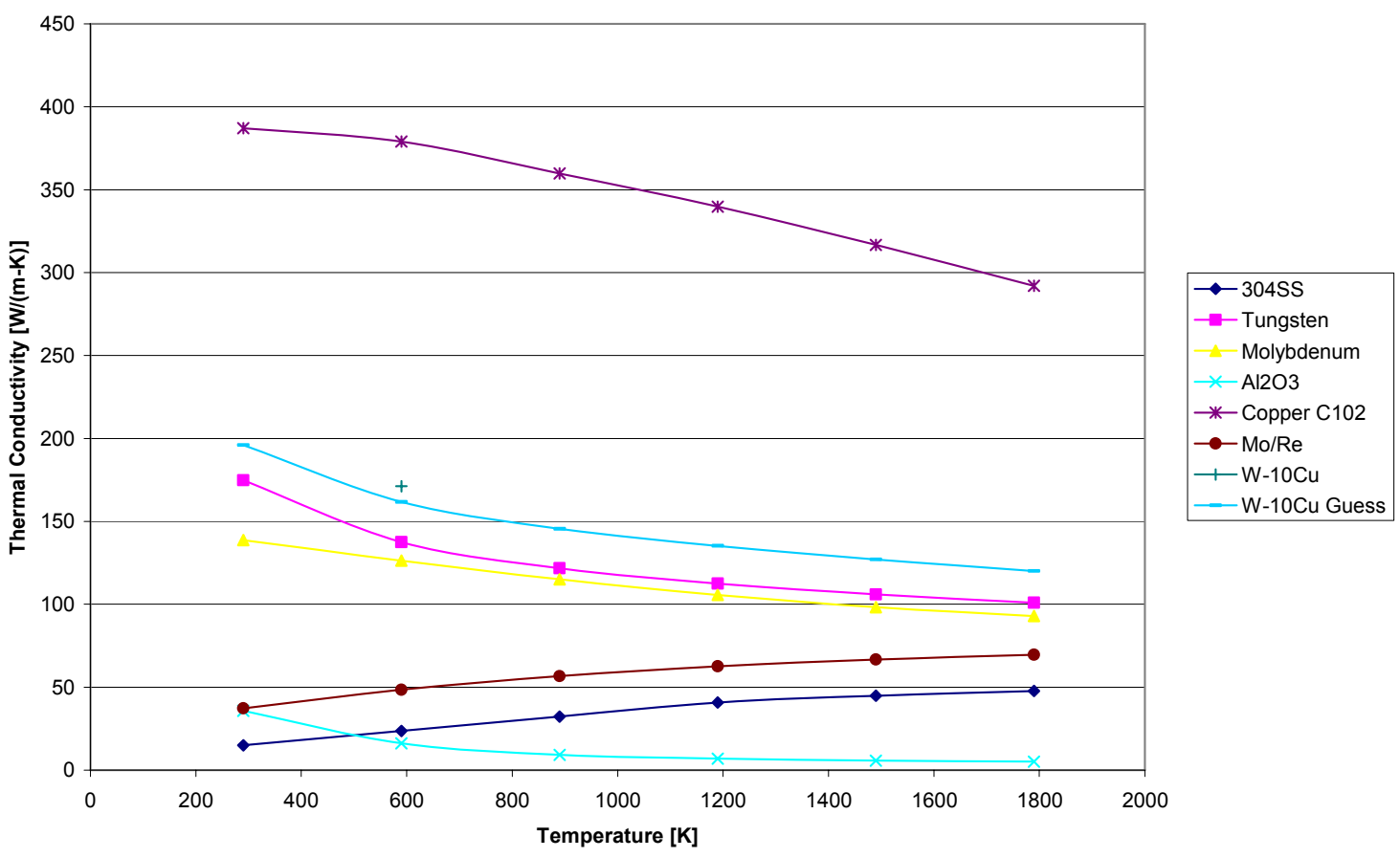

Elastic Modulus [Pa]

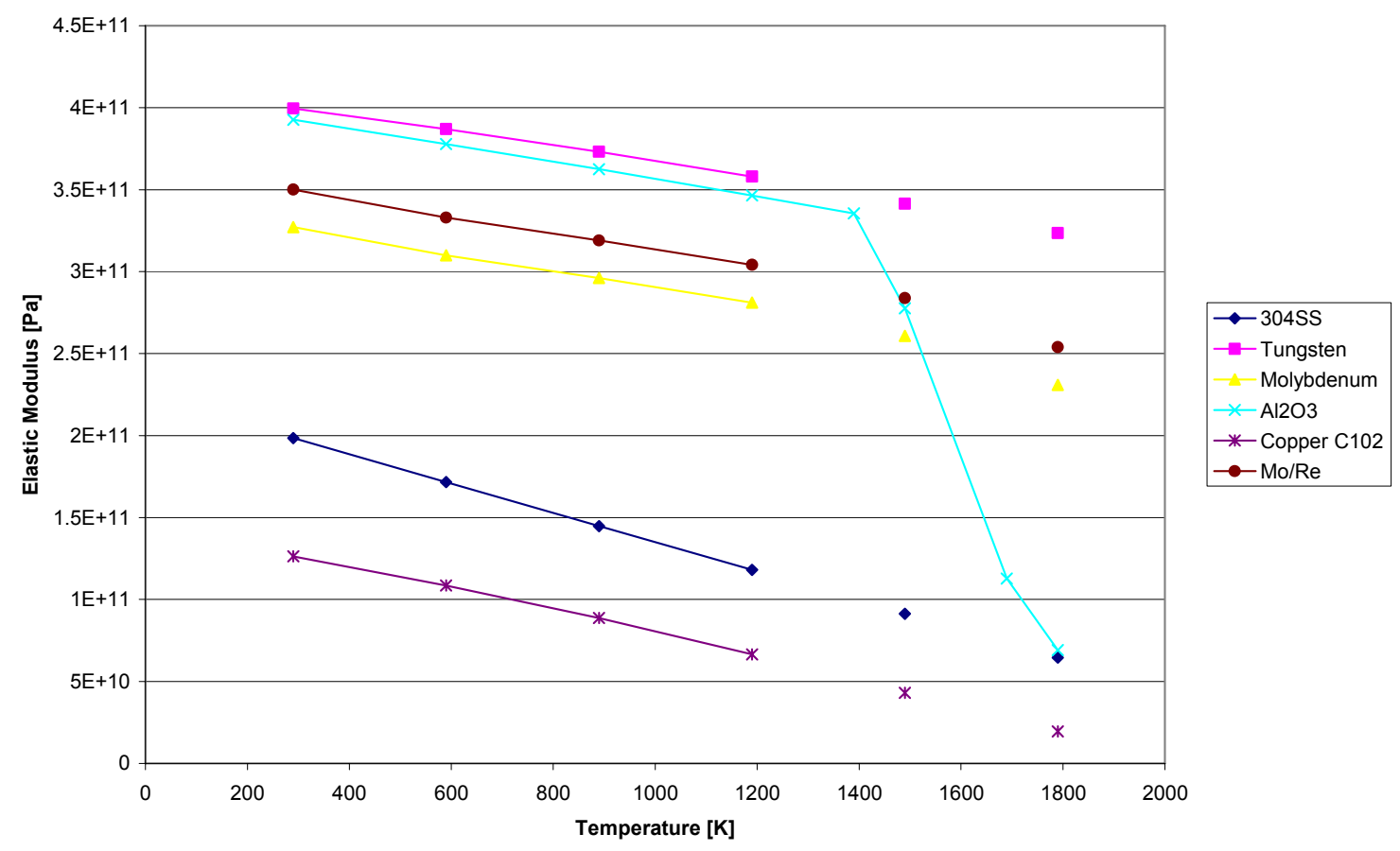


Poisson's Ratio

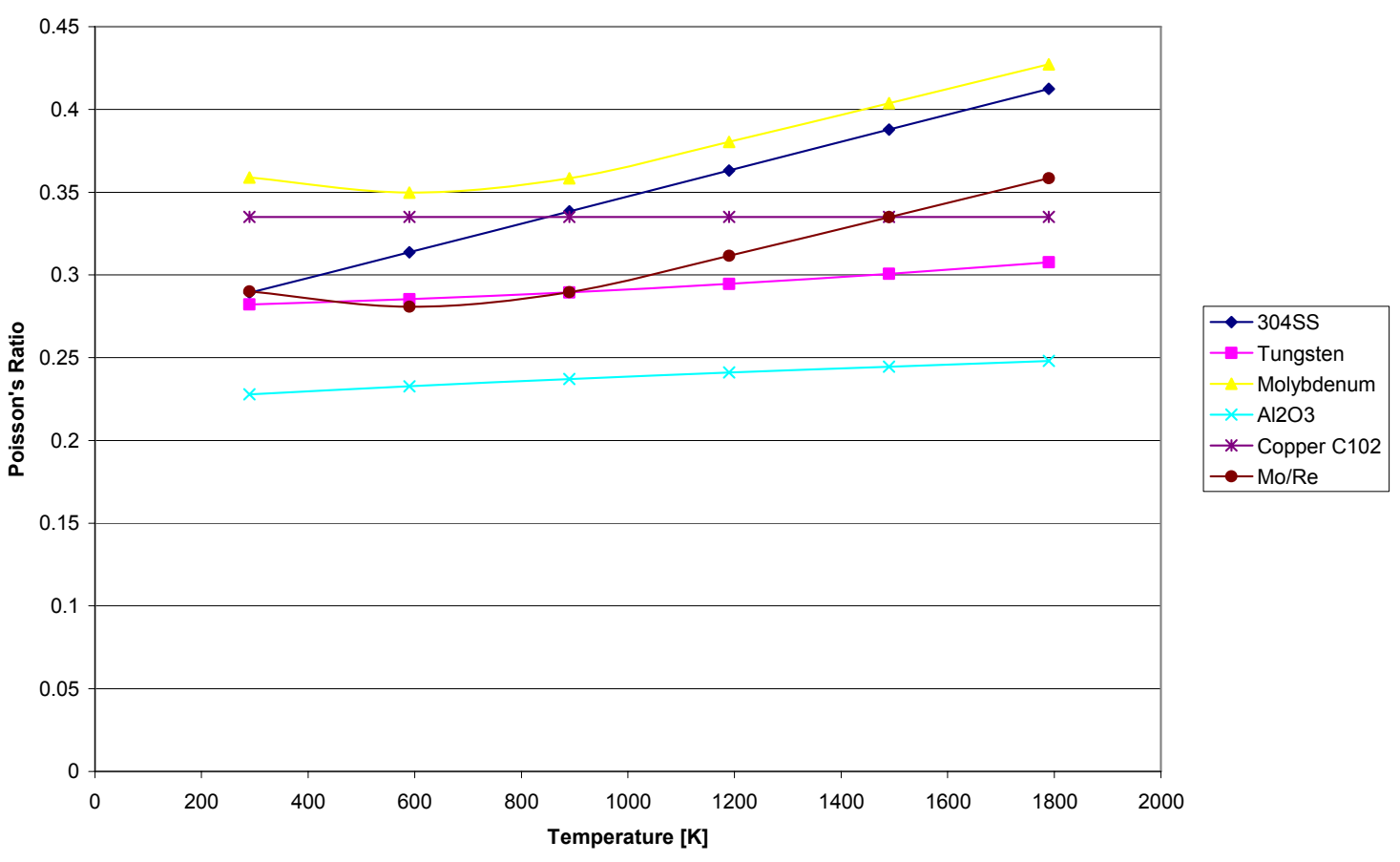

Density

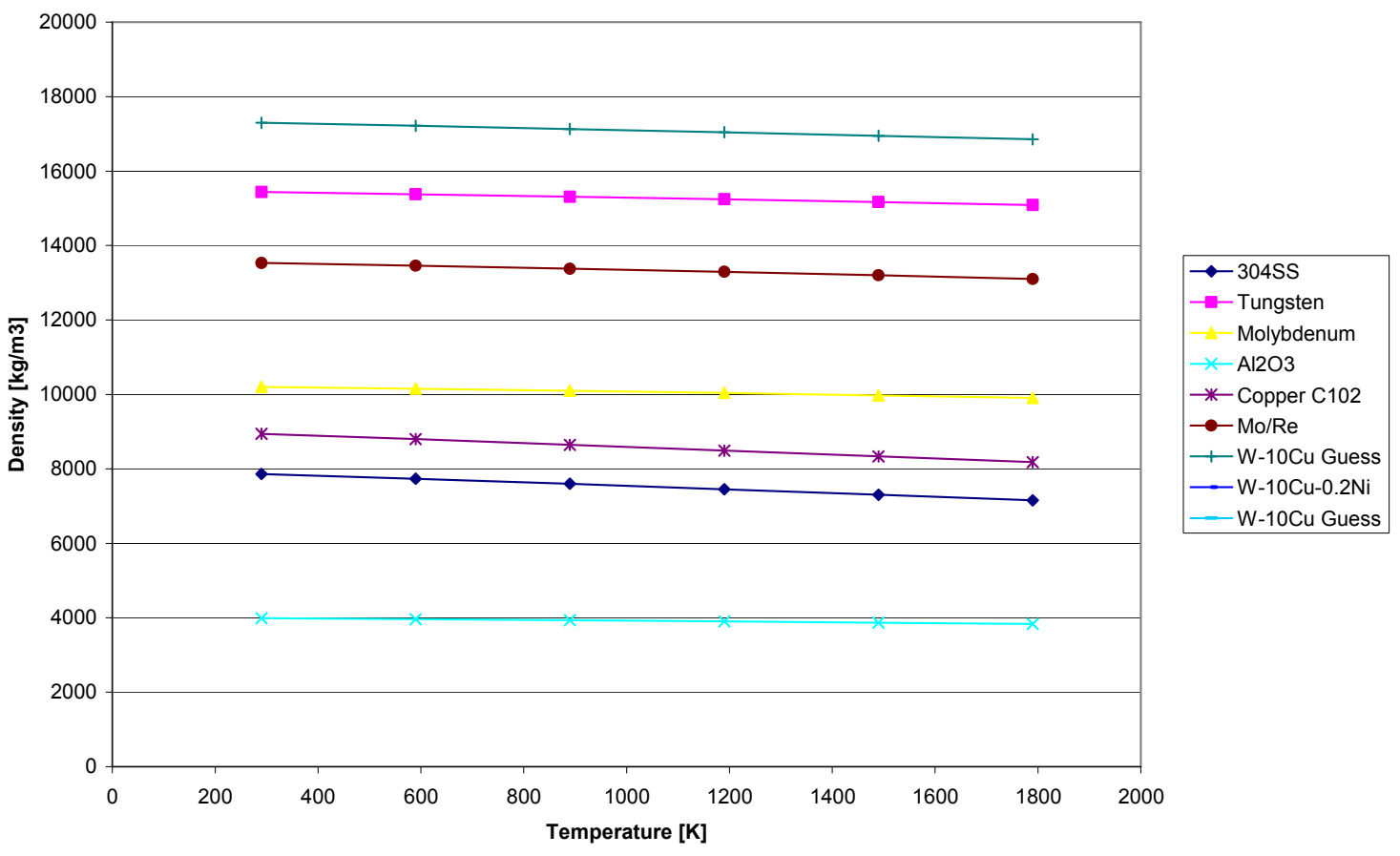




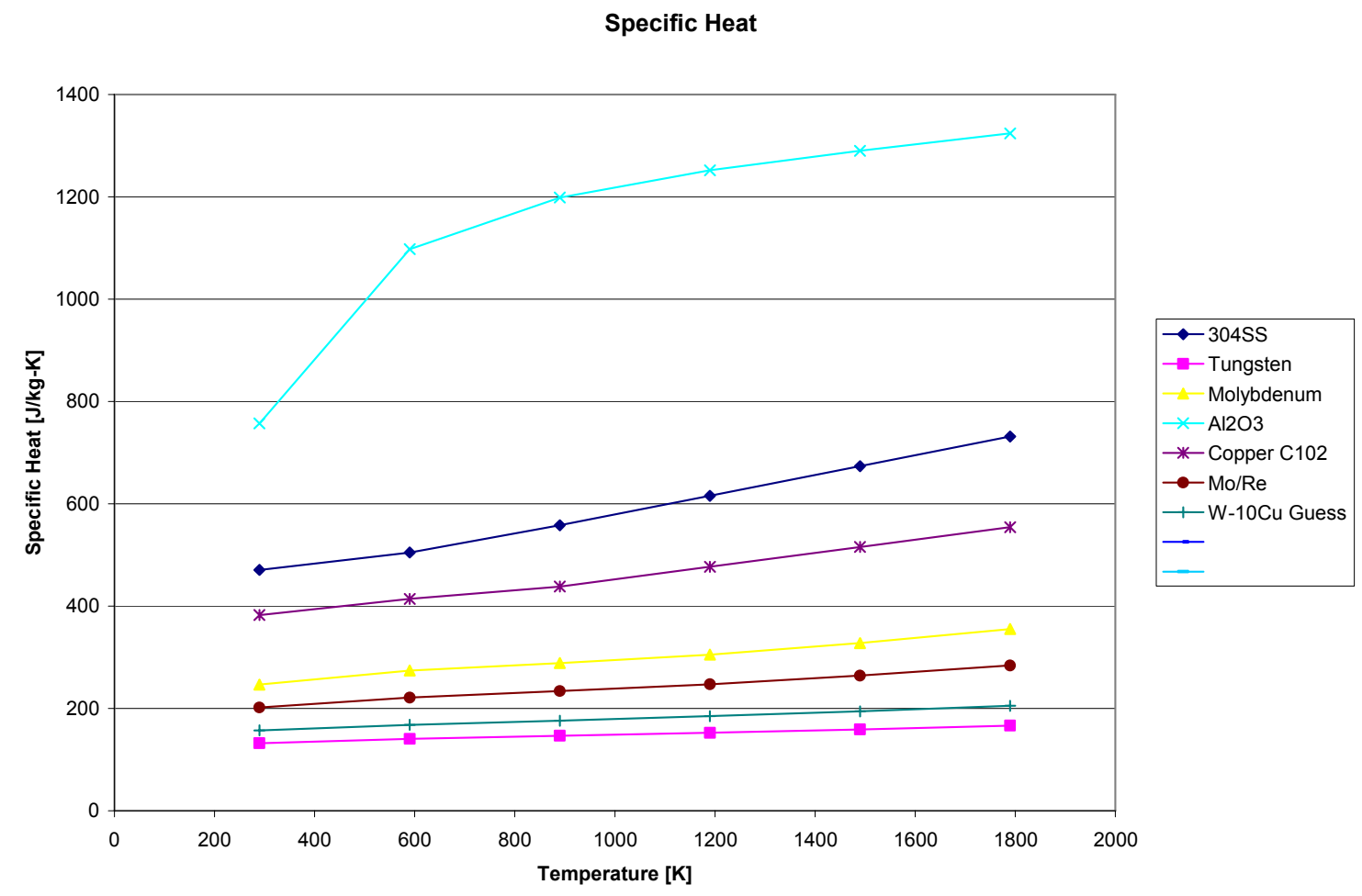

(4) SIMULATION MODEL

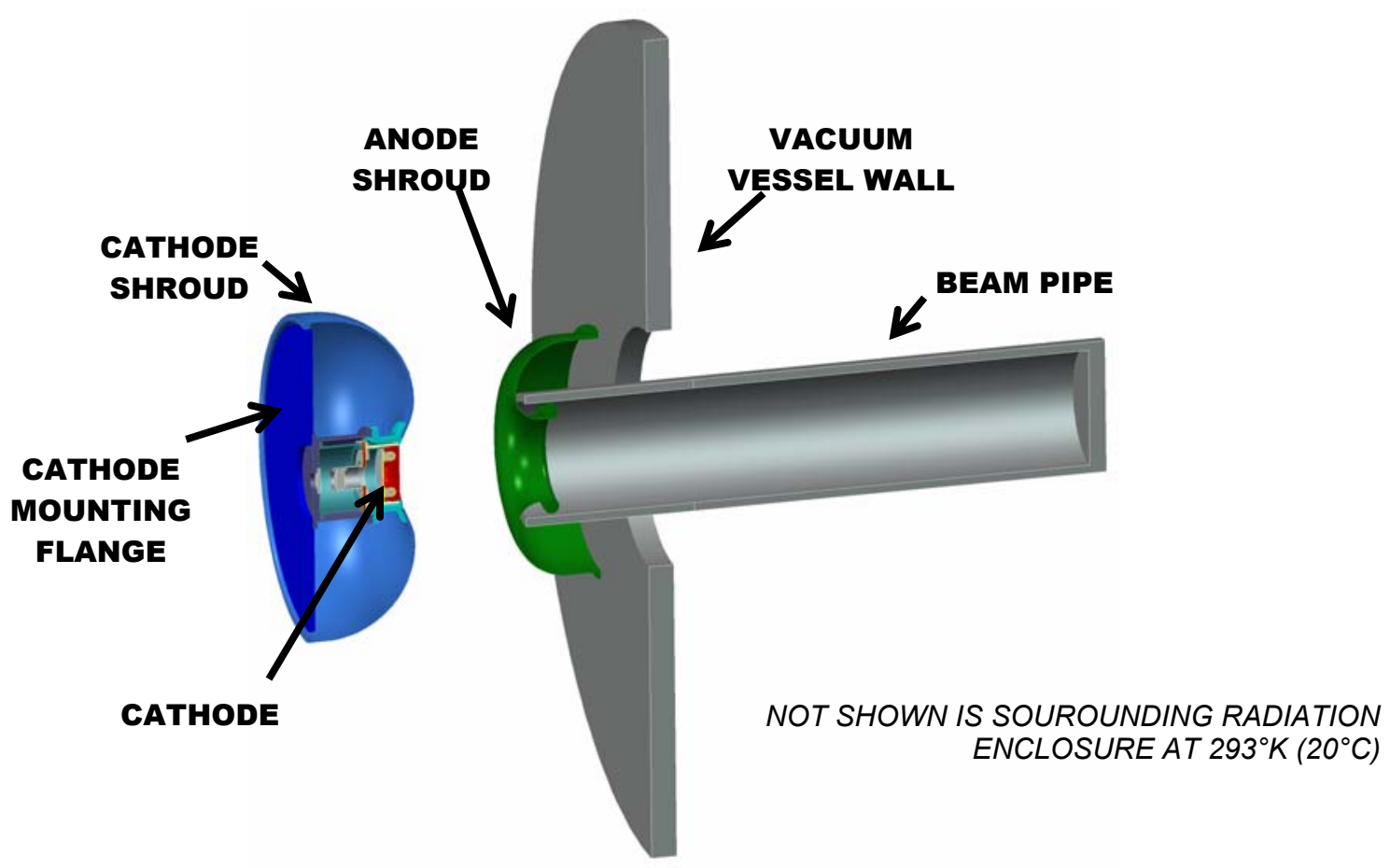



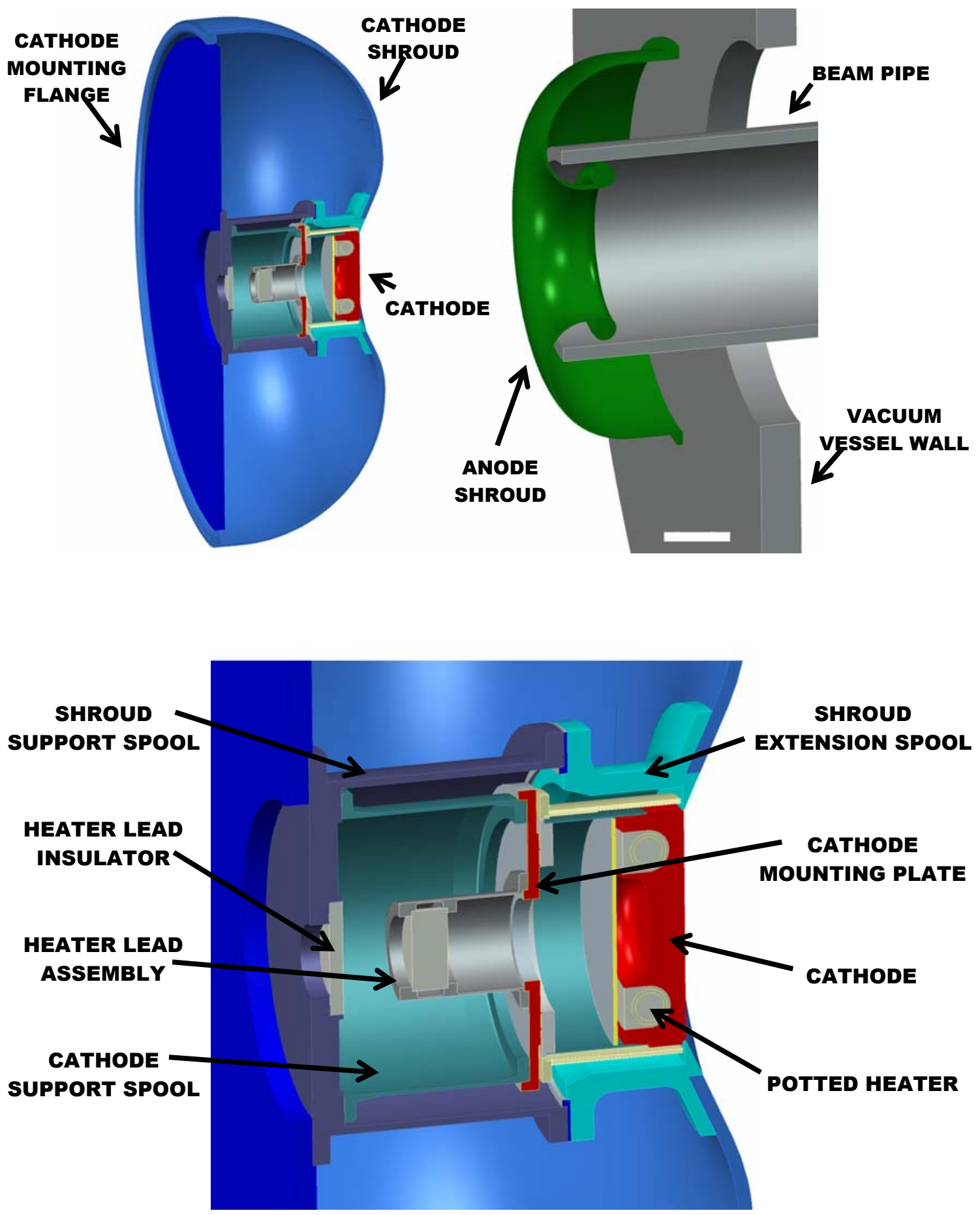


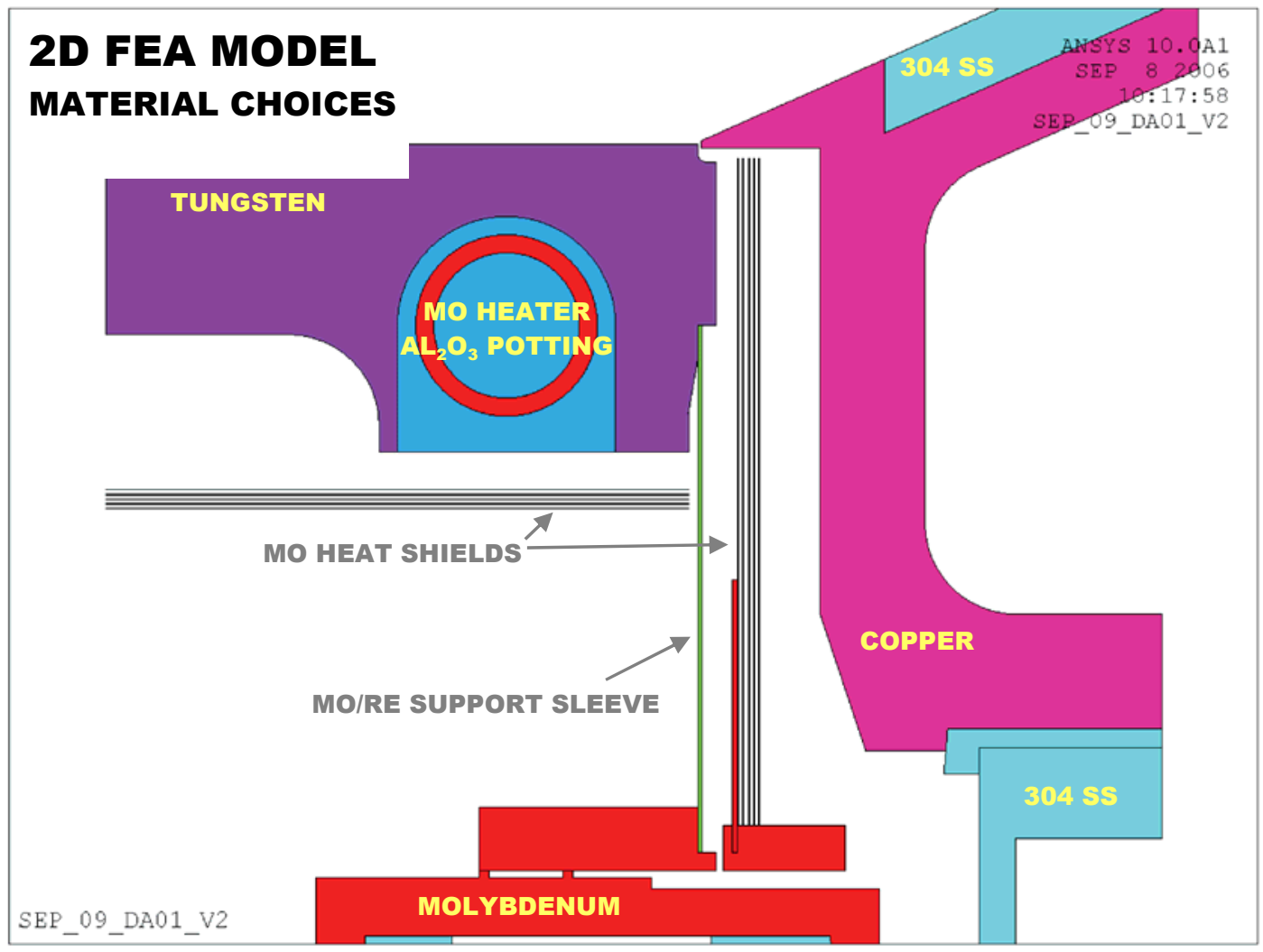

\section{D FEA MODEL}

COLOR INDICATES MATERIAL (SEE PREVIOUS SLIDE)

ANSYS 10.0 A 1

SEP 82006

$10: 17: 25$
SEP_09_DA01_V2

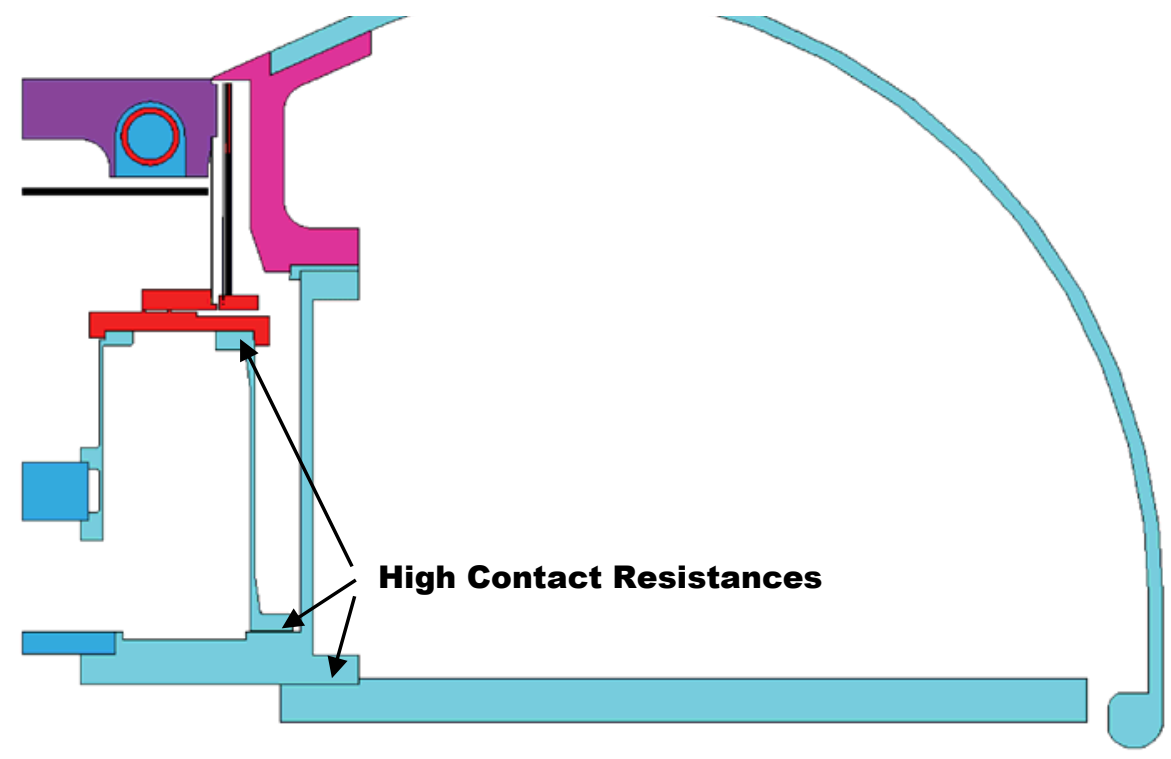




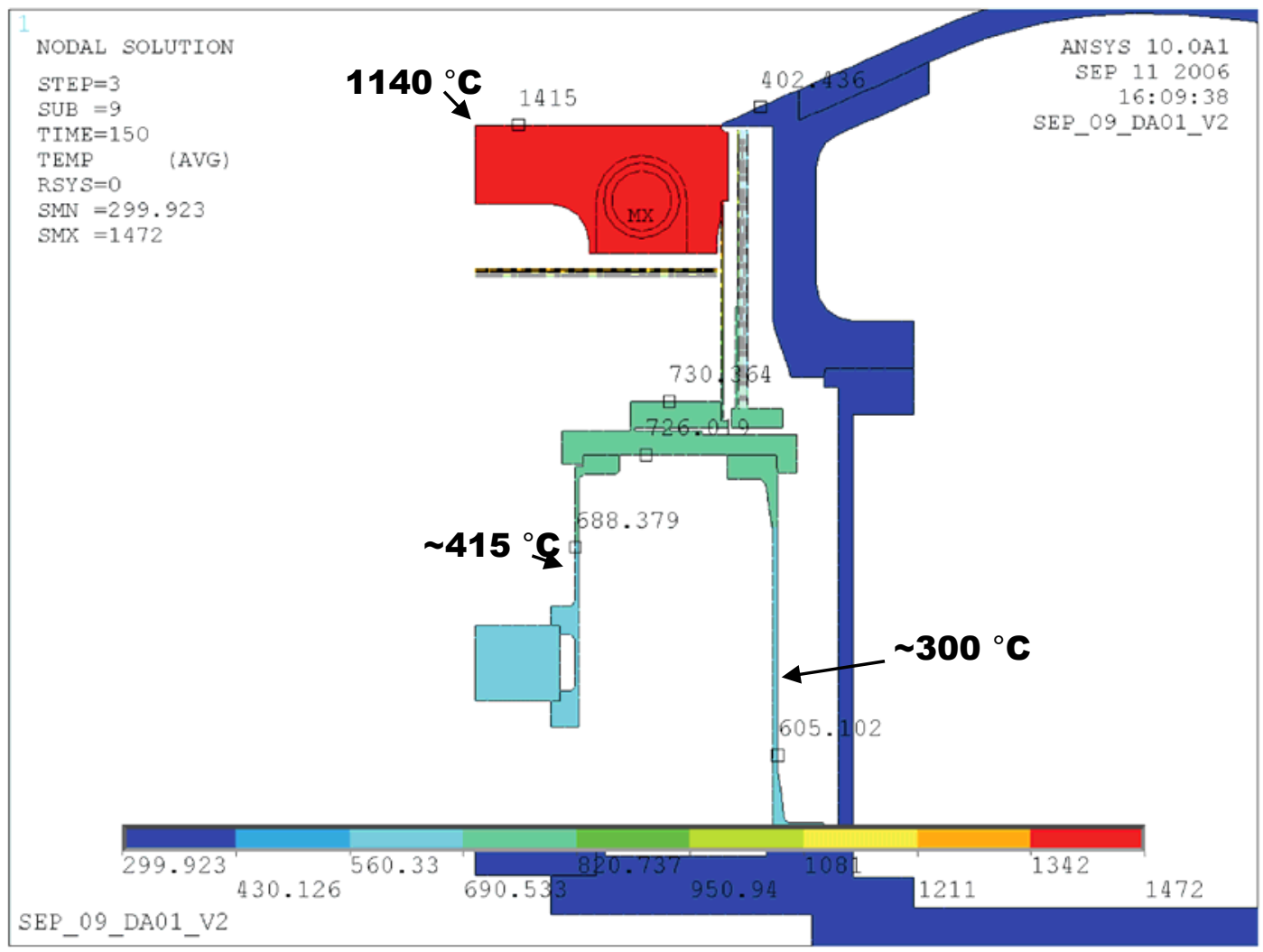

(5) MATERIAL CHOICES

\section{CHANGES TO DESIGN}
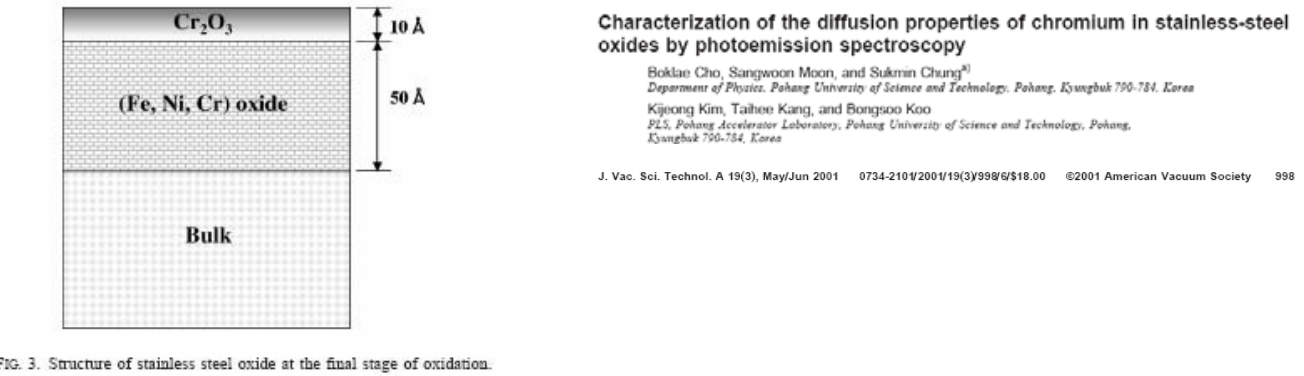

FIC. 3. Structure of stainless steel oxide at the final stage of oxidation

- $\mathrm{Cr}$ diffuses out of bulk material to form either chromium-rich or iron-rich oxide layers.

- Low oxygen partial pressure favors formation of chromium-rich oxide layers. Higher oxygen partial pressures favour formation of iron-rich oxide layers.

- The operation of a pipe diffusion mechanism (diffusion along high diffusion paths such as dislocation or grain boundaries) during the oxidation produces surface metallic chromium . 


\section{(6) RESULTS \\ COMPARISON WITH EXPERIMENT \\ FOR TWO DIFFERENT CATHODE COATINGS}

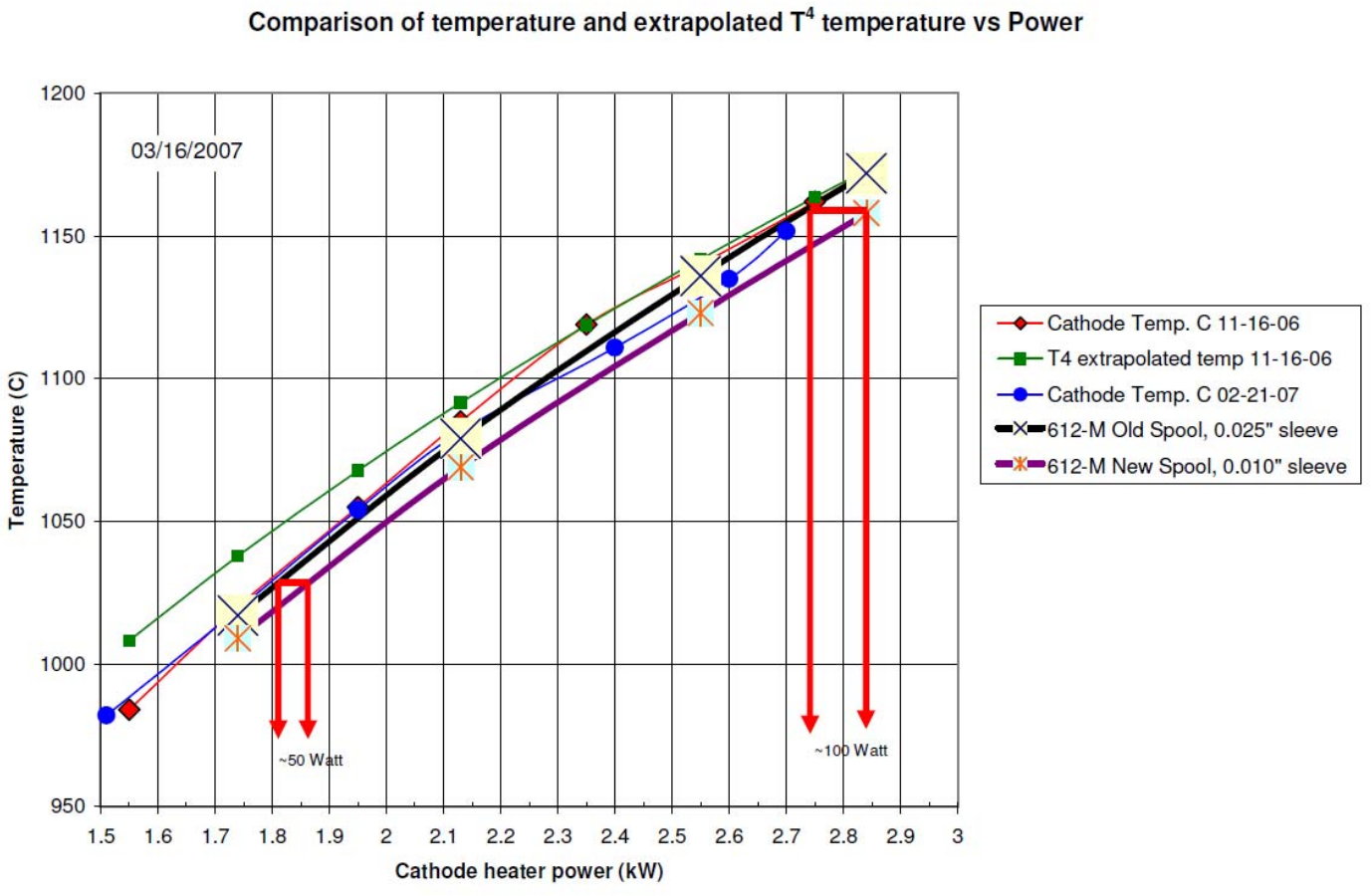




\section{COMPUTER SIMULATION OF BEAM OPTICS}

The extraction diode for the DARHT injector is shown in Fig. 4.1. Previously the separation between the cathode and the anode was set for extracting $2 \mathrm{kA}$ with an applied voltage of 3.2 MV. Recently, the specification was changed to a maximum of $2.5 \mathrm{MV}$ in order to reduce the potential breakdown hazard. Thus it was necessary to reduce the gap distance such that $2 \mathrm{kA}$ can be extracted with the reduced voltage.

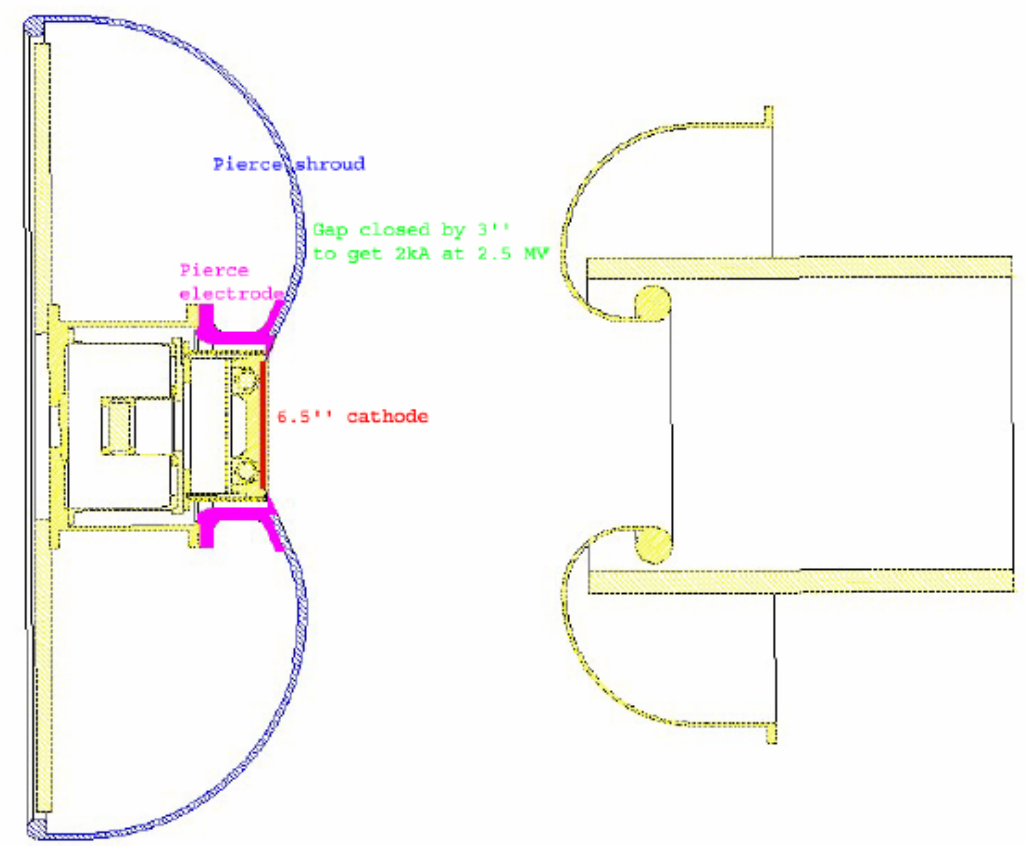

Fig. 4.1. Schematic of diode showing the cathode and anode positions.

Using EGUN, it was shown that the new geometry has peak fields of $140 \mathrm{kV} / \mathrm{cm}$ on the anode and $120 \mathrm{kV} / \mathrm{cm}$ on the cathode. These numbers were not too different from the previous 3.2 MV design. Furthermore, a new set of calculations was performed using the particle-in-cell code WARP, after WARP was improved to include emission from radial surfaces (and sharp corners), as well as higher resolutions obtained by using mesh refinement methods. The purpose of the computational study was to determine the mechanical tolerance required for assembly and to allow for axial motion of the cathode due to thermal expansion while the cathode is hot. 

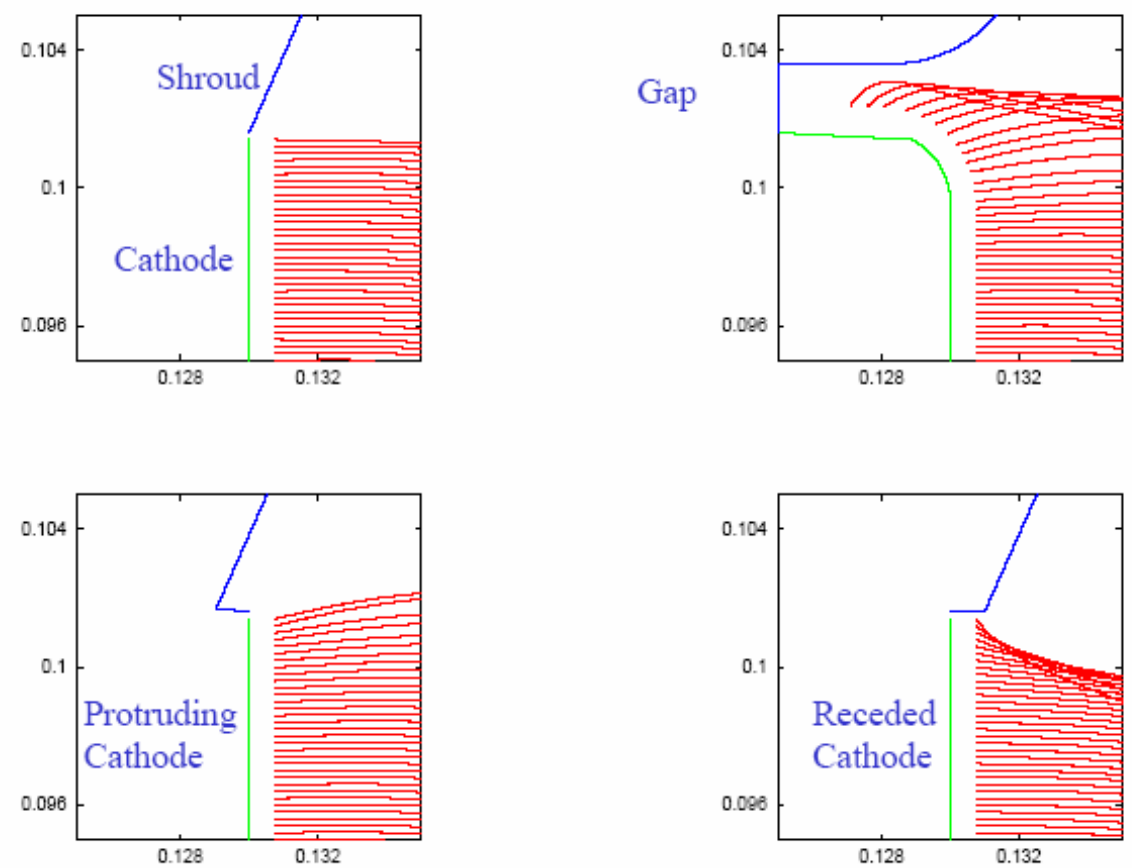

Fig. 4.2. EGUN calculations for several types of cathode-shroud assembly errors.

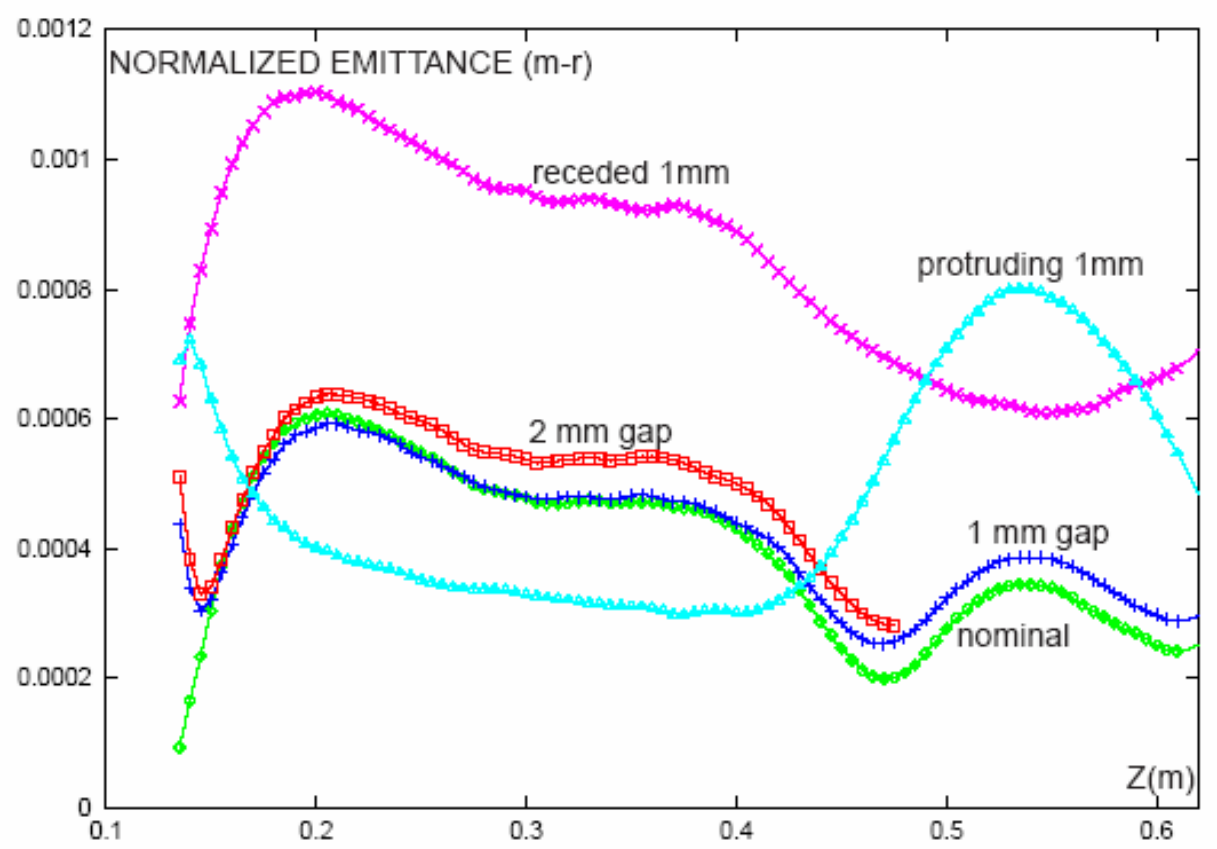

Fig. 4.3. EGUN calculations showing the emittance varying along the diode axis for several types of cathode-shroud assembly errors. 
The study considered sources of beam quality degradation like the errors in axial and transverse positioning, and the size of the radial gap between the cathode and the Pierce electrode (shroud). These effects are illustrated in figure 4.2. The figure of merit used in the parametric study was the RMS beam (edge) emittance at a distance of 1 meter from the cathode. Figure 4.3 shows a typical plot of the emittance varying along the $\mathrm{z}$ axis for different parameter settings. A technical note ${ }^{1}$ which discusses detailed results of this study is attached at the end of this report.

For the case of axial positioning, the effect of receding cathode has less impact than protruding cathode, e.g., a 40-mil receding cathode generates $1.1 \mathrm{~A}$ of translaminar beam compared to $6.6 \mathrm{~A}$ for protruding the cathode by the same amount (40 mils). It was found that an error of $+/-20$ mils will increase the normalized (edge) emittance of the beam by about $50 \pi$-mm-mrad (out of $250 \pi$-mm-mrad), increase (protruding) or decrease (receding) the current by about 50 Amperes, and increase (protruding) or decrease (receding) the beam size by about $2 \mathrm{~mm}$.

Our calculation predicted that heat expansion will move the cathode forward by 20 mils and the OD by 20 mils. Thus a 60 mils radial gap (between the cathode edge and the tip of the Pierce electrode) when the system is cold will end up with a 40 mil radial gap when the cathode is hot. This 40 mils radial gap will increase the emission by $3.2 \mathrm{~A}$ of translaminar beam current, but has minimal emittance increase.

An offset in the transverse position can lead to centroid motion when a beam propagates downstream. Usually, this motion is damped by the external magnetic field. We found an increase of about $20 \%$ in emittance when the center of the cathode was offset by 20 mils, i.e. half the 40-mil radial gap. The compromise here is to use the smallest possible gap but without risking the cathode from touching the Pierce electrode (a severe heat loss situation leading to non-uniform temperature and emission). The recommendation is to use a 40-mil gap and an alignment tolerance of 4 mils.

\footnotetext{
${ }^{1}$ E. Henestroza, Sensitivity Analysis of the DARHT-II 2.5MV/2kA Diode, LBNL-62296, HIFAN-1562, Dec. 22, 2006
} 


\section{Dispenser Cathodes}

\subsection{General Properties}

Dispenser cathodes provide high electron emission current density $\left(5-10 \mathrm{~A} / \mathrm{cm}^{2}\right.$ or greater) at relatively low operating temperature $\left(\sim 1000-1100{ }^{\circ} \mathrm{C}\right)$ [Refs. $\left.1-4\right]$. In a dispenser cathode a thin film of emitting material on the surface of the cathode is continuously replenished from a porous tungsten substrate impregnated with the desired surface coating material. The impregnate in the Type $\mathrm{M}$ dispenser cathode used for DARHT consists of a mixture of the oxides $\mathrm{BaO}, \mathrm{CaO}$, and $\mathrm{Al}_{2} \mathrm{O}_{3}$ and is referred to by the ratio of these three impregnate materials (e.g. 612 or 311). The Type $\mathrm{M}$ cathode has a thin osmium-ruthenium surface coating (designated $612 \mathrm{M}$ or $311 \mathrm{M}$ ) to reduce the surface work function. The alternative osmium-tungsten coated cathode (sometimes referred to as a Type CD cathode) as used on ETA-II was found to have a high thermal surface emissivity and thus required too much heater power to operate on DARHT. An additional scandate $\left(\mathrm{Sc}_{2} \mathrm{O}_{3}\right)$ impregnate is included to provide higher emission capabilities at lower temperature (designated here as $\mathrm{X}$ in 311XM if scandate is present). Matrix density of the porous tungsten substrate is generally $80 \%$. We have purchased our cathodes from Spectra-Mat, Inc. Alternate vendors include Semicon Associates and Heat Wave Labs.

Thermal electron emission from all types of cathodes, including dispenser cathodes, is described by the Richardson-Dushman equation [Ref. 10]:

$$
J_{s}=A_{0} T^{2} \exp (-\phi / k T)
$$

where $J_{s}=$ saturated emission current density, $A_{0}=$ is Richardson's constant (120 $\mathrm{A} / \mathrm{cm}^{2} / \mathrm{deg}^{2}$ ), $T=$ temperature, $\phi=$ effective work function, and $k=$ Boltzmann's constant. The effective work function, $\phi$, is generally not constant, but is a function of the surface condition which can change with temperature. An important contributor to the surface conditions is the partial pressure of contaminant gases such as oxygen or water vapor. The DARHT cathode requires an electron emission current density of slightly less than $10 \mathrm{~A} / \mathrm{cm}^{2}$ to produce a beam current of $2 \mathrm{kA}$ from a cathode of diameter $6.5 "=16.5 \mathrm{~cm}$. 


\subsection{Characteristics of the DARHT-II Cathode}

Type $\mathrm{M}$ cathodes have a nominal work function of $\phi=1.8 \mathrm{eV}$. Based on this work function, the operating temperature to achieve a current density of $10 \mathrm{~A} / \mathrm{cm}^{2}$ should be $<1000{ }^{\circ} \mathrm{C}$. However initial tests of the cathodes on DARHT showed a much higher work function than expected. Typical experimental work functions were in the range $\phi=$ 2.0 to $2.1 \mathrm{eV}$, forcing operation at over $1100{ }^{\circ} \mathrm{C}$ to achieve a beam current of only $1 \mathrm{kA}$. Operation at high temperature results in dramatically reduced cathode lifetime. Concern over the ability to operate the cathodes reliably at $2 \mathrm{kA}$ led to the development effort described in this report.

In this work, cathode surface temperature was measured by a disappearing wire single-color pyrometer $(\lambda=650 \mathrm{~nm})$. This type of pyrometer does not provide the true temperature but a brightness temperature. Brightness temperature is always lower than the true temperature. Conversion from brightness temperature to the true temperature was calculated from the formula:

$$
\frac{1}{T}=\frac{1}{T_{b}}+\frac{\lambda \cdot 2.303 \log \varepsilon_{\lambda}}{C}
$$

where $T=$ true temperature $(\mathrm{K}) ; T_{b}=$ brightness temperature $(\mathrm{K}) ; C=1.433 \mathrm{~cm}$ deg; and $\varepsilon_{\lambda}=$ spectral emissivity at the measurement wavelength $\lambda$ [Ref. 4]. The conversion formula requires a good estimate for the emissivity of the cathode surface. Our emissivity estimates were derived from careful measurements using an absolutelycalibrated multiple-wavelength FAR Pyrometer (FAR Associates, www.pyrometry.com ) on similarly-coated cathodes at the DARHT-II injector. Comparable measurements at the LBNL cathode test stand were not possible because the small diameter of the $1 / 4$ " cathodes under test was not compatible with the optical design of the FAR pyrometer.

Heating of the cathode is usually done by passing electrical current through a potted tungsten filament. The heater power supply should be AC, preferably grounded to the cathode body, to avoid possible chemical reactions in the potting material at high temperature. [Ref. 6]. 
An important practical consideration is avoiding poisoning or contamination of the cathode surface by ambient gases. This requires careful activation of the cathode and operation at a vacuum pressure as low as possible.

Surface analysis of a DARHT-II 612M cathode was performed by CPI using a scanning electron microscope with EDS (x-ray spectroscopy) [Ref 6a] to verify the presence of the Os/Ru coating, on the emitting surface. Measurements and images showed the porous surface and intact coating. This measurement verified that the cathode had good porosity and sufficient quantity of the coating and impregnant near the emitting surface.

\subsection{Cathode Activation}

The activation procedure developed for the DARHT-II cathode is based on published activation guidelines [Ref. 7]. For a large cathode the activation process can take an extended period of time (1-2 weeks). The pressure should be held below $1 \times 10^{-7}$ Torr at the cathode, with two major holds at $400 \mathrm{C}$ to outgas water vapor, and at $900 \mathrm{C}$ to reduce the cathode to pure tungsten. The final step involves heating the cathode to a high temperature $(\sim 1200 \mathrm{C})$ for 2 hours to oxygenate the cathode surface. A typical activation procedure can be found in chapter 6.

Reactivation after exposure to air or transportation of the cathode follows a similar procedure. To minimize introduction of moisture from the air, the cathode should be transported under vacuum or in a dry nitrogen atmosphere. Reactivation tests of the $1 / 4 " 311 \mathrm{XM}$ cathode to simulate this procedure have shown little or no difficulty in reactivating the cathode.

\subsection{Ambient Gas}

A major effort has been made to determine the effect of ambient gas on cathode performance. Poisoning by metal vapors and gases is discussed in Ref. 8-10. Because the DARHT-II injector is not a sealed, baked-out system, ambient gas is always present during operation. Understanding and reducing the level of contaminant gas was probably the single most important factor in improving cathode performance to allow reliable 
operation at $10 \mathrm{~A} / \mathrm{cm}^{2}$. Cathode contamination depends on both material choices and residual gases. Table 1 of Ref. 8 lists materials that can poison dispenser cathodes. These include reactive residual gases or vapors such as oxygen, water vapor, benzene, chlorine, fluorine, sulfur, silicon, and most metals other than molybdenum, rhenium, tungsten, and copper. The metals interact with the cathode surface through their vapor pressure. Ref. 9 shows the threshold effects of some common residual gases or vapors on cathode performance. Ref. 10 also contains useful information on cathodes and poisoning agents. This information is summarized in Ref. 11 and below.

\subsection{Other Poisoning Effects}

Structural components of the cathode assembly may contain steel. At 500-600 C in an oxygen atmosphere chromium oxide may outgas from the steel. [Ref. 12] Steel may also contain silicon, and sulfur at low concentrations. Therefore use of steel should be limited or avoided at high temperature near the cathode. Other materials that should be avoided in the vicinity of the cathode include brass, silver, zinc, non-OFHC copper, silicates, and sulfur-containing lubricants such molybdenum disulfide. Copper that is not OFHC contains oxygen and other impurities and should be avoided. Lubricating screw coatings should be chosen carefully to have no sulfur content.

Macor is an aluminosilicate-based insulator that is not stable at high temperature. Any Macor near the cathode should be replaced by a high-temperature insulator such as

alumina ceramic. Other insulating materials that contain silicates, such as fiber insulating sleeves, should be avoided.

Common sources of contamination that can cause low emission include water, saliva, silicates such as glass dust, etc. Cathodes should be handled in near clean-room conditions to minimize the amount of water vapor on the cathode surface from breathing, etc. Cathodes should also be stored in such as a way as to avoid contact with materials such as glass dust and water vapor.

In chapter 7 we present the experimental data obtained from testing $1 / 4$ " cathodes in a $25 \mathrm{kV}$ test stand in LBNL. The data shows how the various gases affect the emission 
current density and enabled us to determine the required vacuum for high current density emission.

\subsection{References}

1. S. Yamamoto, Fundamental physics of vacuum electron sources, Rep. Prog. Phys. 69 (2006) 181-232.

2. Spectra-Mat TB-104, TB-105, TB-117-C http://www.spectramat.com/cathode.html.

3. Heat Wave Labs TB-117, TB-119, TB-128 http://www.cathode.com/c_cathode.htm.

4. L.R. Falce, Dispenser cathodes: the current state of the technology, and other papers at http://www.semiconassociates.com/library/technical-papers.aspx

5. J.L. Cronin, Modern Dispenser Cathodes, Heat Wave Labs TB-135

6. Spectra-Mat TB-200.

6a. CPI Analysis Report, Cathode Evaluation with SEM/EDS, CPI Process Engineering Chemistry Laboratory Analysis Report, 2/23/06, HIFAR-xxxx (LBNL).

7. Spectra-Mat TB-106, TB-147-C.

8. Heat Wave TB-128, TB-134.

9. W.E. Nexsen and W.C. Turner, Poisoning studies of an osmium-coated dispenser cathode, J. Appl. Phys. 68 (1990) 298-303.

10. Walter H. Kohl, Handbook of materials and techniques for vacuum devices, American Institute of Physics, 1995 (reprint).

11. F. Bieniosek, D. Baca, W. Greenway, M. Leitner, Comments on cathode contamination and the LBNL test stand, LBNL-61978, Nov. 13, 2006.

12. Cho, et.al., J. Vac. Sci. Technol. A 19, p. 998 (2001) 


\section{TESTING OF THE 6.5” CATHODE AT LBNL}

\subsection{The Motivation}

The Relativistic Two-Beam Accelerator (RTA) test stand at LBNL was modified to accept the full-size (6.5") DARHT-II cathode in an effort to assist the cathode development and commissioning for DARHT-II. The purpose was to test the cathode off-line from DARHT-II, we can save time and money for the project. The cost of running the RTA test stand was many times less than running DARHT-II. Furthermore, the RTA test stand may provide better controls and diagnostics in testing the cathode than what can be done on DARHT-II.

The dispenser type cathodes usually require an "activation" process before they can emit full current density. The process involves slowly bringing up the cathode temperature while keeping the vacuum in check. Chemical reactions occur during this phase and eventually the cathode surface will reach an equilibrium condition with the proper work function for electron emission. It was thought that the RTA test stand can be used to pre-activate the cathode before shipping it to mount on the DARHT-II injector, thus minimizing DARHT-II's down-time.

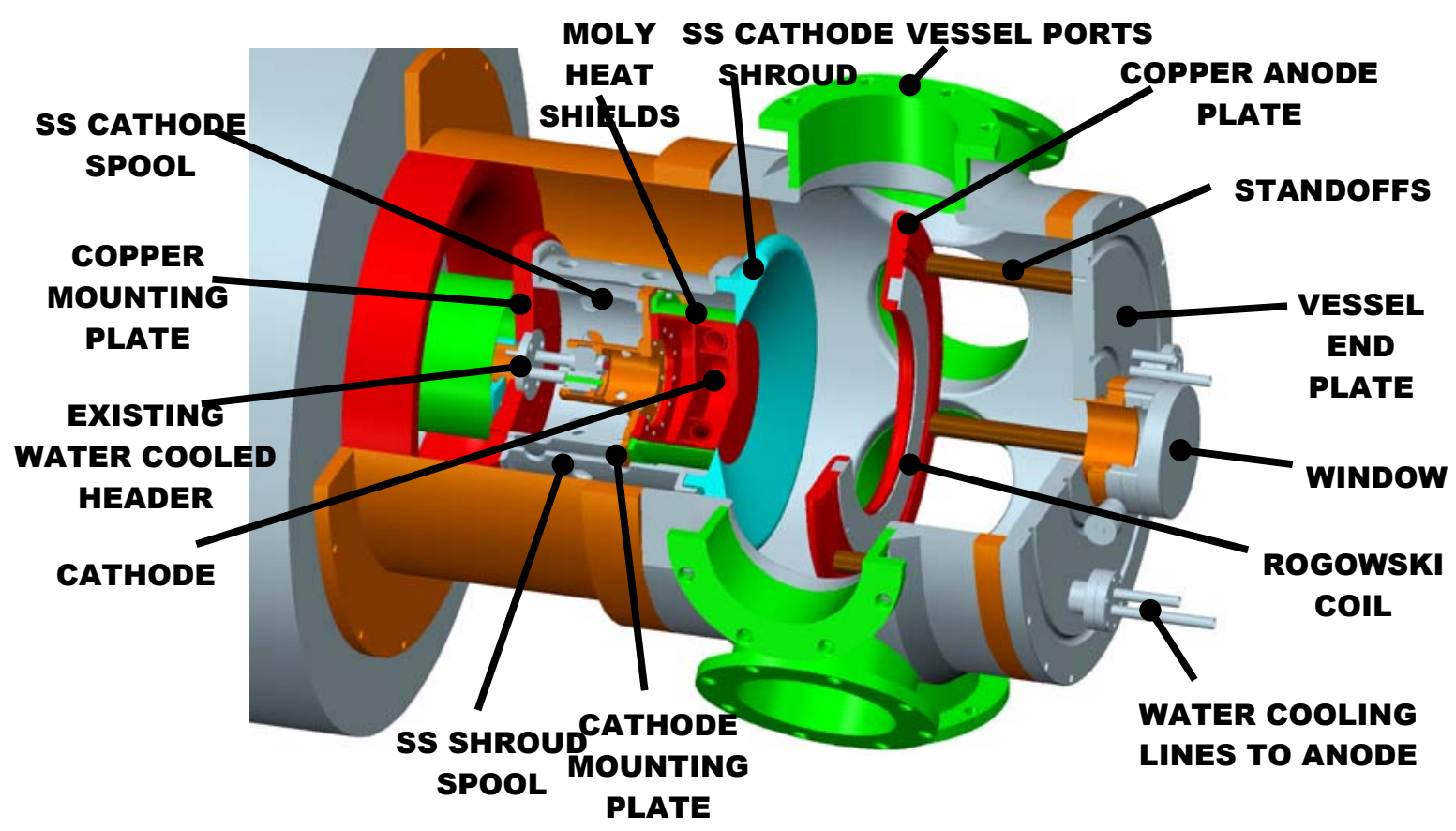

Fig. 6.1. Exploded view of the RTA test stand with a 6.5 " cathode. 


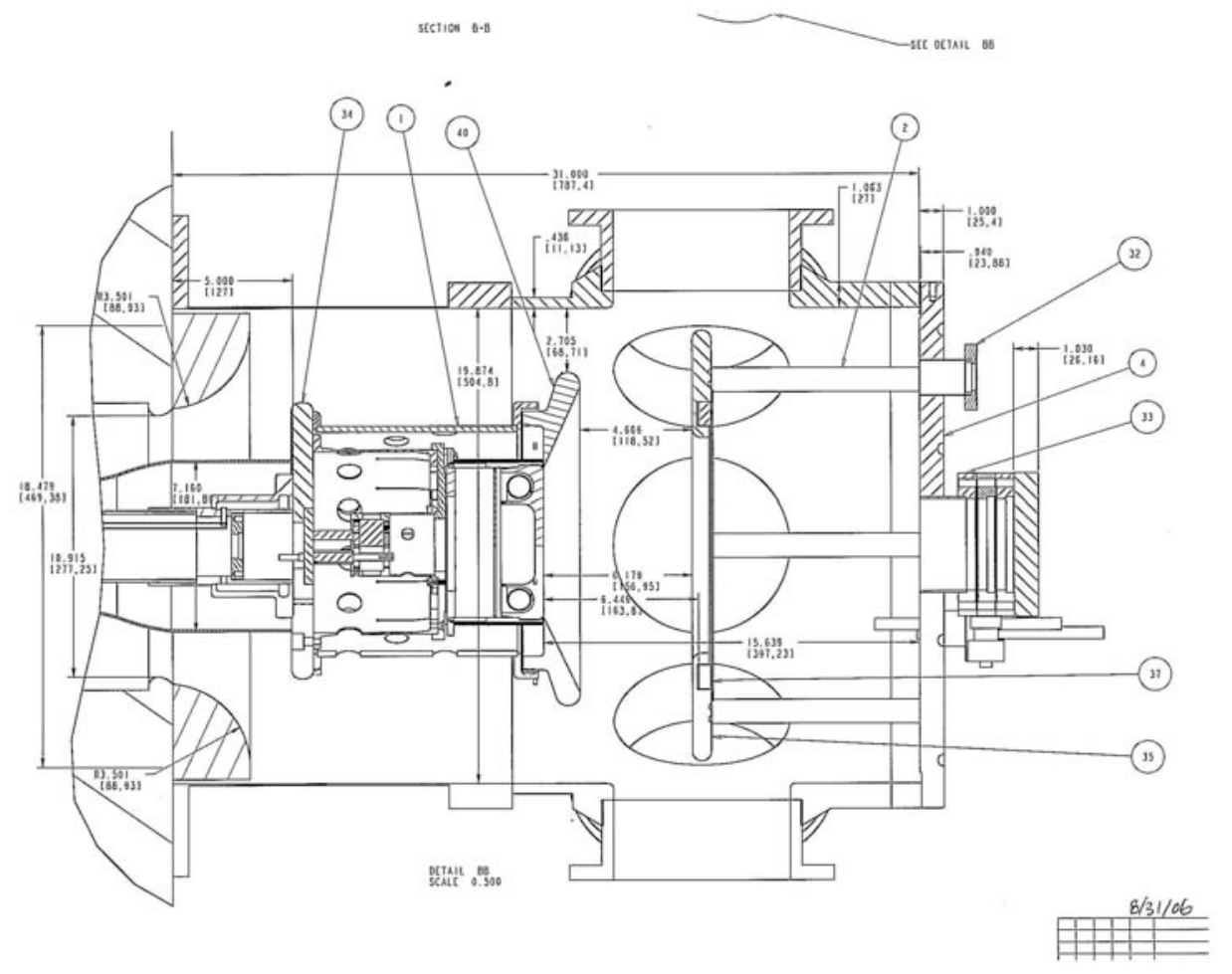

Fig. 6.2. Schematic diagram of the 6.5 " cathode mounted in RTA.

\subsection{Experimental Set $U$ p}

Figure 6.1 is an exploded view of the RTA test stand with a 6.5 " cathode and Fig 6.2 is a schematic diagram of the set up. The window downstream provided access for optical pyrometry to measure the cathode surface temperature. Figure 6.3 (a, b, c, d) are photographs of the components.

In planning this experiment, we assumed that once the cathode was activated, the work function could be measured and that the value of the measured work function would remain constant during operation in DARHT-II. Furthermore, it was assumed that the work function $(\phi)$ remains a constant independent of the operating temperature. The electron emission would be described by the Richardson-Dushman equation (5.1). 

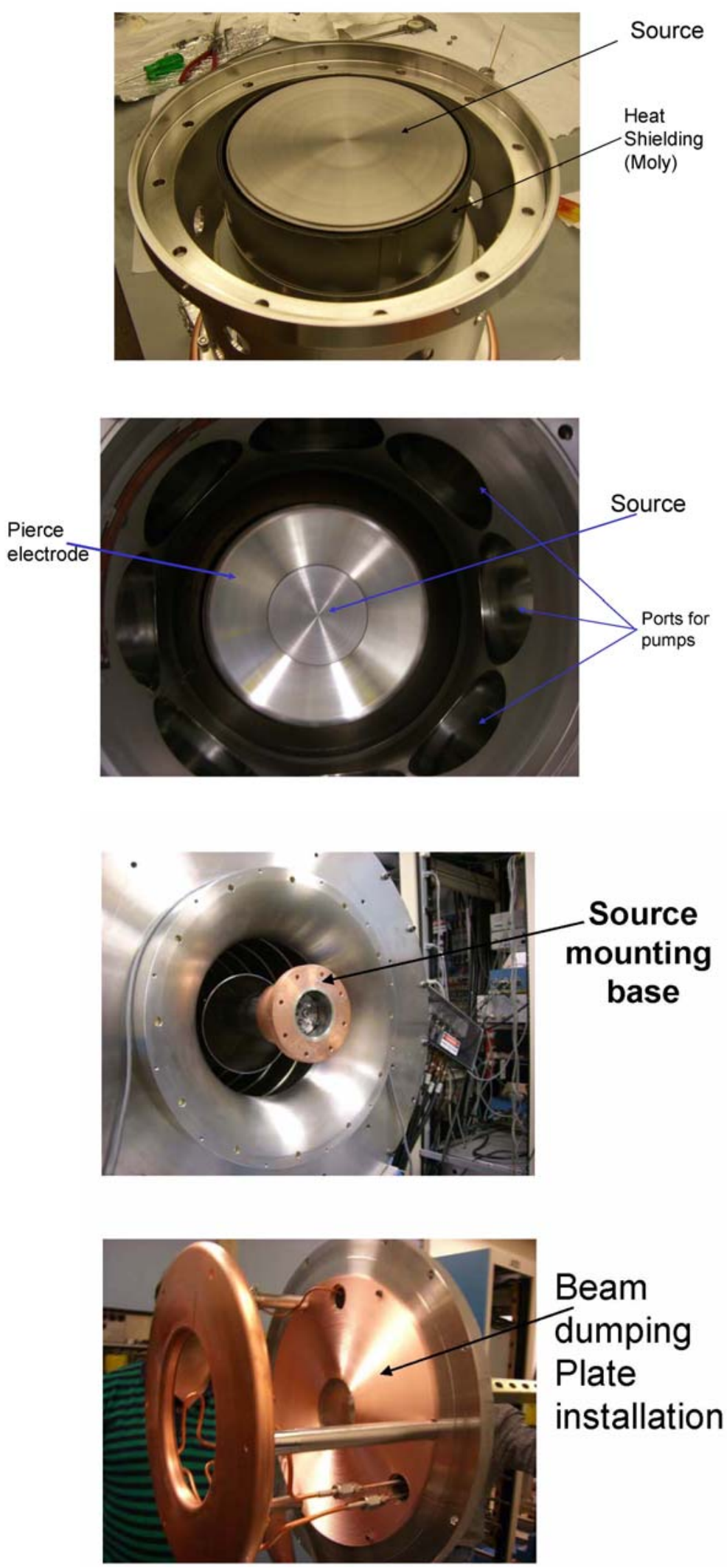

Fig. 6.3. Photographs of the RTA test stand with a 6.5 " cathode. 
From equation (5.1), the effective work function can be determined by measuring the current density and the temperature. In the emission limited regime, the beam current will be determined by the temperature, not by the voltage applied across the extraction diode (between the cathode and the anode). Computer simulation indicated that a beam current of $16 \mathrm{~A}$ can be extracted when $50 \mathrm{kV}$ diode gap voltage was applied. Beam optics was not essential in this case as long as all the beam current was collected (without losing secondary electrons). Our task was to measure the required temperature in order to reach $16 \mathrm{~A}$ of beam current. The setting of $50 \mathrm{kV}$, with a pulse width of $200 \mathrm{~ns}$, was chosen in order to limit the x-ray radiation hazard (to get approval for radiation safety). The test stand was capable of much higher voltage and we could revise the administrative limit, if necessary, after initial radiation survey. Initial operation used a DC supply (Lambda EMI TCR100T120-4, 100V, 120A) for the heater filament, but it was later replaced by a $60 \mathrm{~Hz}$ AC power supply (variac, Superior Electric Powerstat 60MB1156D-2P, 120VAC, 100A) to avoid reactions which may deposit conductive material on the Alumina potting (see Spectra-Mat bulletin).

\subsection{Activation Procedures and Handling Guideline}

The guidelines for activation of dispenser cathodes from SpectraMat can be found in their company technical bulletin TB-147-C 12/04. These guidelines were written mainly for small cathodes in vacuum tubes that can be baked-out to achieve good vacuum down to below $10^{-8}$ Torr range. But the DARHT-II Injector can not be baked and the 6.5 " cathode is massive, so it was necessary to modify the activation procedure accordingly. Furthermore, the vacuum gauges in DARHT-II are at a considerable distance from the cathode, therefore one has to make an educated guess of the true pressure in front of the cathode surface.

The ETA-II has a $12.5 \mathrm{~cm}$ diameter cathode and their system is also not baked. Therefore the ETA-II experience may be more relevant to DARHT-II than that prescribed in the Spectra-Mat bulletin. The main difference is in the length of time used in accordance with the size of the cathode. In ETA-II, after installation of the cathode, the system is pumped overnight without heating the cathode to establish a baseline vacuum condition. If the weather has been moist or the injector has been open for several days, 
the pumping may take as long as a few days. After an initial heating to about $1 / 5$ of nominal operating power (1750 watts at 70 amps and 25 volts), the cathode is soaked at this medium temperature overnight (i.e. minimum twelve hours). Then in the next step, the cathode is slowly brought to the nominal operating temperature $\left(1061^{\circ} \mathrm{C}\right)$ and is soaked again overnight at that temperature. Finally, the cathode temperature is raised to the "red-line" level and held there for 8 hours before returning to the standby power level (1/5 nominal power).

Based on the Spectra-Mat bulletin and the ETA-II experience, we have written the following procedure to be used for activating a new cathode in the DARHT-II injector. The complete technical note can be found in the attachment section at the end of this report.

- Before starting, make sure that the vacuum is good. Lower vacuum is always better and it should be at least in the low $10^{-7}$ Torr range.

- Increase the Cathode Heater Power in small increments (typically $0.05 \mathrm{~kW}$ per step) while keeping the injector vacuum stabilized below $3 \times 10^{-7}$ Torr.

- When the Cathode Heater Power set point reaches $0.4 \mathrm{~kW}$, hold this Power setting for 12 hours (overnight). The vacuum must be stabilized before resuming Heater Power ramp and pressure control.

- Ensure the FAR Pyrometer is on when Heater Power reaches $1 \mathrm{~kW}$.

- When the Far Pyrometer reads a stable temperature of $875 \pm 25^{\circ} \mathrm{C}$, hold the Cathode Heater Power constant for 8 hours. The vacuum must be stabilized before resuming Heater Power ramp and pressure control.

- When Far Pyrometer temperature reaches $1025^{\circ} \mathrm{C}$ (nominal operating temperature) hold this power setting and temperature for 8 hours (overnight). The vacuum must be stabilized before resuming Heater Power ramp and pressure control.

- When Far Pyrometer temperature reaches $1050^{\circ} \mathrm{C}$ hold this power setting and temperature for 2-4 hours or more until the temperature stabilized.

- The activation is done when the vacuum is also stabilized.

- Either lower temperature to nominal operating temperature for beam extraction, or turn down to standby mode at $875 \pm 25^{\circ} \mathrm{C}$.

Another issue is the handling of the cathode during storage and transportation because moisture in ambient air can be damaging to a $\mathrm{BaO}$ dispenser cathode. This includes what kind of gas (or vacuum) should used to store the cathode be stored inside a canister, and when the cathode is removed from the canister, how long can it stay in air before pumping down. Based on input from Spectramat, we have decided to store the cathode in nitrogen, and limit air exposure to 8 hours. That means the cathode should be 
installed within a working shift, following normal clean room procedure, and not left in air overnight. Good record keeping is essential to track the life history of a cathode. A note providing guidelines for the handling and storage is in the attachment section.

\subsection{Experimental Results}

As mentioned in sections 6.1 and 6.2, our main goal on the RTA test stand was to activate (or re-activate in the case of a used cathode sent back from DARHT-II) a 6.5" cathode and to measure its work function. The first problem we found was that although the base pressure at room temperature was in the low $10^{-8}$ Torr range, the vacuum pumping (using 2 turbo pumps and 2 cryo-pumps) was not good enough to keep the system below the mid $10^{-8}$ Torr range when the cathode was hot. Test data later found in the quarter-inch cathode test stand (see chapter 7) confirmed that our cathode should operate in the low $10^{-8}$ torr or below in order to have good emission. Thus we were never able to operate the cathodes at sufficiently low pressure. It took up to 7 days of continuously monitored heating and pumping to reach the activation temperature of $1050^{\circ} \mathrm{C}$. The situation was complicated by the fact that we were trying to recycle used cathodes that were taken from the DARHT-II injector. One of these cathodes had experienced a vacuum accident (exposure to air while hot) and the others were stored in air under an uncontrolled environment. Thus it was possible that these cathodes could not be revived in any case by activation in the RTA test stand.

In the activation run for the Os-W coated 311-XW cathode, the filament power was $43.86 \mathrm{~V}, 66.81 \mathrm{~A},(2930 \mathrm{~W}, 0.66 \mathrm{ohm})$ and pressure at $2.114 \mathrm{E}^{-7}$ Torr. Temperature measured with a 2-color pyrometer indicated the cathode surface at $1050^{\circ} \mathrm{C}$. The temp vs. power was closely repeating the result previously obtained at DARHT-II, see Fig. 6.4. After raising the temperature to $1071^{\circ} \mathrm{C}(3084 \mathrm{~W}, 45.5 \mathrm{~V}, 67.7 \mathrm{~A}, 3.0 \mathrm{E}-7$ Torr $)$, the heater power suddenly dropped to 27.34V, 67.7A. According to John Paff from Spectramat, the practical limit for the filament is about $1600 \mathrm{C}$, corresponding to a filament resistance of $0.74 \mathrm{Ohm}$. The left half of the cathode became significantly darker than the right half indicating that the heater filament (bifilar winding) failed and was shorted near the mid point, thus stopping power flow to the left side. Since both Os-W coated $311 \mathrm{X}$ cathodes (one at DARHT-II and one at LBNL) failed before reaching the desirable operating 
temperature, we concluded that this design was not suitable for DARHT-II. Apparently the 311-XW was acceptable for ETA-II because that cathode was smaller and consequently required less heating power, so the filament temperature was lower. In chapter 7, we show that the Os-W coating has a higher emissivity and therefore higher heat loss. Changing to a Os-Ru coating (M coating) reduced the heat loss and the 311$\mathrm{XM}$ type cathode was later proved to be successful in producing $2 \mathrm{kA}$ of emission at DARHT-II.

311-X Pyrometer Temperature $\left[{ }^{\circ} \mathrm{C}\right]$ vs Power

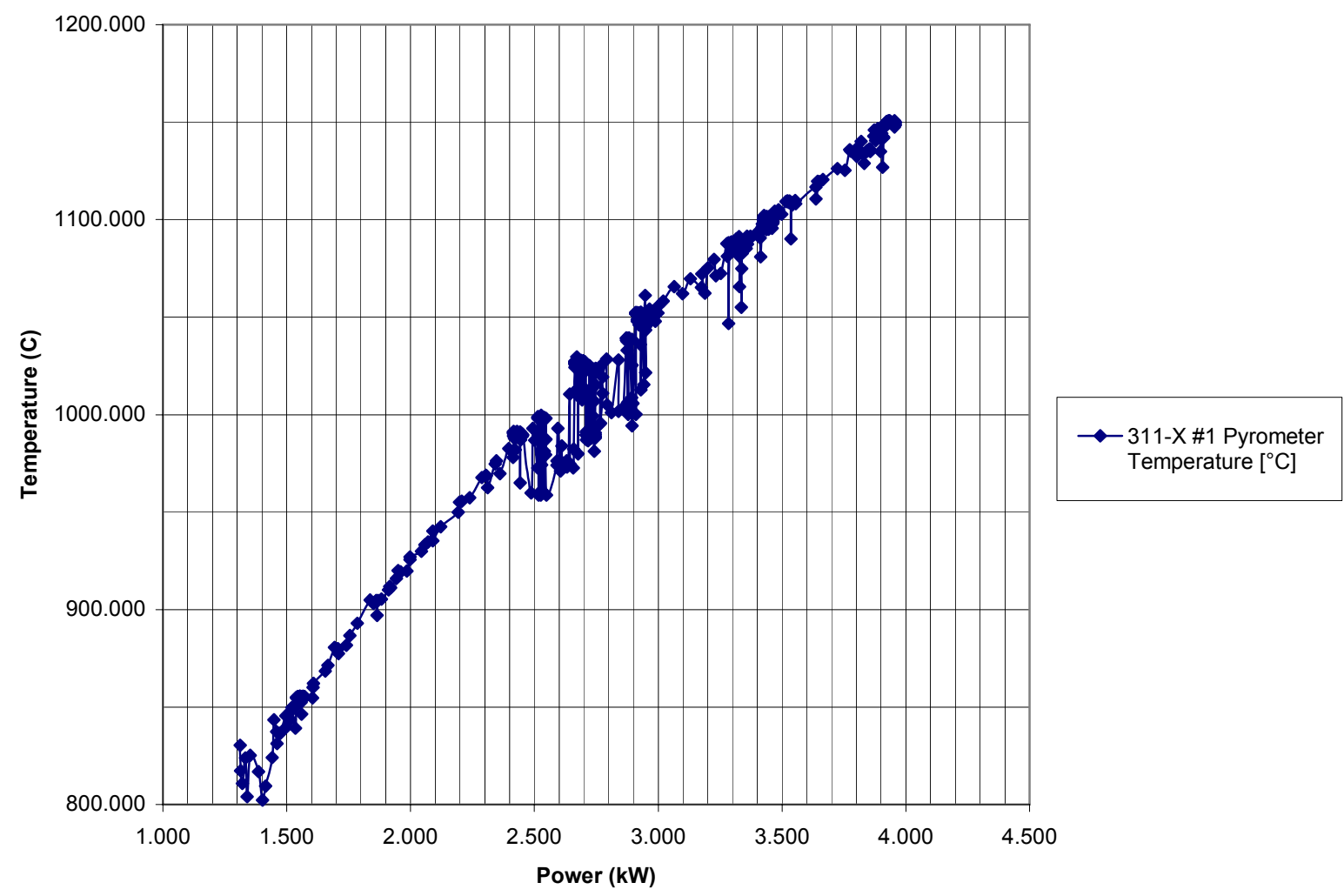

Fig. 6.4. Heating characteristic of the Os-W coated 311-X cathode (data obtained at DARHT-II).

We encountered another issue due to the long cooling time of the cathode. As in the quarter-inch size cathode test results, discussed in chapter 7, the work function does not stay constant when the system has less than ideal vacuum condition. In other words, 
the work function was a result of the surface condition that was dynamically balanced between the diffusion rate of the impregnated material $(\mathrm{BaO})$, and the poisoning effect from impurities in the vacuum. Thus measuring the work function at a lower temperature when the cathode is only emitting $16 \mathrm{~A}$ will not reveal the work function that we are interested to know when the cathode is required to emit $2 \mathrm{kA}$ at a higher temperature. Furthermore, we measured J and T to derive the work function according to Richardson's equation (Eq. 5.1). The measurement must be done rapidly in order to prevent the work function from changing over time. Usually the heater power was turn down to allow the cathode to cool, thus giving simultaneously the readings for $\mathrm{J}$ and $\mathrm{T}$. Unfortunately, this condition could not be achieve because the cooling time of the cathode was very long. Figure 6.5 shows the cooling characteristic after the heater power was turned off. More useful data was eventually obtained from the quarter-inch size cathode, which cools much more rapidly to allow a valid work function measurement.

DARHT CATHODE COOLDOWN

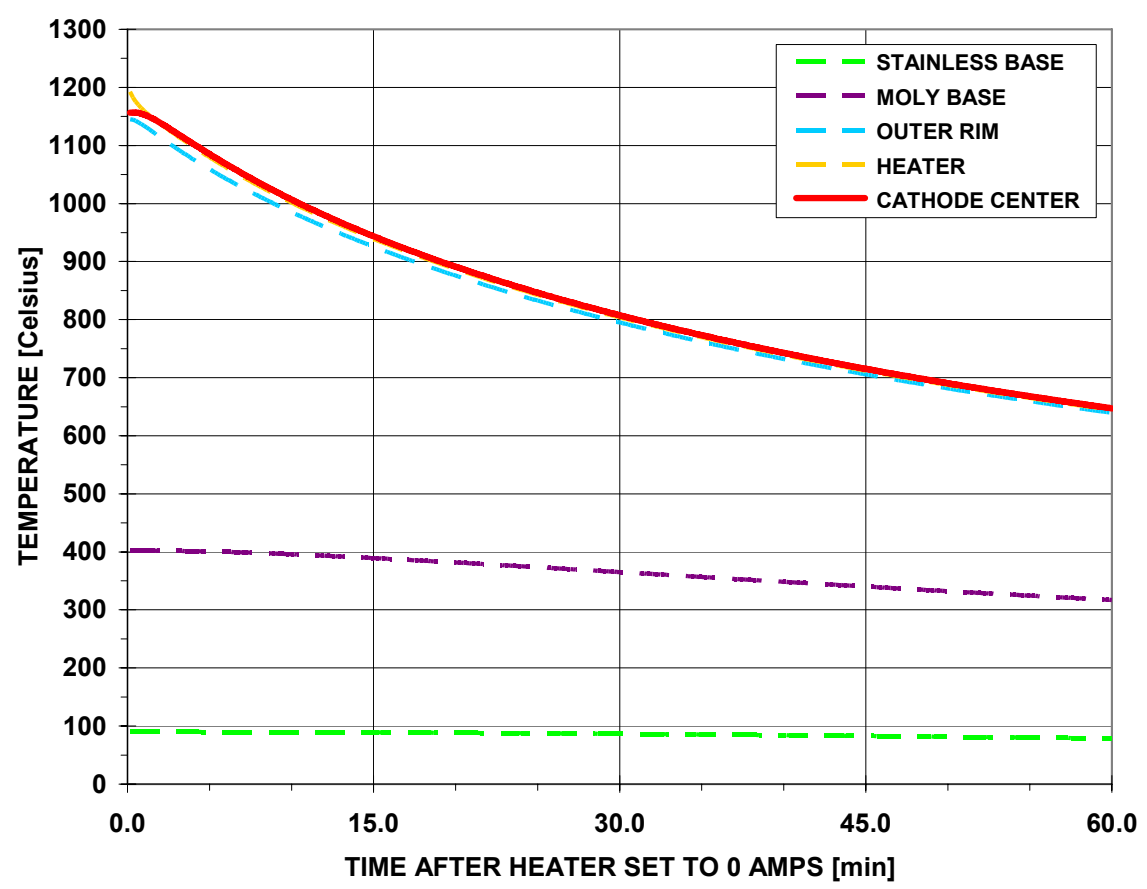

Fig. 6.5. Cooling characteristic of the Os-W coated 311-X cathode (data obtained at LBNL). 


\section{TESTING OF THE QUARTER-INCH CATHODE AT LBNL}

\subsection{Experimental Set $U p$}

In order to measure the performance of cathodes with various combinations of impregnation and coating, and also run the experiments under controlled environment, we modified an existing ion source test stand to test quarter-inch size cathodes. The HV power supply polarity was inverted to provide up to $27 \mathrm{kV}$ to extract electrons. The Faraday cup geometry was modified and the gap distance between the cathode and the anode was adjusted. According to EGUN simulation, the new set up allows $10 \mathrm{~A} / \mathrm{cm}^{2}$ maximum current density of electron emission. A schematic diagram of the set up is shown in Fig. 7.1, and the computer simulation results are shown in Fig. 7.2. Some photographs of the test stand are shown in Fig. 7.3.

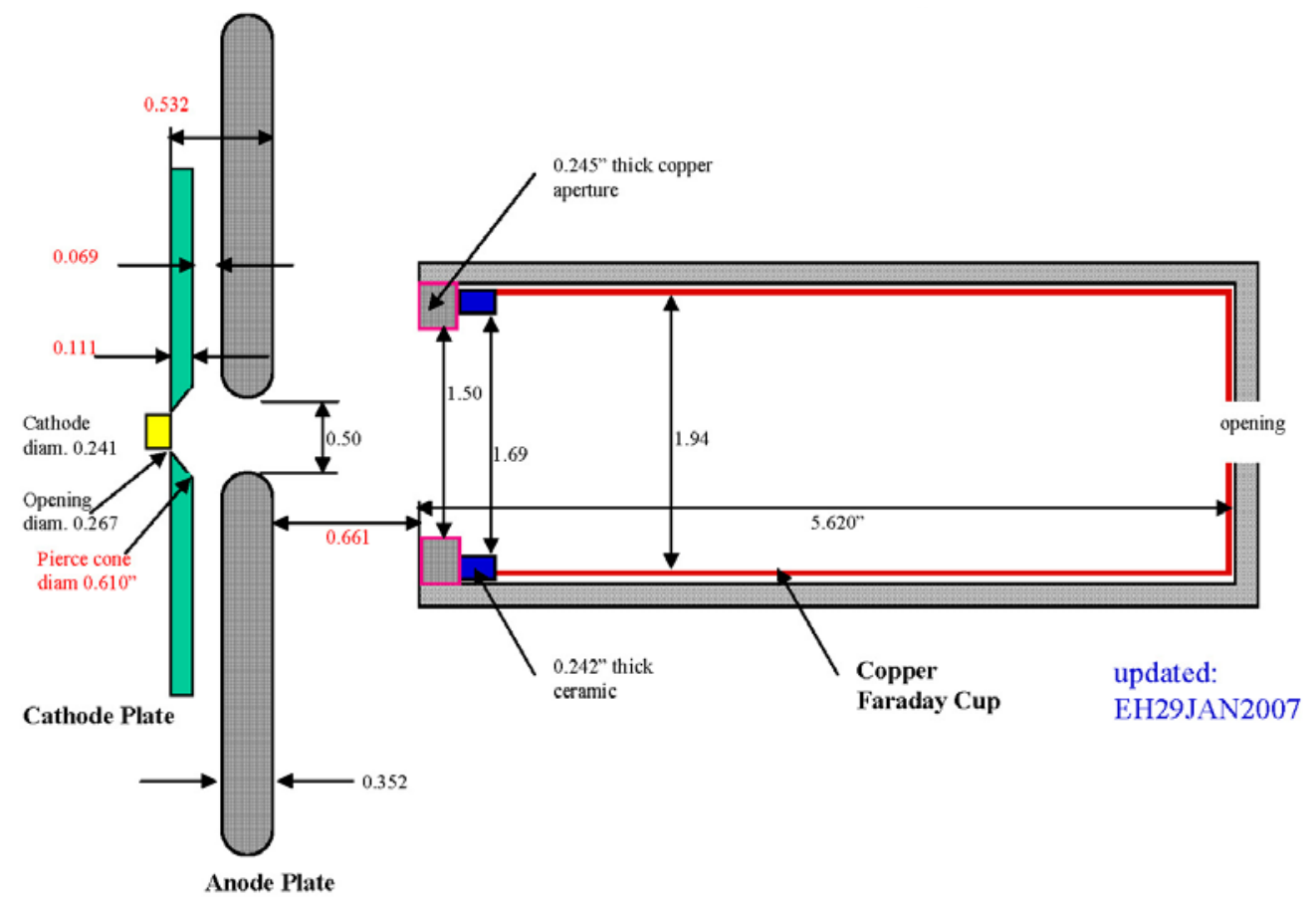

Fig. 7.1. The $1 / 4^{\prime \prime}$ cathode test set up with up to $26 \mathrm{kV}$ extraction voltage. 


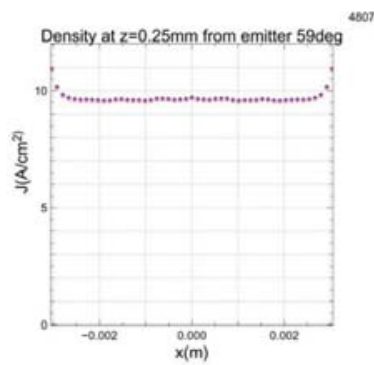

$\operatorname{Somp} 4000, T=0.00400-6$ s. $20000 \mathrm{~m}=0.0000 \mathrm{~m}$

OAPOT2 PC RZ SMULLATIONS

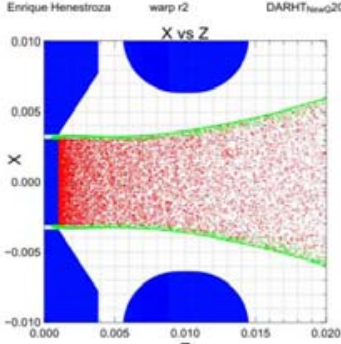

$\mathrm{z}$ window0 $=0.0000 \mathrm{e}+00,1.7780 \mathrm{e}-0$

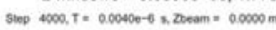

DNFrT2 PIC RZ SIMULATIONS

Enrique Heneatorata waph

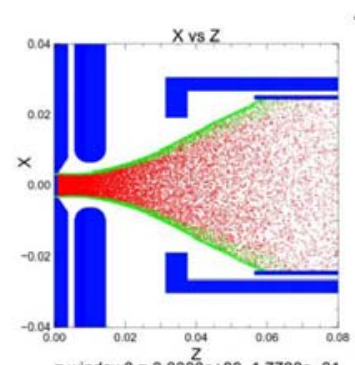

$z$ window $0=0.0000 \mathrm{e}+00,1.7780 \mathrm{e}-0$

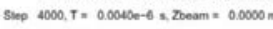
DAPAT2 PIC RZ SIMULATIONS

neowr. - may

The diode extracts 2.9 Amps

$\left(\sim 10 \mathrm{~A} / \mathrm{cm}^{\wedge} 2\right)$, with $20 \mathrm{kV}$

applied in the A-K gap.

The Pierce angle is $59 \mathrm{deg}$.

The copper Faraday cup

is biased at $4 \mathrm{kV}$, the casing is biased at $3 \mathrm{kV}$.

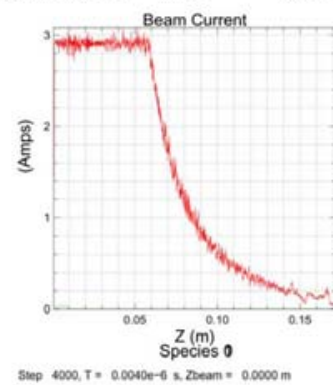

Davertz PIC RZ SimuLations

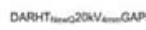

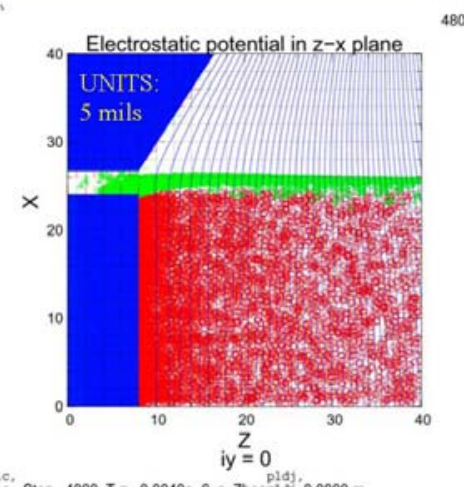

Fig. 7.2. EGUN simulation of the $1 / 4$ " size cathode testing.

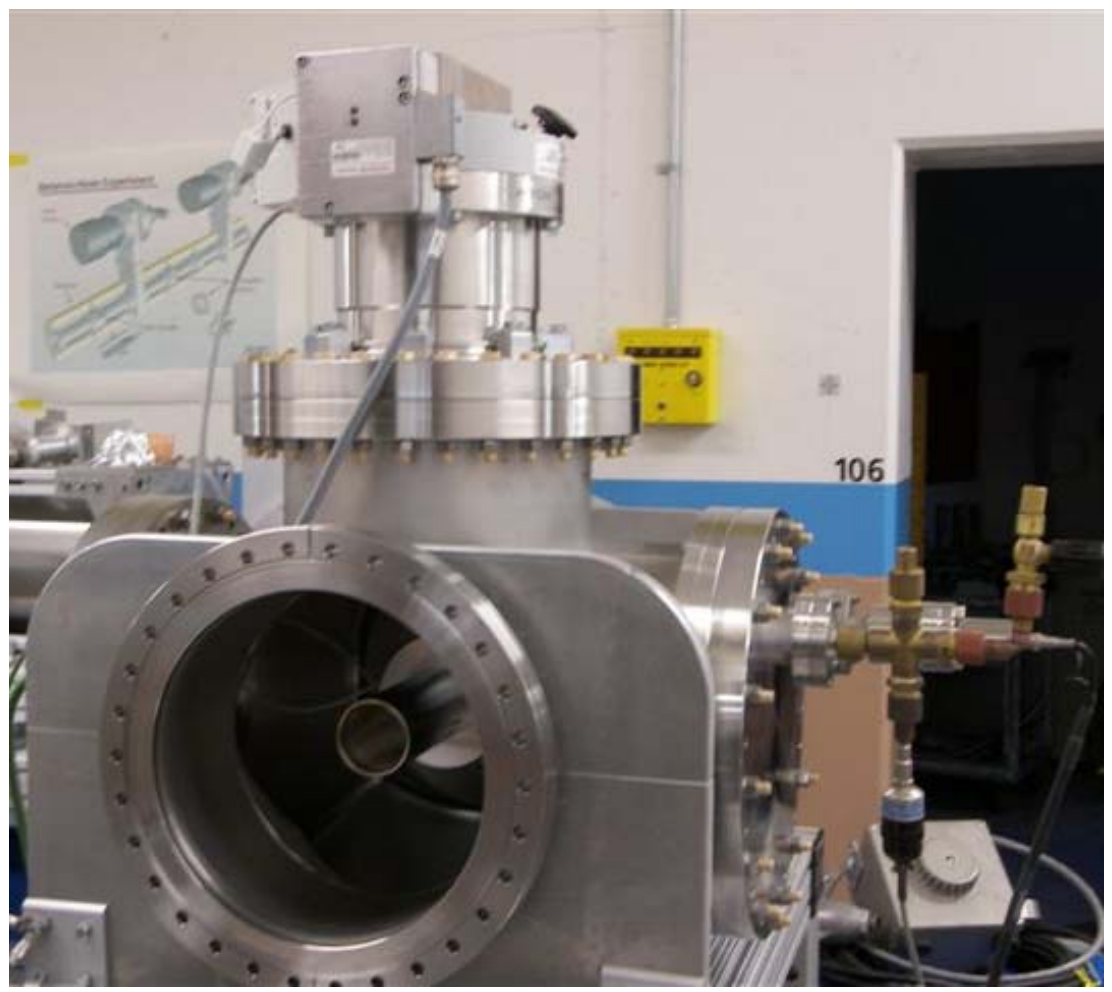




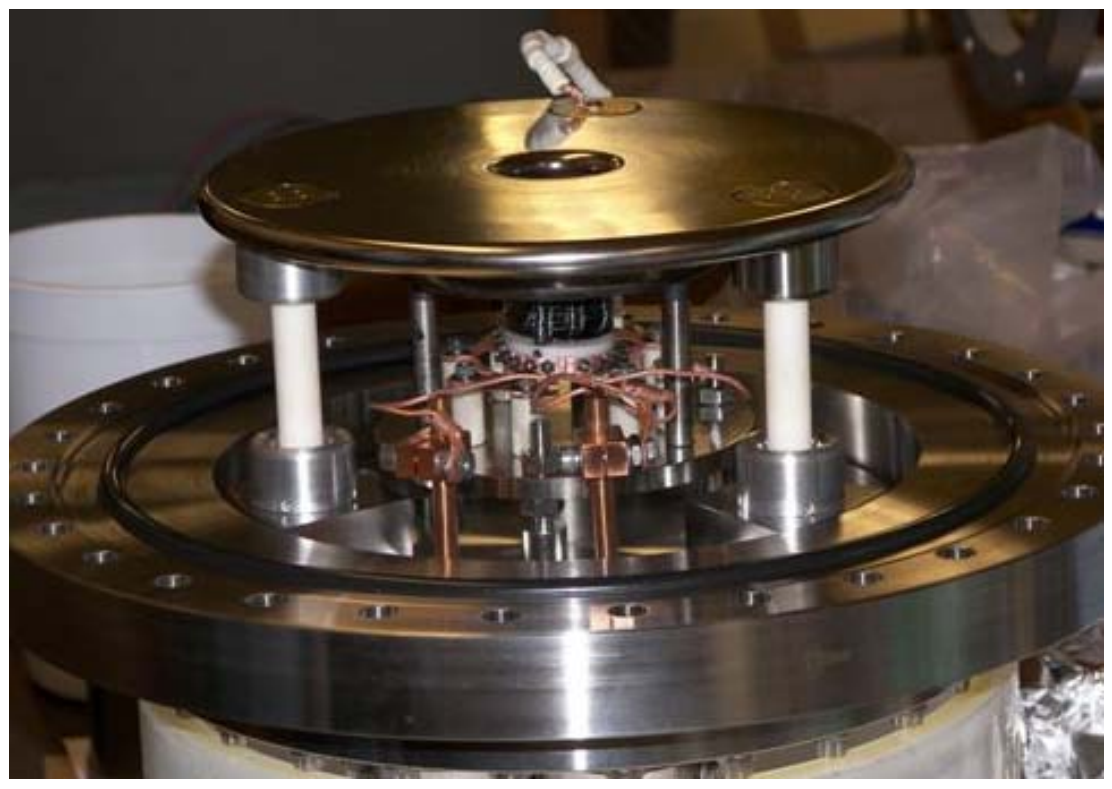

Fig. 7.3. Photographs of the " $26 \mathrm{kV}$ " test stand with $1 / 4$ " size cathode testing.

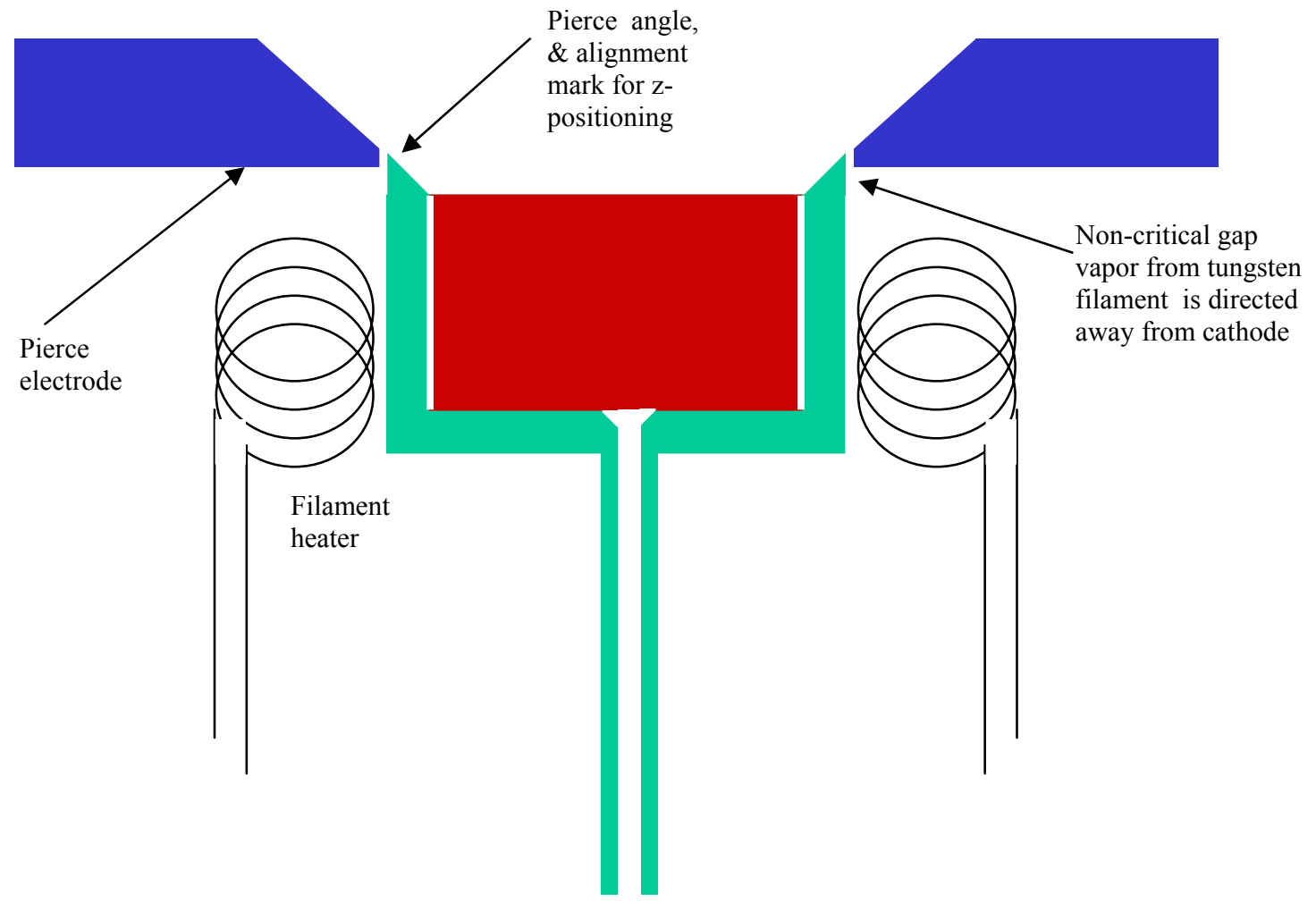

Fig. 7.4 Cathode and heater assembly. 
The electron gun was designed to mount vertically, and the $1 / 4$ " cathode was simply a "button" with no built-in heater. The button could be dropped into a cup holder. Heating was done by a set of 4 filaments surrounding the cup holder, connected in series. Figure 7.4 depicts the cathode and heater assembly. The filament was powered by a DC power supply in current control mode with the voltage limit set just above operating voltage (Sorenson DCS50-20E, 50V, 20A). While the cathode assembly was at ground potential, electrons were extracted when high voltage was applied to the extraction electrode. The HV Pulser was a solid-state modulator feeding into a step-up transformer with a negative bias voltage to suppress DC electron emission when the pulser was not on, see Fig. 7.5. After extraction, the electrons would decelerate as they approach the Faraday cup which was normally biased at about $+3.5 \mathrm{kV}$. The housing of the Faraday cup was at a slightly lower potential (about $+2.5 \mathrm{kV}$ ) but still positive w.r.t. ground potential in order to keep the electrons from stalling before entering the cup.

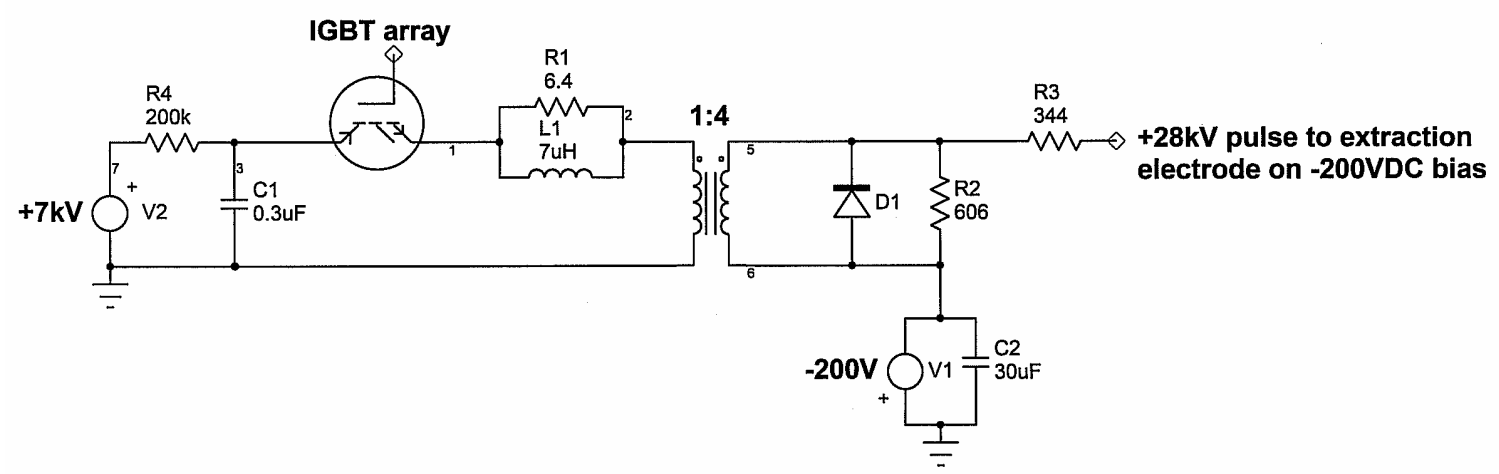

Fig.7.5. Circuit diagram of the biased HV pulser for extraction electrode.

The experiment required continuous $24 / 7$ operation, therefore it was necessary to upgrade the control system, using LabView and VNC to remotely monitor and (partially) control the operating parameters during night time and over the weekend.

The vacuum tank was thoroughly cleaned, and we used metal seals for the flanges in order to be able to bake the vacuum tank. Typical vacuum base pressure was in the $10^{-9}$ Torr range when the cathode heater was turned off. Given the small cathode size, the system was able to maintain pressure in the high $10^{-9}$ Torr range even when the cathode was hot. 
The Faraday cup was designed with a small opening at the rear end such that the cathode temperature can be measured by an optical pyrometer. According to the computer simulation, this small opening at the rear does not significantly affect the beam current measurement. Since it usually took more than 2 seconds to obtain a good reading from the manually operated optical pyrometer, it was not always possible to obtain the cathode temperature simultaneously with the current measurement. This was a problem during the rapid turndown experiment in which we measured the work function as a function of initial temperature. As a result we relied on the cathode being cooled in a reproducible way to derive the cathode temperature from a calibration curve.

A number of cathode buttons were purchased from Spectra-Mat. Table 7.1 shows the combination of impregnation and coating material. Due to the availability of time, only the 612M, 311XW and 311XM were tested (X stands for having Scandate in the cathode, $\mathrm{M}$ for Os-Ru coating and $\mathrm{W}$ for Os-W coating).

Table 7.1. 1/4" size button made by SpectraMat

\begin{tabular}{r|r|r|r|r|} 
Run & Block & $\begin{array}{l}\text { Factor 1 } \\
\text { A:Impregnan }\end{array}$ & $\begin{array}{c}\text { Factor 2 } \\
\text { B:Scandate }\end{array}$ & $\begin{array}{c}\text { Factor 3 } \\
\text { C:Coating }\end{array}$ \\
\hline 1 & Block 1 & 612 & w/Scandate & Os-W \\
\hline 2 & Block 1 & 612 & $w /$ Scandate & Os-Ru \\
\hline 3 & Block 1 & 612 & $w /$ Scandate & None \\
\hline 4 & Block 1 & 612 & w/Scandate & Os-Ru \\
\hline 5 & Block 1 & 311 & w/Scandate & Os-W \\
\hline 6 & Block 1 & 311 & $w /$ Scandate & Os-Ru \\
\hline 7 & Block 1 & 311 & w/Scandate & None \\
\hline 8 & Block 1 & 311 & $w /$ Scandate & Os-W \\
\hline 9 & Block 1 & 612 & None & Os-Ru \\
\hline 10 & Block 1 & 612 & None & None \\
\hline 11 & Block 1 & 612 & None & Os-W \\
\hline 12 & Block 1 & 612 & None & Os-W \\
\hline 13 & Block 1 & 311 & None & Os-Ru \\
\hline 14 & Block 1 & 311 & None & None \\
\hline 15 & Block 1 & 311 & None & Os-W \\
\hline 16 & Block 1 & 311 & None & Os-Ru \\
\hline
\end{tabular}




\subsection{Cathode Temperature vs. Heating Power}

An important issue with the 6.5 " cathode operation was the heating power required to reach the operating temperature of $\sim 1050^{\circ} \mathrm{C}$. The equilibrium temperature was governed by the filament power and the radiation heat loss as a function of the emissivity of a hot surface. In running the $311 \mathrm{XW}$ cathode, it was found that more heating power was required for that cathode to reach the same temperature as the $612 \mathrm{M}$ cathode.

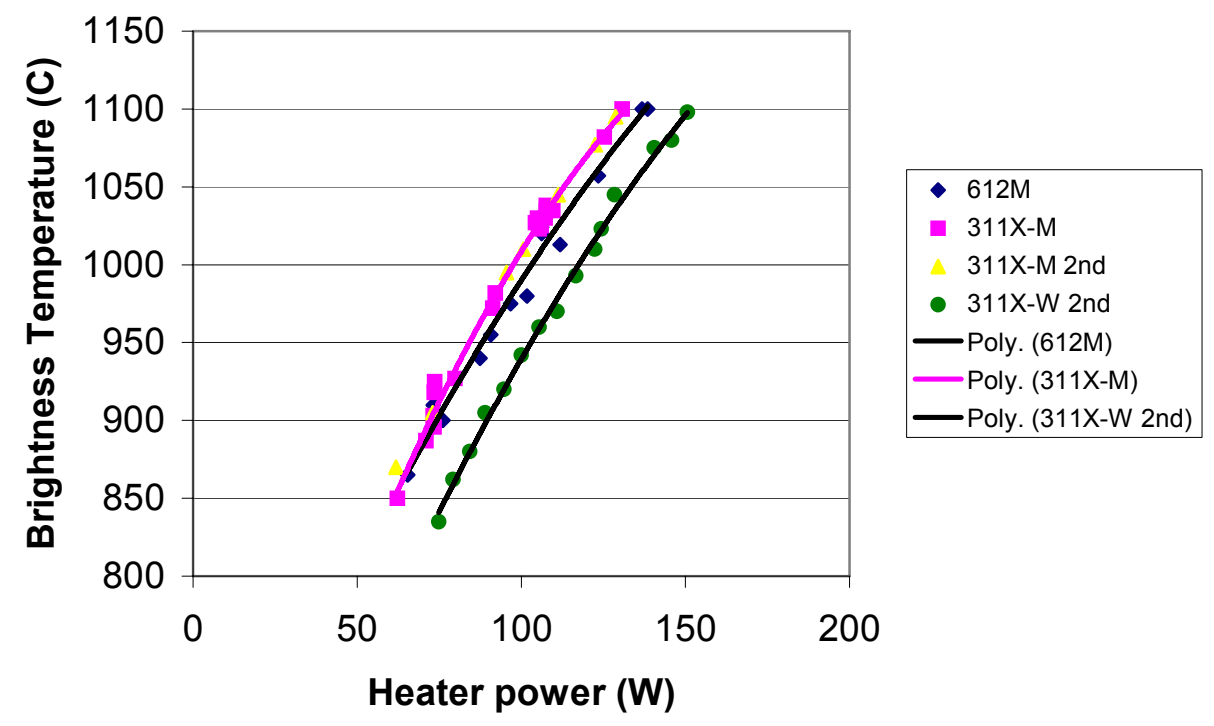

Fig. 7.6 Temperature of a $1 / 4$ " cathode as a function of heater power. (Temperature was measured by an L\&M disappearing filament type optical pyrometer.)

After finding that the $6.5 " 311 \mathrm{XW}$ cathode could not reach the desired activation temperature of $1100{ }^{\circ} \mathrm{C}$ before damaging the heater filament, we decided to try the $311 \mathrm{XM}$ to determine whether it has a low function similar to the $311 \mathrm{XW}$, with heating characteristics similar to the $612 \mathrm{M}$, based on their similar coating material. If both assumptions were true, then the combination of these two properties would provide the proper condition for reaching $2 \mathrm{kA}$ within the filament power supply and temperature limits of the 6.5" cathode. We performed an experiment with quarter-inch size buttons to confirm the temperature behavior before procuring a full-size $311 \mathrm{XM}$ cathode from 
Spectra-Mat. That result is shown in Fig. 7.6. For a given heater power the $311 \mathrm{XM} 1 / 4$ " button exhibited the highest brightness temperature, followed by the $612 \mathrm{M}$ and $311 \mathrm{XW}$. As a result the $311 \mathrm{XM}$ is clearly preferred from the point of view of its thermal characteristics.

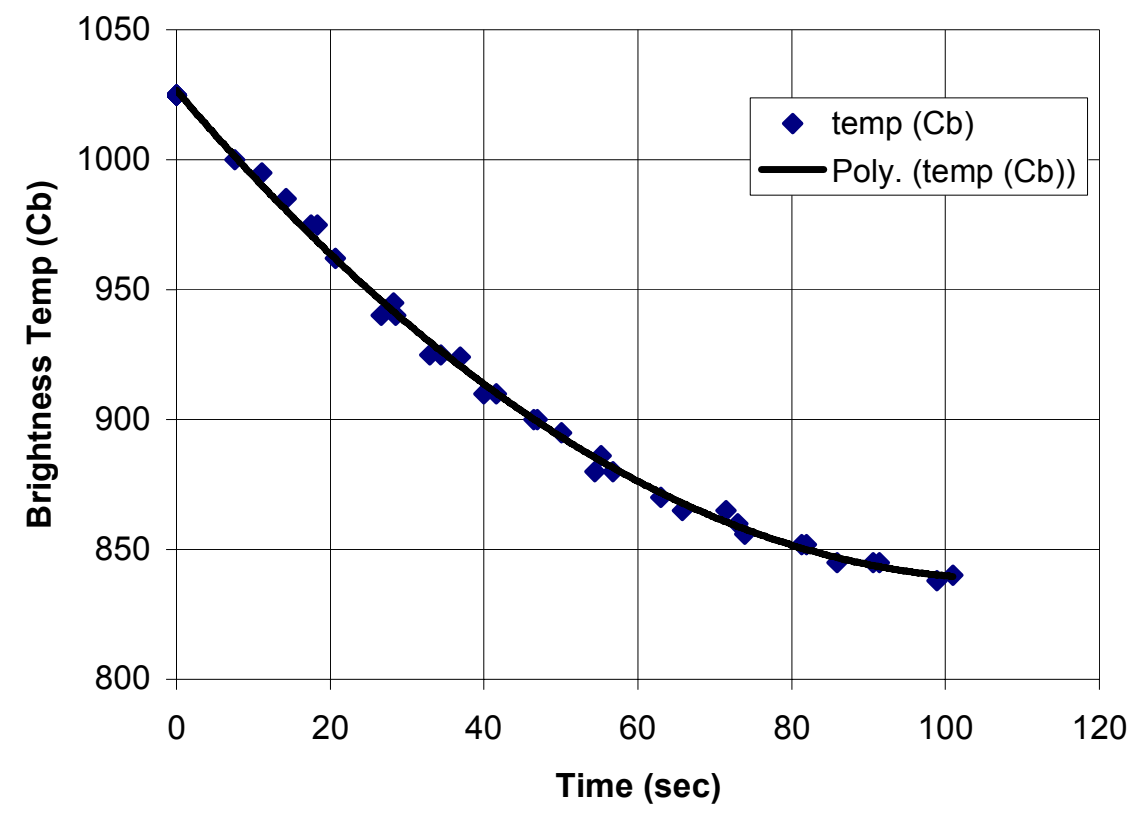

Fig. 7.7 Cathode temperature ramping down after heater power reduced from $14.8 \mathrm{~V}, 7 \mathrm{~A}$ to $10 \mathrm{~V}, 5.5 \mathrm{~A}$. Solid line is a polynomial fit of the data points.

Figure 7.7 shows a typical response curve for a $1 / 4$ " button when the heater power was suddenly reduced to a lower level. This kind of temperature calibration curve was used to correlate the cathode temperature when it was necessary to measure the beam current as a function of temperature rapidly. Taking the measurement rapidly, e.g. within 1-2 minutes, minimizes the chemical change due to surface contamination, thus minimizing changes the work function during the measurement.

\subsection{Measuring Current as a Function of Temperature Under Good Vacuum}

Before making beam current measurement, we checked the gun perveance by plotting beam current as a function of extraction voltage (Fig. 7.8). The data displayed a $\mathrm{V}^{3 / 2}$ scaling according to space charge limit beam extraction. The perveance was found to be in generally agreement with the designed value, therefore gave us the confidence 
that the secondary electrons that could contaminate the measured beam current were properly suppressed by the Faraday cup.

The plot of current density vs. temperature in Fig. 7.9 shows that the $311 \mathrm{XM}$ cathode emission reached $10 \mathrm{~A} / \mathrm{cm}^{2}$ (i.e. $2 \mathrm{kA}$ for the 6.5 " cathode) with the cathode temperature at $<1075^{\circ} \mathrm{C}$. The different data series corresponded to extraction voltage settings at 8,12,16, 20 and $24.6 \mathrm{kV}$. Each data series would reach saturation according to the space charge limit for the applied extraction voltage. By comparing the experimental results with the Richardson equation curves for fixed work function as indicated (curves without dots), we conclude that the effective work function of this cathode was between $1.85 \mathrm{eV}$ to $1.95 \mathrm{eV}$.

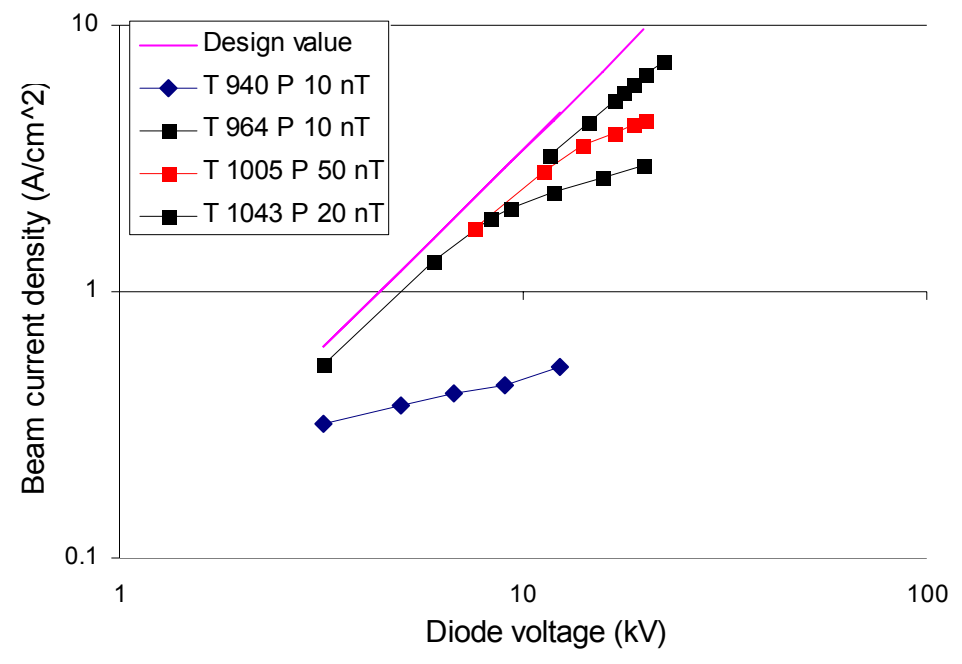

Fig. 7.8 Beam current reaching space charge limit according to gun perveance.

As previously mentioned, the data for each data series was taken within 1-2 minutes immediately after dropping the heater power from $109 \mathrm{~W}$ to $54 \mathrm{~W}$ while the cathode cooled from $1100{ }^{\circ} \mathrm{C}$ to $900{ }^{\circ} \mathrm{C}$. In order to provide a convenient comparison between this testing and those obtained from DARHT-II, we plot a corrected "true" temperature in Fig. 7.9. Here the true temperature was calculated from the measured brightness temperature (as provided by the L\&M pyrometer) by assuming that the emissivity $=0.4$. The conversion from brightness temperature [in absolute unit] to true temperature can be done by using equation $5.2 .^{1}$

\footnotetext{
${ }^{1}$ Temperature, Its Measurement and control in Science and Industry", Reinhold Publishing Corp, NY, 1941
} 
311XM 1/4" button $\left(0.3 \mathrm{~cm}^{\wedge} 2\right)$ emission characteristic

Button temperature starts at $1025 \mathrm{Cb}$, Heater power $109 \mathrm{~W}$ to $54 \mathrm{~W}$

(Pressure at $1.2 \times 10^{\wedge}-8$ Torr)

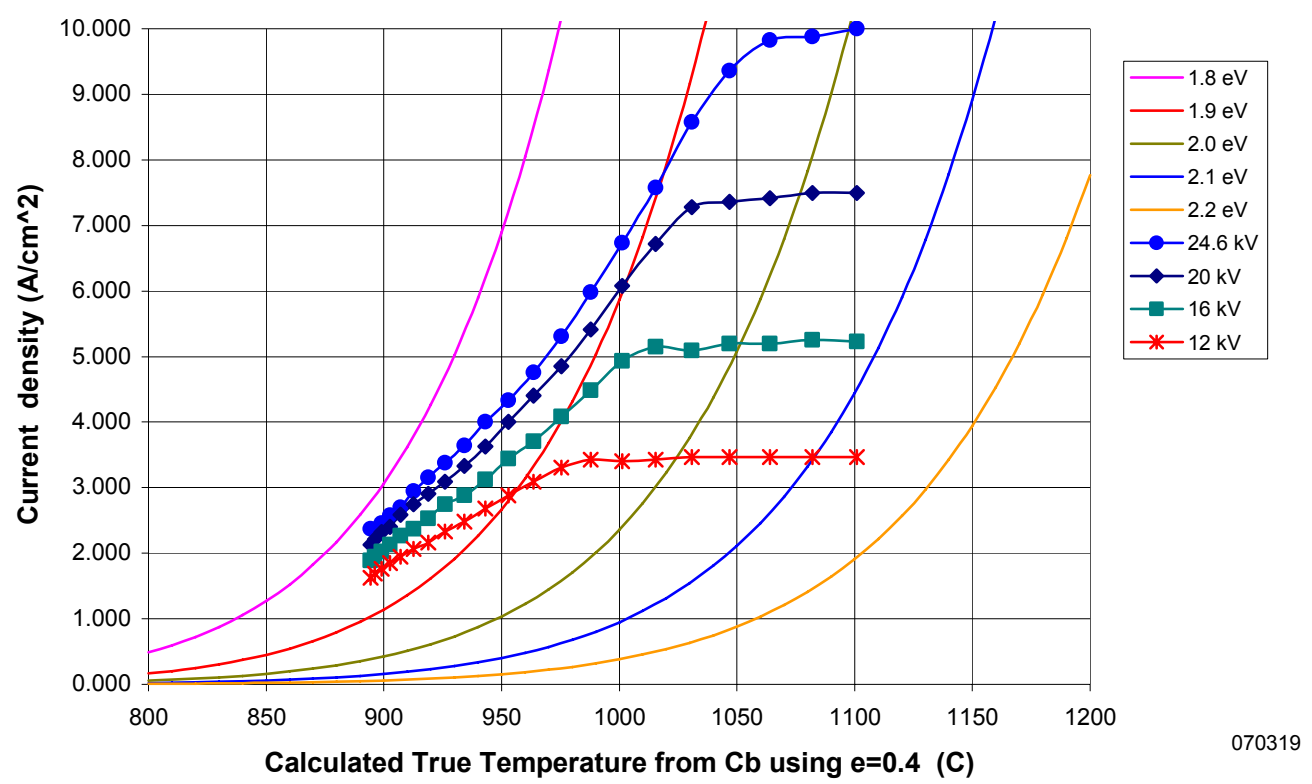

Fig. 7.9 Beam current density vs. temperature for 311XM.

The data in Fig. 7.9 can be plotted in different ways to produce either the "cathode loading curves" as shown in Fig. 7.10a or the "Miram Curves" in Fig. 7.10b. According to George Miram, these normalized plots are often used in the cathode industry to evaluate the performance of individual cathodes. For example, the Miram curve of a good cathode will peak at a low work function value and have a narrow profile. 
311XM Normalized Emission Characteristics after activated at $1025 \mathrm{Cb}$, at $1.2 \times 10^{\wedge}-8$ Torr

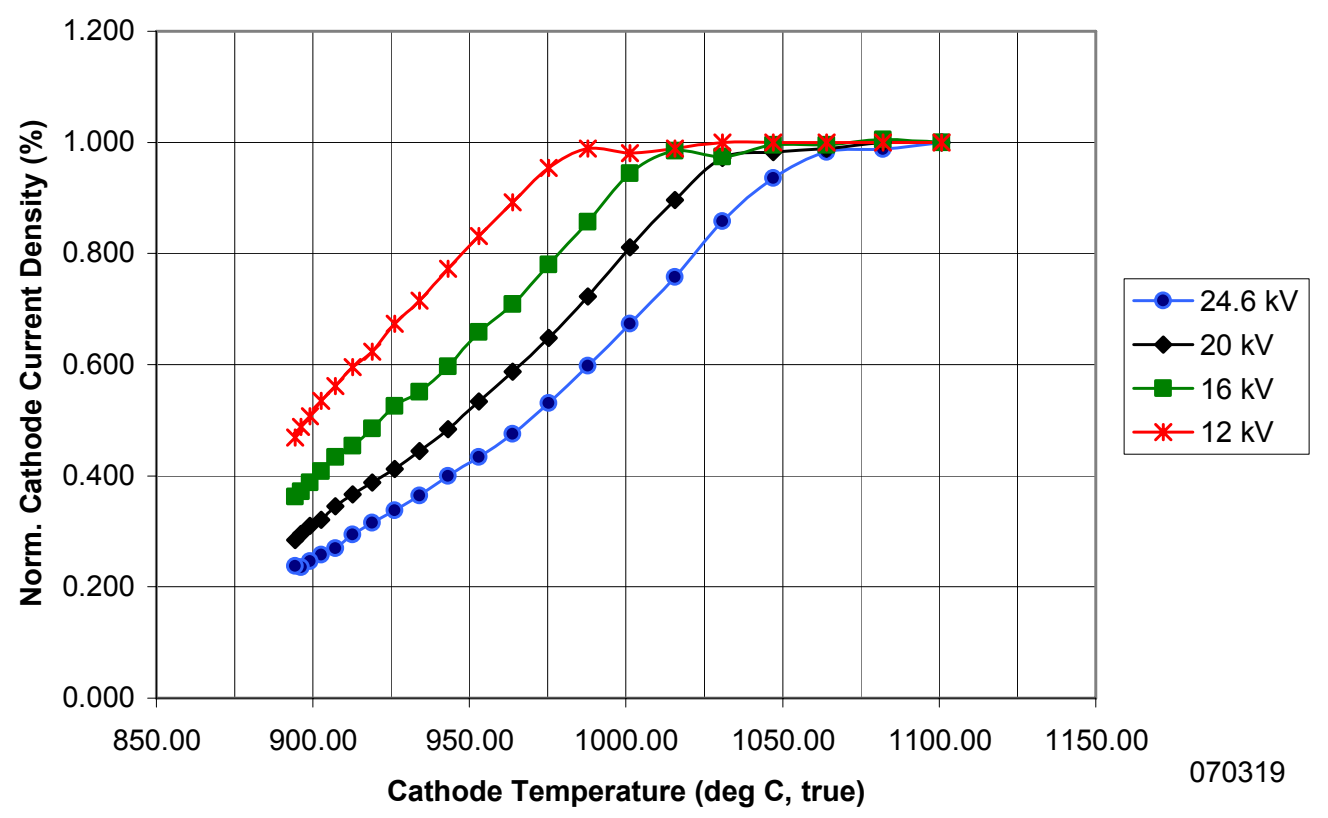

PWFD for 311X-M 0.25" cathode

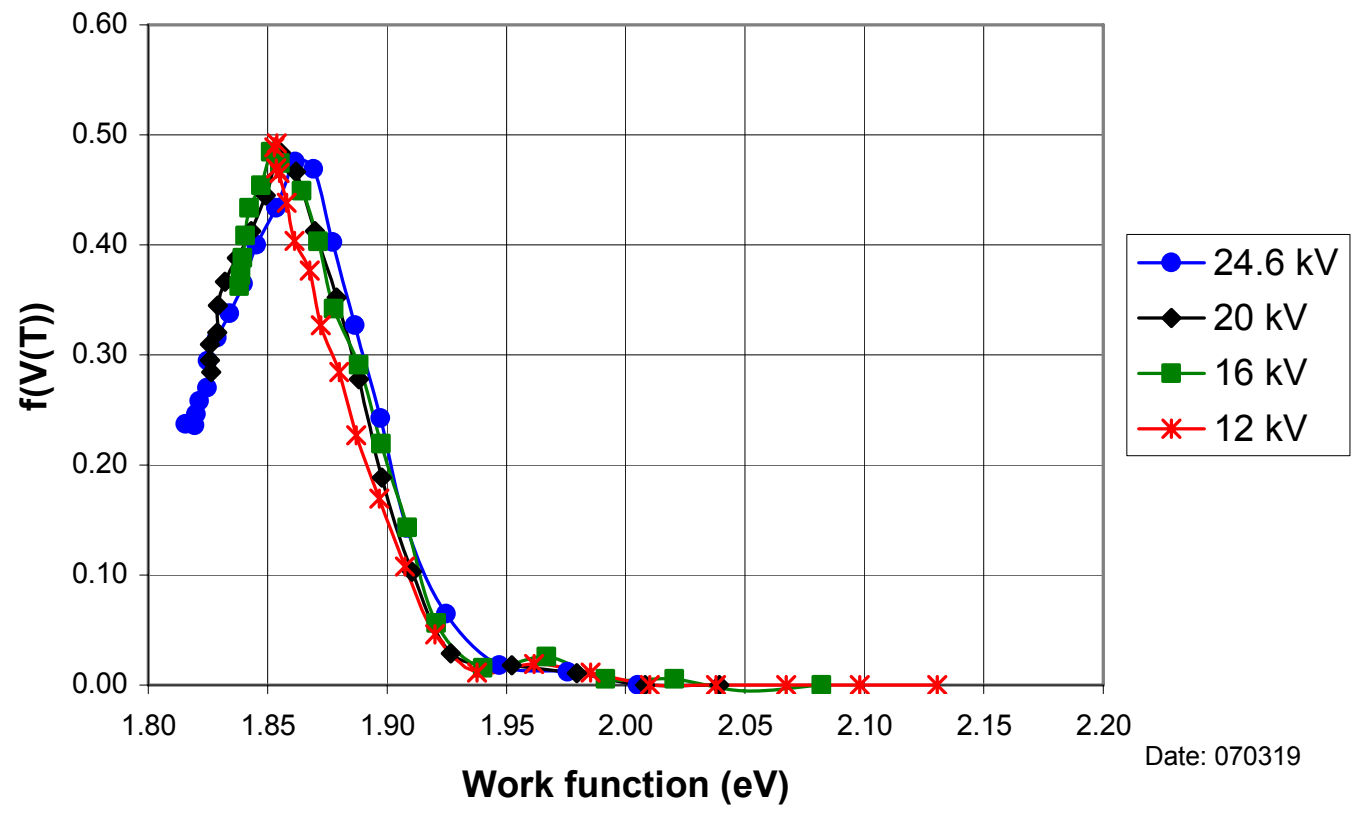

Fig. 7.10 (a) Cathode loading curves, and (b) Miram (pwfd) Curves. 


\subsection{Transient Effect Due to Cathode Poisoning}

Figure 7.11 shows how the beam current evolved as a function of time after the heating power was suddenly dropped from $109 \mathrm{~W}$ to $54 \mathrm{~W}$, and then later raised back to $109 \mathrm{~W}$. We observed that there were two distinct periods. In the first period, which lasted only a couple of minutes, the cathode temperature dropped to reach a steady state, the current also dropped rapidly as governed by the Richardson equation. Within this short period, we expected minimal change to the surface condition of the cathode and therefore the work function would be relatively constant. In the second period the cathode temperature remained constant, but the there was a gradual reduction in beam current probably due to the slowly changing surface condition.

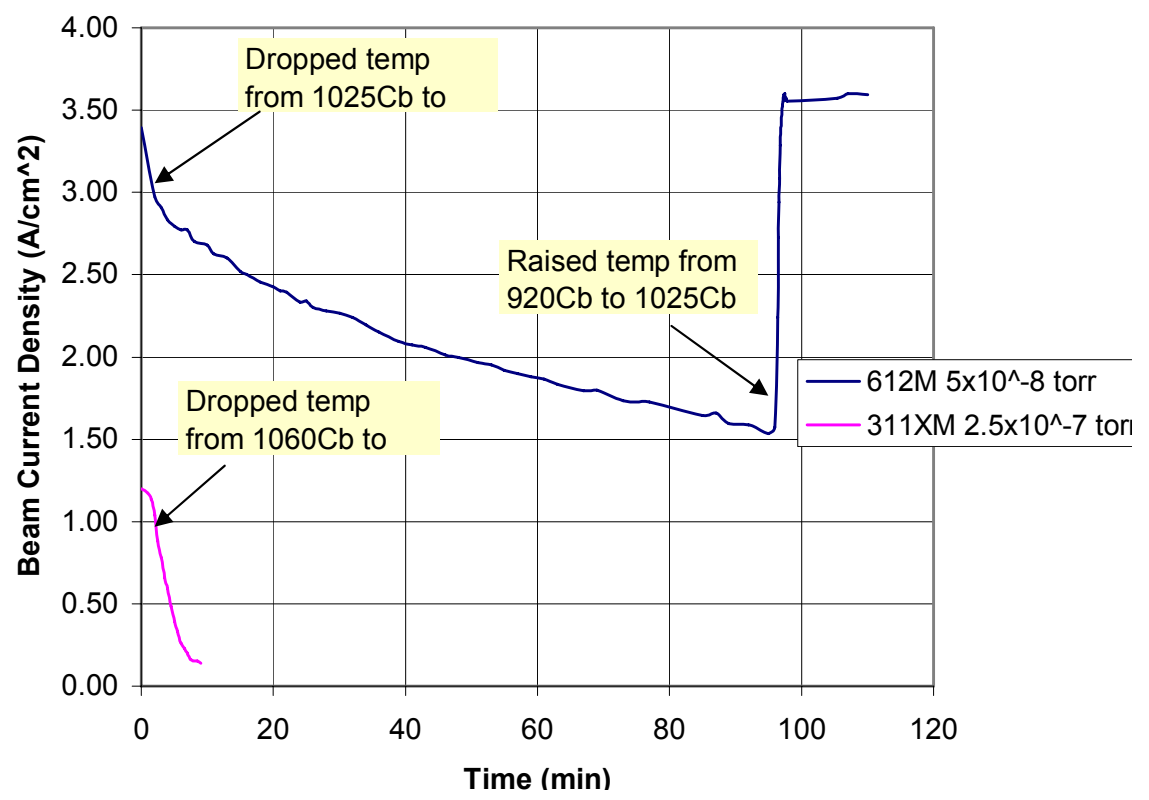

Fig. 7.11 Beam current reduction after dropping the heating power.

The slow degradation during the second period can be explained by a gradual increase in the work function due to poisoning of the cathode under the influence of poor vacuum. This model was further confirmed by the fact that the time constant of degradation depended on the partial pressure in the vacuum. Higher pressure corresponded to higher reaction rate and therefore shorter time to reach equilibrium. At high pressure (poor vacuum) of mid- $10^{-7}$ Torr, the emission was poor and it usually took less than an hour to reach a new equilibrium after dropping the heater power. On the 
other hand at low pressure (good vacuum) of below $1 \times 10^{-8}$ Torr, the emission was good and it could take many hours, sometimes overnight, to reach new equilibrium. In fact taking data was very time consuming and one had to be very patient when working with good vacuum condition. Automation in data acquisition and remote control became a necessity in order to collect trustworthy data.

When the cathode is subjected to poisoning, the surface condition of the cathode is in a dynamic equilibrium between the contamination rate and the diffusion rate of the $\mathrm{BaO}$ which helps to overcome the poisoning. Besides the issue of long time constant, we also observed minor hysteresis effect making it possible to see the same beam current emission under multiple temperature readings.

These issues of poisoning and transient behavior generally do not occur in cathodes that are manufactured in sealed tube with baking to attain good vacuum. However, for open systems like the one in DARHT, where Viton O-rings are used in many places, and baking is not allowed, the issue of poisoning can dictate the cathode performance. In this case, the best strategy is to choose the type of cathode that has the most resistance against poisoning.

\subsection{Measuring Temperature vs. Pressure of Various Gases at $10 \mathrm{~A} / \mathrm{cm}^{2}$}

Our goal was to develop a DARHT cathode that could produce $2 \mathrm{kA}$ of electron beam. With a cathode size of 6.5 inch diameter, the corresponding current density was $10 \mathrm{~A} / \mathrm{cm}^{2}$. The required cathode temperature that could produce such current density varied depending on the types of background gas and its partial pressure. We have carried out a series of measurement to compare the effects of argon, carbon dioxide, nitrogen, air, dry air, and water vapor for the $612 \mathrm{M}$ and $311 \mathrm{XM}$ cathodes. The extraction voltage was set at $25 \mathrm{kV}$ with a corresponding space charge limited current density of $10 \mathrm{~A} / \mathrm{cm}^{2}$; this is the similar space charge limited condition that DARHT will operate. Figure 7.12 shows the data taken by bleeding in ambient air with a $311 \mathrm{XM}$ quarter-inch button cathode. As expected, the current density increased with temperature until it reached the space charge limited saturation level. Higher temperature was needed (to produce the same beam current) for higher pressure. 


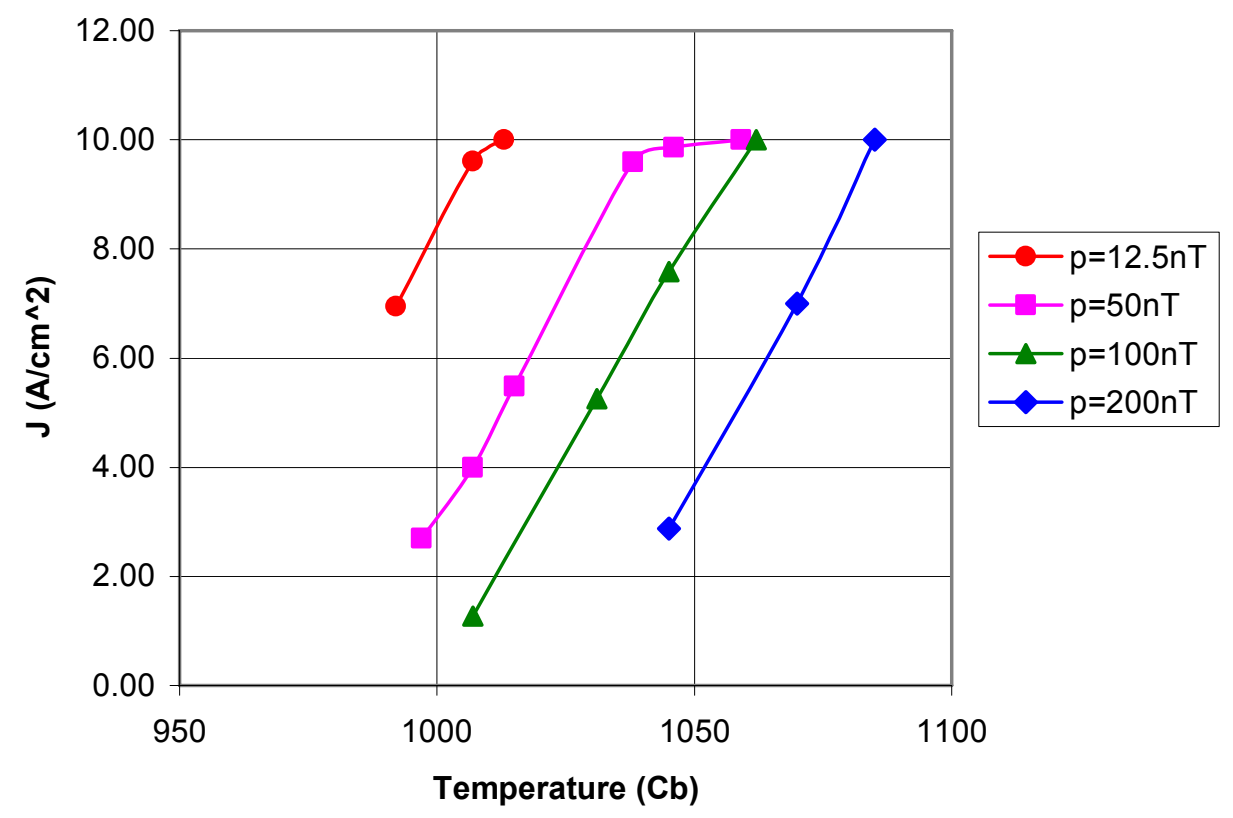

Fig. 7.12 Cathode performance at various levels of air pressure.

Extraction is at $25 \mathrm{kV}$ such that the space charge limit is $10 \mathrm{~A} / \mathrm{cm}^{2}$.

The "critical" temperature at the knee of the curves (at $10 \mathrm{~A} / \mathrm{cm}^{2}$ ) can be plotted as a function of pressure. The experiment was repeated for several gas species. Figure 7.13 compares the effect of various types of gas for the $612 \mathrm{M}$ cathode. All the data in the graph were taken with the same quarter-inch button cathode. We were able to verify that the cathode was not permanently contaminated in each run (thus no accumulated poisoning effect) except the very last run when using water vapor. The data suggested that nitrogen was most friendly to the cathode, while carbon dioxide and dry air (presumably due to the oxygen) were similar in effect, and water vapor was the worst contaminant tested.

Results from a similar effort to measure the $311 \mathrm{XM}$ performance are shown in Fig. 7.14. Again the trend was the same with argon and nitrogen being the most friendly gases, carbon dioxide was not as good, and the worst was water vapor and ambient air (presumably due to water moisture in the air). By comparing Fig. 7.13 with Fig. 7.14, we found that the critical temperature for $10 \mathrm{~A} / \mathrm{cm}^{2}$ at very good vacuum, e.g. below 10 
nTorr, was nearly the same for both $612 \mathrm{M}$ and $311 \mathrm{XM}$ cathodes. However, at $100 \mathrm{nTorr}$, the critical temperature was higher for the $612 \mathrm{M}$ cathode than the $311 \mathrm{XM}$ cathode. In other words the $612 \mathrm{M}$ and $311 \mathrm{XM}$ were equally good under good vacuum (e.g. below 10 nTorr), but if the vacuum is poor then the $311 \mathrm{XM}$ is preferred because it is less affected by gas poisoning. 

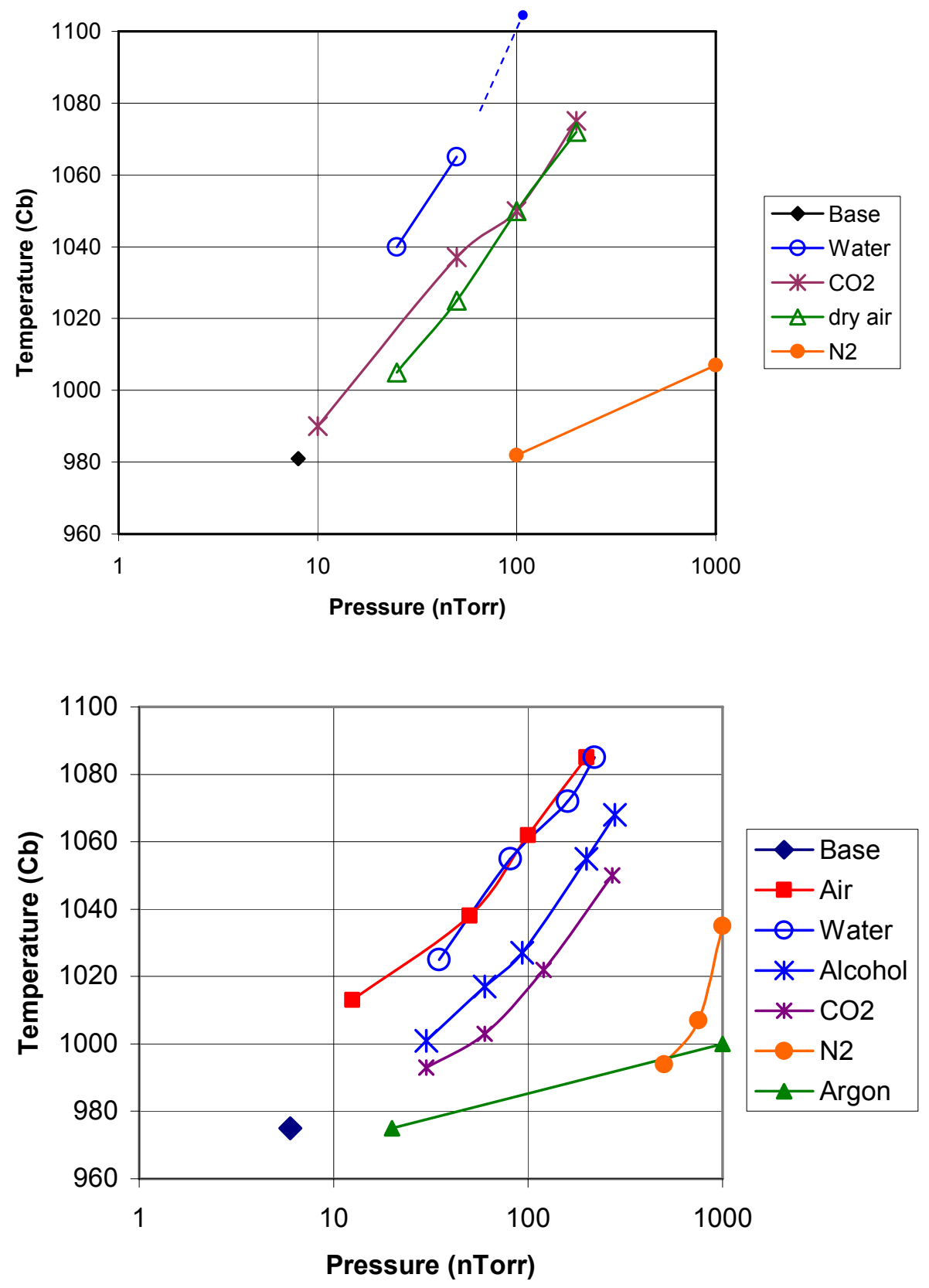

Fig 7.13 Critical temperature for $10 \mathrm{~A} / \mathrm{cm}^{2}$ emission as a function of gas pressure. (a) for the $612 \mathrm{M}$ and, (b) for the $311 \mathrm{XM}$. 


\section{ACTIVATION \& TESTING OF THE DARHT-II CATHODE AT LANL}

\section{Introduction}

The testing of the DARHT II cathode at LANL is limited by DARHT II operations. The facility operations restrict the amount of time that is available for cathode tests and the modes in which the cathode can be operated. Therefore much of the DARHT II cathode performance must be understood in the context of operations. Elements effecting diagnosis of the cathode performance include but are not limited to:

1. The method of cathode temperature measurement,

2. The thermal conditions of other elements in the injector,

3. The vacuum conditions in the injector,

4. Calibration of various detectors such as the injector voltage monitors, and

5. Component alignment.

Temperature measurements, thermal conditions and vacuum conditions are described in more detail in sections below. The Source Dome Voltage and the Marx Dome Voltage are typically measured with capacitive monitors facing the Source Dome in the injector or the Marx Dome in the Marx Voltage Generator. These two Domes are connected by a stalk passing up through the injector column (see figure 2.1). The stalk encloses cables from power supplies in the Marx Dome connecting power supplies such as the cathode heating supply to the cathode heater, which is in the Source Dome. The calibration of the Source Dome and Marx Dome voltage monitors have undergone multiple calibration efforts, and it is felt that the calibration factors currently used are still not correct. For example, the monitors read 2. 9MV for the source Dome, 2.8 MV for the Marx Dome, and a third monitor is reading $2.7 \mathrm{MV}$ for what we actually believe is $2.5 \mathrm{MV}$. The press of operations has not allowed the time needed to accurately calibrate the voltage and synchronize all voltage monitors. It would theoretically be nice to remove some of the DARHT II injector cells in order to install the spectrometer for a calibrated energy measurement. Then all voltage monitors could be cross-calibrated to the spectrometer energy measurement, but such a measurement is not planned. 
Before the mechanical modifications of the A-K gap and the cathode mounting hardware were made as part of the Cathode Campaign, cathode alignment was a much more difficult task. There is strong evidence that some of the early 612-M cathodes suffered from misalignment. It is suspected in particular that one of these early cathodes was installed in a recessed position by as much as 100 mils and therefore its space charge limited operation resulted in a substantially reduced current. The mechanical modifications of the Cathode Campaign have resulted in substantially improved alignment reproducibility and accuracy.

Tests at LBNL have clarified the impact of temperature and vacuum pressure on cathode performance. The results of this improved understanding have been implemented successfully at LANL. 2kA operation of the injector has been routinely achieved with the new cathodes in the new configuration. The significant temperature and vacuum improvements are discussed below. The results of the various DARHT II cathodes are discussed in the final sections below.

\section{Cathode Temperature Measurement at LANL}

Some of the early confusion over cathode performance at LANL has been traced to the difference in temperature measurement techniques. The cathode temperature at LANL is measured with a FAR pyrometer model FMP-2. The performance of this pyrometer, as applied to DARHT II, has been described by Carl Ekdahl ${ }^{1}$. The FAR pyrometer uses multiple wavelengths and gives a "true temperature." In contrast to the measurement technique used at DARHT, cathode measurements quoted at LBNL, LNLL, and the vendor Spectra-Mat have been almost exclusively "brightness temperature" measurements. Therefore, when comparing data, the LANL temperature measurements need to be reduced by $\sim 50-70$ degrees $\mathrm{C}$ to correspond to the brightness numbers of LBNL/LLNL/Spectra-Mat, or conversely the LBNL/LLNL/Spectra-mat measured temperatures need to be raised by $\sim 50-70$ degrees $C$ to correspond with the LANL

\footnotetext{
${ }^{1}$ Ekdahl, Carl, DARHT-II dispenser-cathode temperature and emissivity measurements, DARHT Tech Note, LA-UR-06-7283
} 
measured temperatures. LBNL purchased a more advance FAR pyrometer, intended to confirm this difference, but the Cathode Campaign was concluded before that pyrometer could fully be brought into operation thereby confirming the true temperature/brightness temperature offset.

However, using temperature corrected data measured at LBNL, has allowed operation of the $311 \mathrm{X}-\mathrm{M}$ to be performed at LANL with rather precise predictability. Button test measurement at LBNL have been used with the $\sim 50-70$ degree $\mathrm{C}$ correction, and the expected performance has been achieved with the temperature correction.

\section{Cathode Thermal Conditions}

The shear mass of the DARHT II injector introduces multiple long thermal time constants. The 6.5 in cathode itself is massive compared to more ordinary sized cathodes and the buttons tested at LBNL. If the DARHT II cathode heater power supply is turned on instantly to "full operating power" it takes $~ 20-30$ minutes for the cathode to achieve stable thermal equilibrium or operating temperature. Because of the large change in cathode heater resistance from room temperature to full operating temperature $(\sim 1100 \mathrm{C})$, and the potential of shocking the system with an instantaneous full power turn-on, the cathode is ramped up in a programmed fashion according to an algorithm prepared by Tim Houck. This results in an elapsed time of about $1 \mathrm{hr}$ for the cathode to reach full and stable operating temperature.

Once the cathode nears full operating temperature, it begins to heat the surrounding hardware. The cathode is centered in a large electrode assembly called the Cathode Shroud. The Cathode Shroud is approximately $4 \mathrm{ft}$ diameter and weighs $\sim 250 \mathrm{lbs}$. The Cathode Shroud faces the Anode Shroud defining the A-K gap. The two shrouds are separated by roughly a foot and are of comparable size. The Cathode Shroud is connected to the Injector or Source Dome and the Anode Shroud is connected to the injector vacuum tank wall. All of this hardware is heated by the radiating cathode and has a 6-8hr time constant reaching a final temperature of a few hundred degrees C. As the temperature of this hardware rises, so does its outgassing rate. This increase in 
outgassing rate gives rise to an increased base pressure of the injector over roughly a shift of operation.

\section{Injector Vacuum Conditions}

It had been noted early on and reported by Trent McCuistian at the 2-16-2006 Diode Workshop that the cathode performance appeared to decline during the day's operation. Later, button testing at LBNL identified that increases in vacuum pressure decreased cathode performance. It is now thought that the decline reported by Trent is caused by the slow rise in injector base pressure due to the slow heating and increased outgassing of injector hardware. The 6-8 hour thermal time constants of the Cathode and Anode Shrouds, the commensurate increase in outgassing rate with temperature, the related rise in injector base pressure, and the slow decline in cathode performance reported by Trent all appear to be related.

The observation of pressure effects, and the poor vacuum design of the original cathode mounting hardware led to significant changes to vacuum design during the Cathode Campaign. The original design had large trapped volumes behind the Cathode Shroud which were vented only around the rim of the cathode. This created a high-localized pressure region around the emitting face of the cathode. This localized pressure region worsened as the Cathode Shroud was heated and its outgassing increased. This problem was relieved during the Cathode Campaign by fabricating vent holes in the rim of the Cathode Shroud and creating vent paths through the cathode support spools to allow any trapped gasses to be directed away from the cathode region. These changes have eliminated the localized high-pressure region around the cathode and eliminated the slow daily decline in cathode performance.

After several days of pumping following venting, the injector base pressure drops slightly below $2 \times 10^{-8}$ Torr. During the days operation, as the Cathode Shroud and related hardware heat up, the increased outgassing at temperature increases the injector base pressure to $3-4 \times 10^{-8}$ Torr. The improved venting of the volume behind the cathode and 
routing of that gas to the rim of the Cathode Shroud have eliminated the pressure effects seen in earlier cathode operation. Also special attention has been paid to the reduction of water vapor, which was found in LBNL button tests to be especially harmful to 612-M cathode operation.

\section{2-M Cathode Experience at LANL}

The original DARHT II cathodes were 612-M cathodes. It was noted that their performance was somewhat variable from cathode to cathode. It was also noted that they required a higher than expected temperature for activation and operation and that they showed some performance degradation during the day. The cathode-to-cathode variation has been traced at least in a substantial amount to alignment variation with abnormally recessed cathodes giving sub par performance. The higher than expected operating temperature has been traced to degradation of the cathode work function by localized high pressures in the vicinity of the cathode emitting-surface and in some part to "true temperature" measurement of the FAR pyrometer vs. the "brightness temperatures" used elsewhere.

The 612-M cathode has been found to be very sensitive to water vapor and it has been replace with a $311 \mathrm{X}$ cathode which is less sensitive to the same. At one point it was thought that a bifilar cathode heater give better performance than the original centerreturn cathode heater, but this change was found to not be a performance factor and the center-return heater has been found to be more robust.

The improvements in cathode performance and handing resulting from studies at LBNL began to be implemented with the 612-M cathode \#5. The discussions of individual cathodes below highlight the handling and construction changes tested in arriving at the current configuration. 
The first four 612-M cathodes operated on DARHT II reflected the original hardware design and handling practices. The cathode heater was a "quasi-biflar" filament wound as a coil with the return lead passing back through the center of the coil. Handling and activation processes approximated the guidance found in the Spectra-Mat Technical bulletins to the extent possible with the DARHT I II environment and operations constraints. In general cathodes 1-4 required higher than expected activation and operating temperatures, and there was some cathode-to-cathode variation in performance. Some degradation during the day was seen in cathode performance. The work function of the cathodes were measure to be higher than the values expected and the overall beam current was less than the project goals. A maximum beam current of $\sim 1.4 \mathrm{kA}$ had been achieved. Normal operation was nearer $1 \mathrm{kA}$ compared to the project goal of $2 \mathrm{kA}$. The original $2 \mathrm{kA}$ goal was to be achieved at an injector voltage of $3.2 \mathrm{MV}$, but early operation seemed to indicate that lower voltage operation would be more prudent.

The cathode campaign was undertaken to achieve $2 \mathrm{kA}$ beam operation at an injector voltage of $2.5 \mathrm{MV}$. In the end this goal was reached by improving cathode handling procedures, changing the cathode type, improving vacuum performance at the emitting surface of the cathode, and improving the installation/alignment capabilities of the mechanical design.

Some emphasis was given to the handling processes employed with cathode $612 \# 4$, however the completion of this cathode run was cut short by an unplanned vacuum venting of the accelerator that destroyed the 612-M\#4 cathode. The thermal shock of the venting destroyed the 612-M\#4 coating on the emitting surface.

\section{$\underline{612-\mathrm{M} \# 5}$}

The emphasis with the 612-M\#5 cathode was careful control and monitoring of the cathode handling process. It was subjected to a lower temperature and longer activation process. The measurements of the 612-M\#5 cathode performance after this slow low temperature activation highlighted the difference between the "true temperature" as 
measured with the FAR pyrometer as contrasted with the "brightness temperature" measured by others. The activation process of cathode $612-\mathrm{M} \# 5$ is summarized in the table below.

\begin{tabular}{|l|l|}
\hline Step & Action \\
\hline 1 & $\begin{array}{l}\text { Slowly raise cathode temperature to } 400 \mathrm{C} \text { keeping the pressure below } \\
1 \times 10^{-7} \text { Torr }\end{array}$ \\
\hline 2 & Hold at $400 \mathrm{C}$ over night \\
\hline 3 & $\begin{array}{l}\text { Slowly raise the temperature to just below } 900 \mathrm{C} \text { keeping pressure in } \\
10^{-8} \text { Torr range }\end{array}$ \\
\hline 4 & Hold at slightly less than $900 \mathrm{C}$ overnight \\
\hline 5 & Slowly raise the cathode to $1000 \mathrm{C}$ with the pressure in $10^{-8}$ Torr range \\
\hline 6 & Hold at $1000 \mathrm{C}$ for a minimum of 2 hrs \\
\hline 7 & Raise the cathode to $1100 \mathrm{C}$ \\
\hline 8 & Hold ate $1100 \mathrm{C}$ for 2 hrs. \\
\hline 9 & Activation is considered complete \\
\hline
\end{tabular}

After following this procedure the cathode was operated, and it only produced 45 Amps of beam current. Over a couple of days the operating temperature was raised, and then the current was seen to start increasing substantially as the temperature approached 11701180C. The current rose from an initial level of $45 \mathrm{~A}$ to $1100 \mathrm{~A}$ (the space charge limit) over a few days operation at the elevated temperatures. The performance of cathode 612$\mathrm{M} \# 5$ is shown in the Figure 8.1 below and compared with other 612-M cathodes 


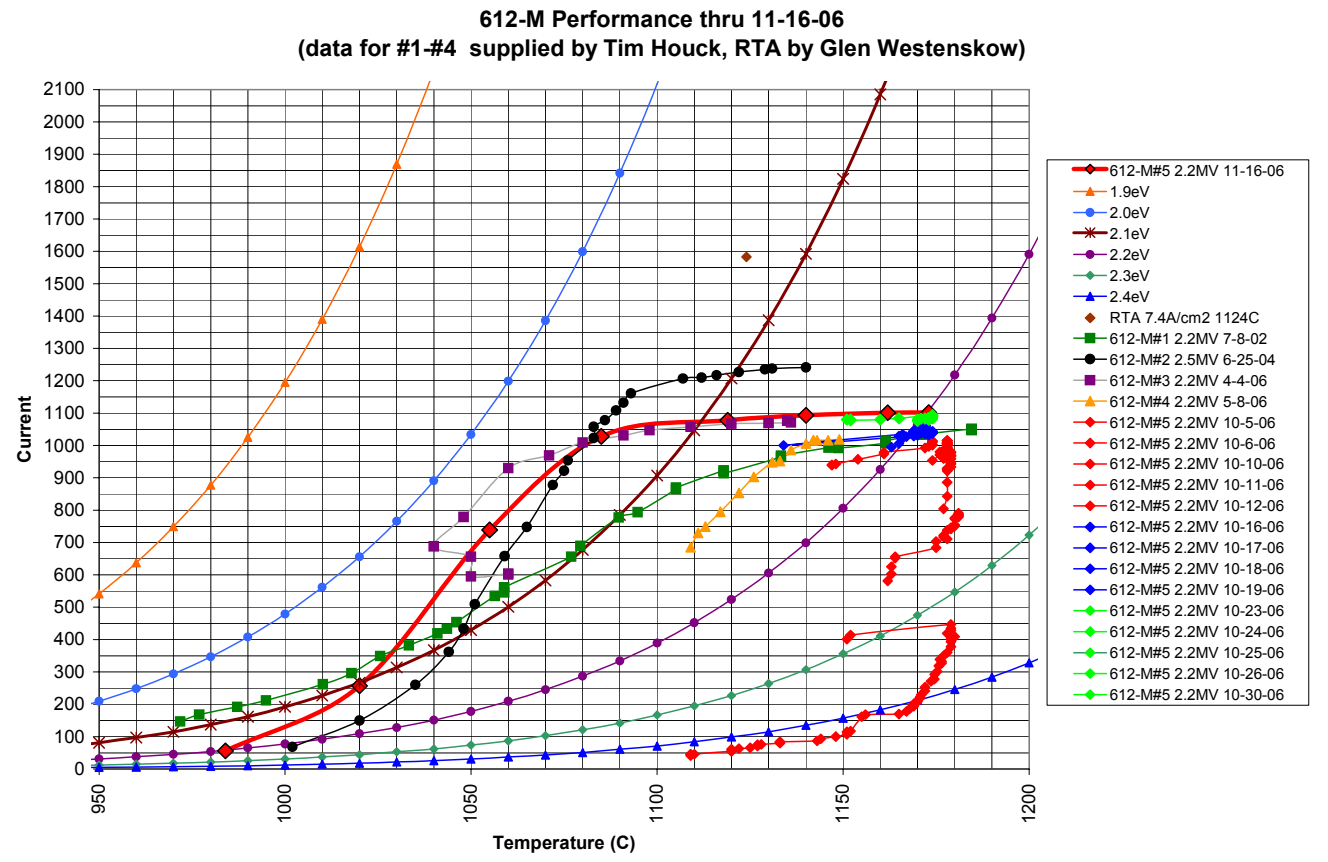

Figure 8.1 Performance of 612-M\#5 compared with other 612-M cathodes and RTA.

As can be seen from the figure, cathodes 612-M\#2, \#3 and \#5 were similar in their performance; cathodes 612-M\#1 and 612-M\#4 were not as good. The 612-M\#5 did not fully activate until raised to temperatures of $1170-1180 \mathrm{C}$ measured by the FAR pyrometer. After a substantial period of operation the temperature could be dropped and the effective work function measured as was done on 11-16-06.

\section{$\underline{612-\mathrm{M} \# 6}$}

After operation of cathode 612-M\#5 was completed, evidence from the button test and successful use of a 311-X cathode at LLNL indicated that switching to a 311-X cathode would be beneficial. An order was placed for a 311-X cathode, but problems with the initial 311-X indicated further changes were needed. Another 612-M (unit\#6) and a modified 311-X (M) were ordered. 612-M \#6 never completed testing. An attempt was made to test this unit after the testing of the modified 311X-M. The reason 612-M \#6 never was tested is that its coating was damaged during cold cathode hipot testing. This is the only unit to experience this form of failure on DARHT II. When cathode 612-M\#6 was installed it was noted that the surface finish was not normal in appearance. Various 
individuals described the surface as looking blotchy, dusty, or grainy. It is assumed that the 612-M\#6 cathode coating was somehow defective, but there is no quantification of this statement. One can only stated that the surface was uniformly recognized as looking different.

During cold cathode hipot testing, breakdown occurred following an number of successful pulses around $10 \%$ above the normal operating voltage. This breakdown could not be recovered from and left the cathode surface pealed up with small flakes of coating over about $10 \%$ of the cathode surface near the center of the cathode as seen in the photograph below.

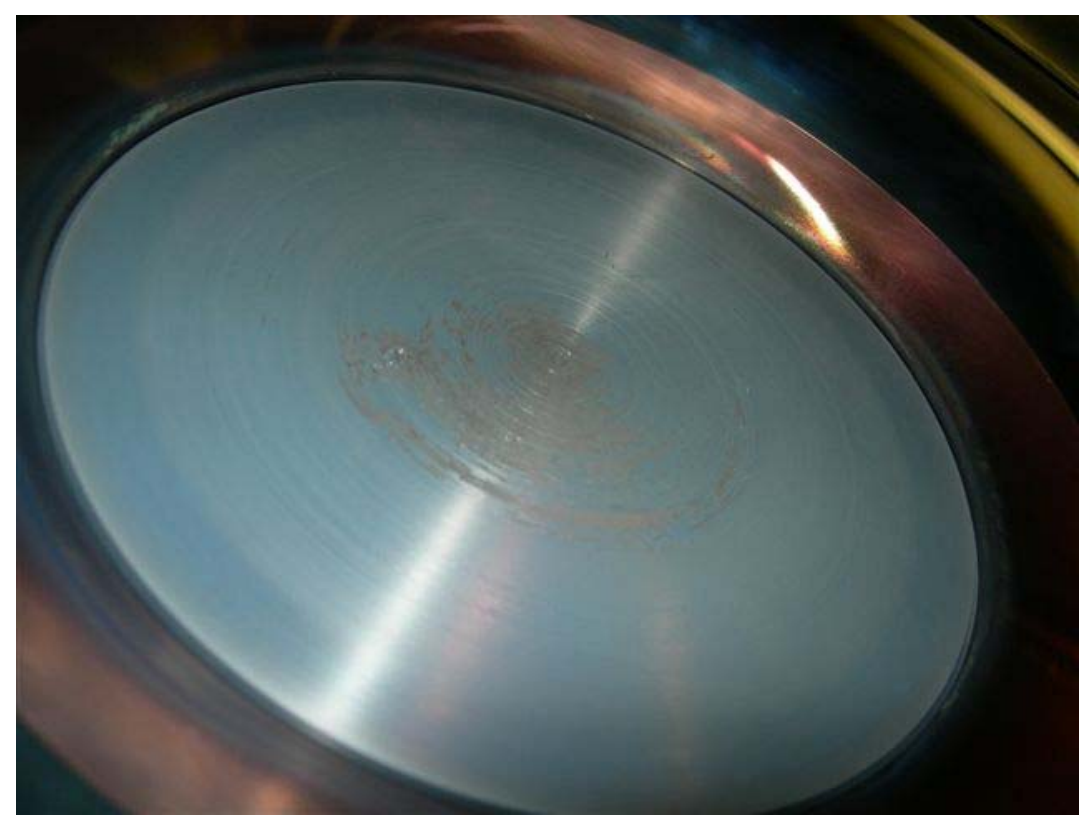

Figure 8.2: Damaged surface of cathode 612-M\#6 after cold cathode hipot breakdown

Prior to the cold cathode hipot testing a very careful pump down of the injector was performed and a careful activation had been performed. It had been discovered by this time that 612-M cathodes were much more sensitive to water vapor than the 311-X cathodes. The hope was that extensive efforts to reduce any water vapor present would enhance the operation of the $612-\mathrm{M}$ cathode and make it viable for $2 \mathrm{kA}$ operation. The experiment was never completed because the cold cathode failure prevented any attempt at beam operation. 
The activation of cathode 612-M\#6 followed the procedure below:

\begin{tabular}{|l|l|}
\hline Step & Action \\
\hline 1 & $\begin{array}{l}\text { Slowly raise cathode heating power to } 400 \mathrm{Watts}(\sim 400 \mathrm{C}) \text { keeping the } \\
\text { injector vacuum below } 1 \times 10^{-7} \text { Torr }\end{array}$ \\
\hline 2 & Cathode was held at 400 Watts for approximately $500 \mathrm{hrs}(\sim 21$ days $)$ \\
\hline 3 & $\begin{array}{l}\text { Slowly raise the temperature to } 875 \mathrm{C} \text { keeping pressure in } 10^{-8} \text { Torr } \\
\text { range }\end{array}$ \\
\hline 4 & Hold at $875 \mathrm{C}$ for $24 \mathrm{hrs}$. \\
\hline 5 & Slowly raise the cathode to $1000 \mathrm{C}$ with the pressure in $10^{-8}$ Torr range \\
\hline 7 & Hold at $1000 \mathrm{C}$ for $4 \mathrm{hrs}$ \\
\hline 8 & Raise the cathode to $1185 \mathrm{C}$ \\
\hline 9 & Hold at $1185 \mathrm{C}$ for $3.5 \mathrm{hrs}$. \\
\hline
\end{tabular}

The very long hold at $\sim 400 \mathrm{C}$ was used to eliminate water vapor and was made possible by a DARHT II installation activity that allowed the hold to continue until the installation was complete. Unfortunately, the experiment to measure the performance of the 612M\#6 cathode following this aggressive attempt to remove water vapor could never be completed due to the hipot failure.

Below are the pages from a power point presentation summarizing the analysis of the particles found in the bottom of the injector after the 612-M\#6 failure. Some of the particles may come from various installation-machining operations conducted in the injector associated with the Cathode Campaign, but many were felt to be peel-off from the 612-M \#6 cathode during the cold cathode breakdown. The particles were collected with vacuum tape, and they were analyzed in the forensics lab by George Havrilla. 


\section{Report on Particles From Bottom of Injector Vacuum Tank 10/30/07}

George J. Havrilla

C-CSE

November 07, 2007

Particle analysis report Page 1 


\section{Experimental}

- Sample analyzed as received

- Metal particles collected on 'vacuum tape'

- Tape placed on sample holder and put into instrument

- EDAX Eagle II, Rh tube, vacuum, $35 \mathrm{kV}$, $100 \mu \mathrm{A}$

- Both elemental maps and single point spectra were obtained

Particle analysis report Page 2

\section{Elemental Maps of One Area of Particles on Tape}
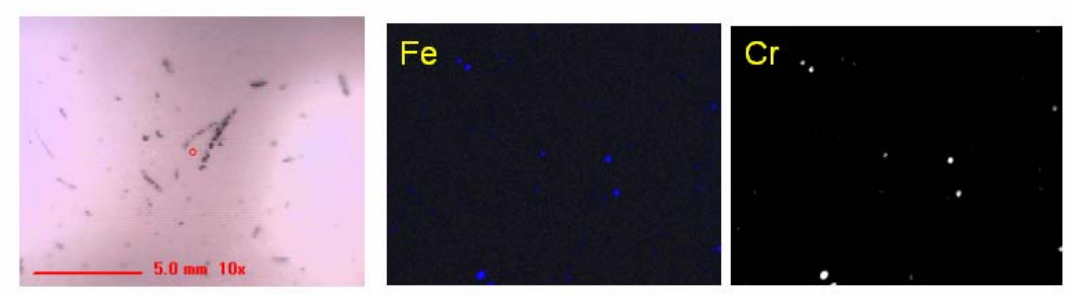

Area scanned $27 \times 20 \mathrm{~mm}$ Step size $53 \times 50 \mu \mathrm{m}$
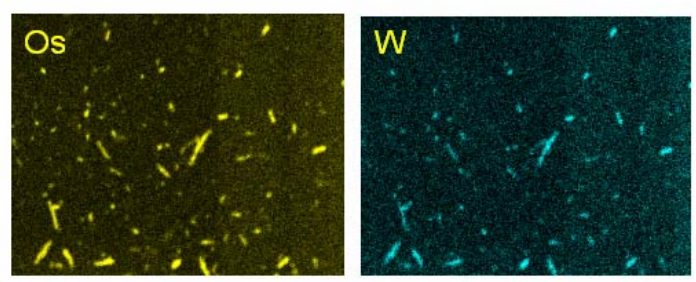

Particle analysis report Page 3 


\section{Steel Particles}
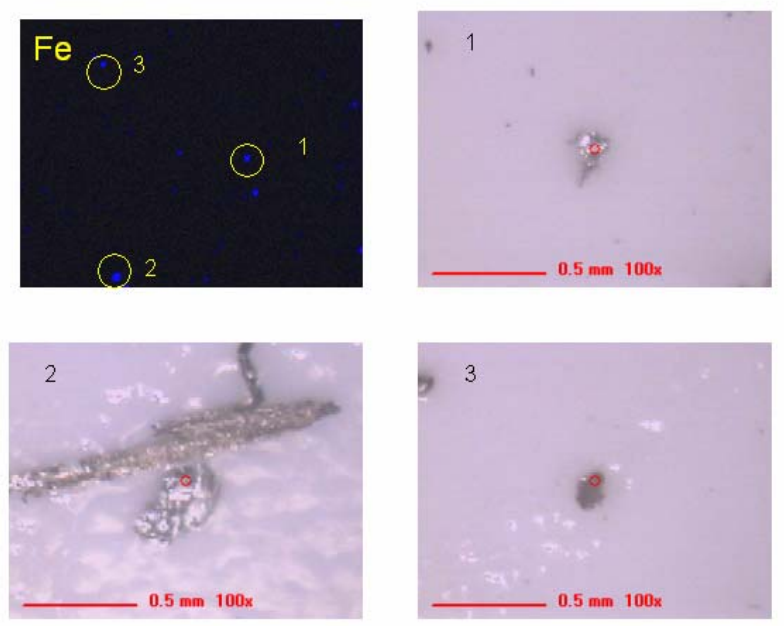

Particle analysis report Page 4

\section{Steel Particle Spectrum}

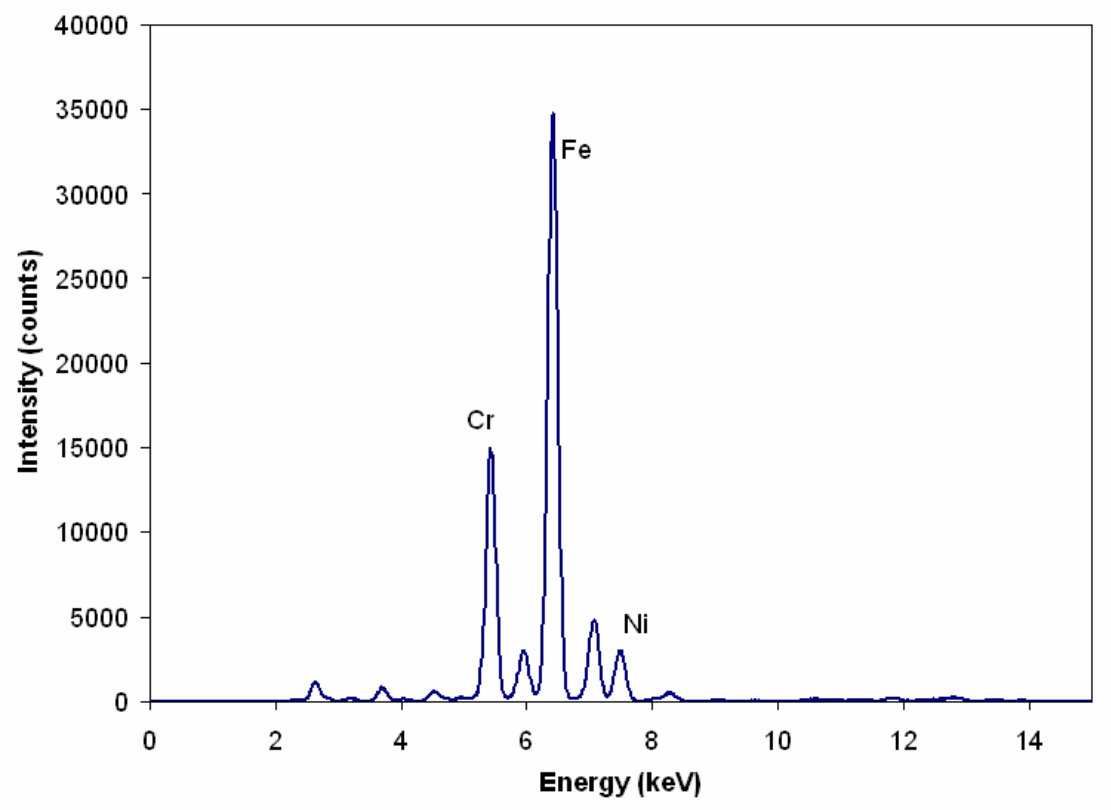

Particle analysis report Page 5 


\section{Os/W Particles from Cathode}
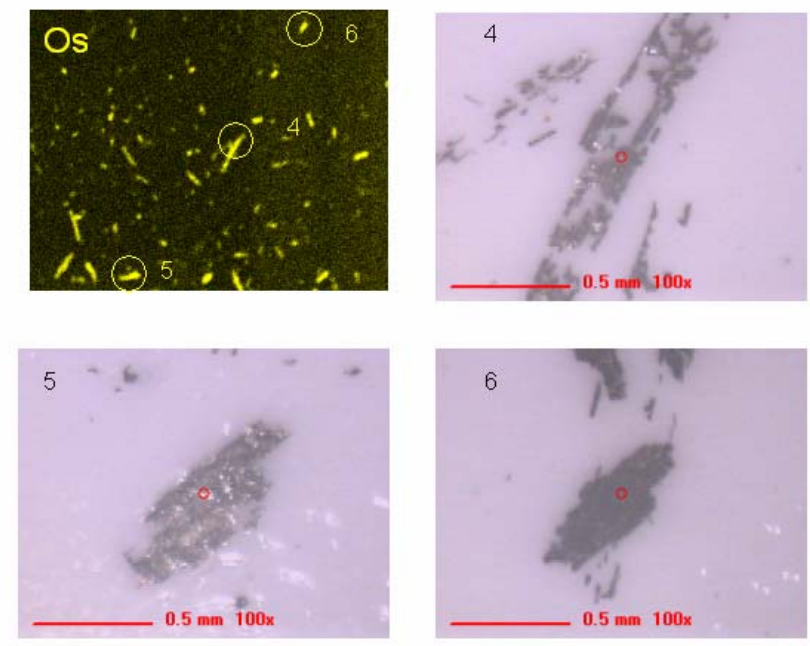

Particle analysis report Page 6

\section{Os/W Particle Spectrum}

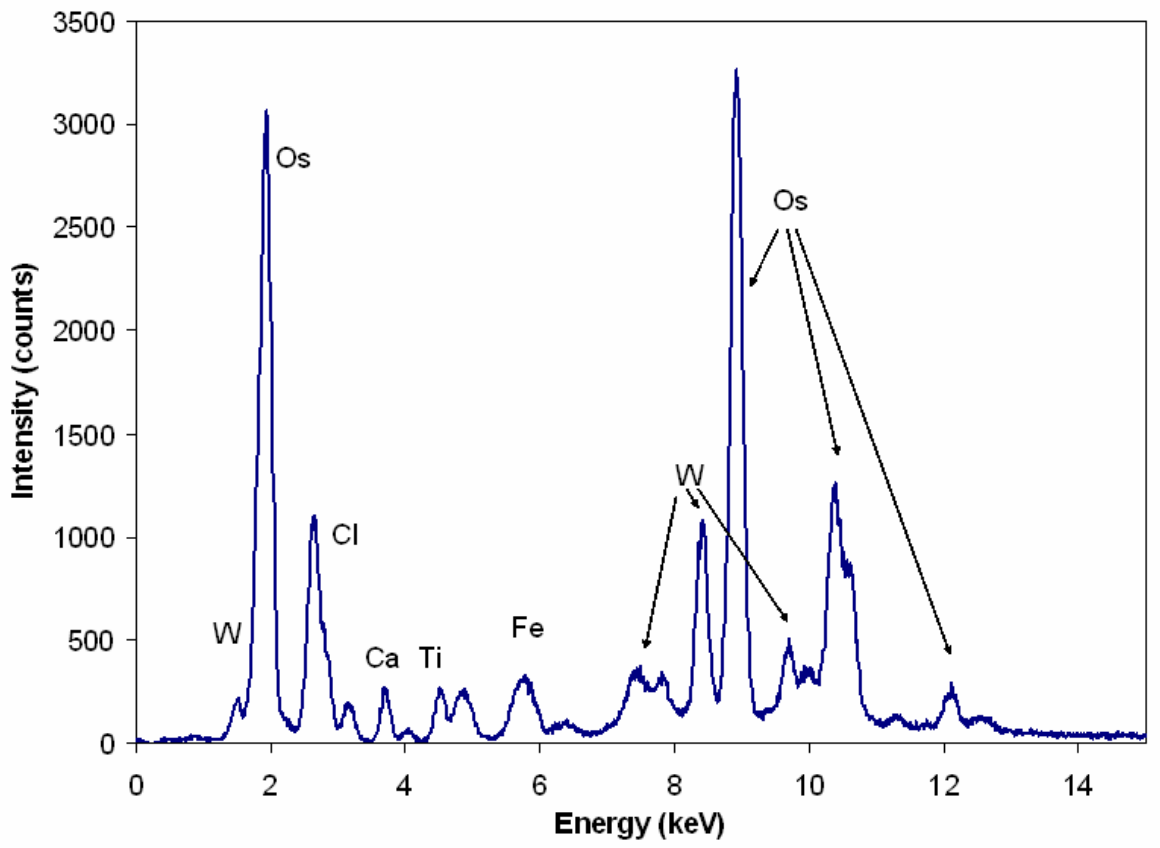

Particle analysis report Page 7 


\section{Composition Determined by No Standards Calculation}

- Steel-Cr $16.2 \%$ Fe $71.5 \%$ Ni $12.4 \%$

- Os/W - W $4.9 \%$ Os $95.2 \%$

Particle analysis report Page 8

\section{Elemental Maps of Both Particle Types}
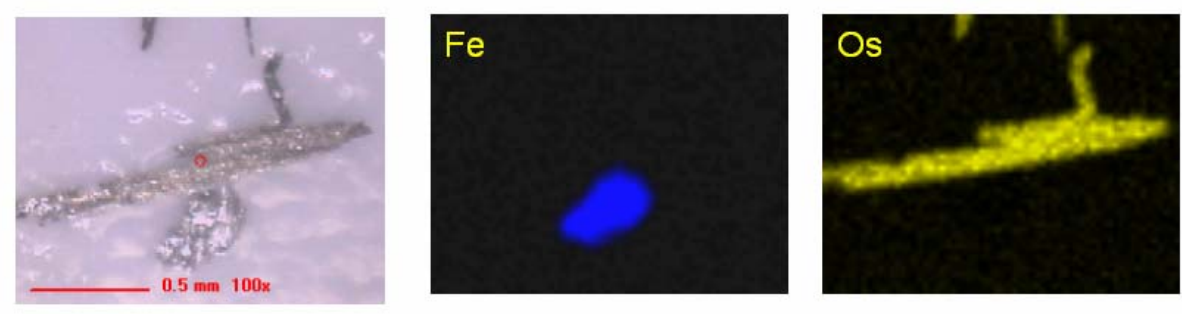

Area scanned $1.2 \times 1 \mathrm{~mm}$ Step size $25 \times 25 \mu \mathrm{m}$ Pixels $64 \times 50$ $100 \mathrm{~ms}$ dwell time

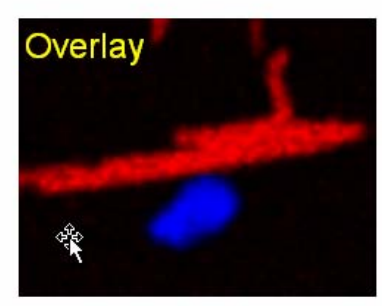

Particle analysis report Page 9 


\section{Tape Spectrum}

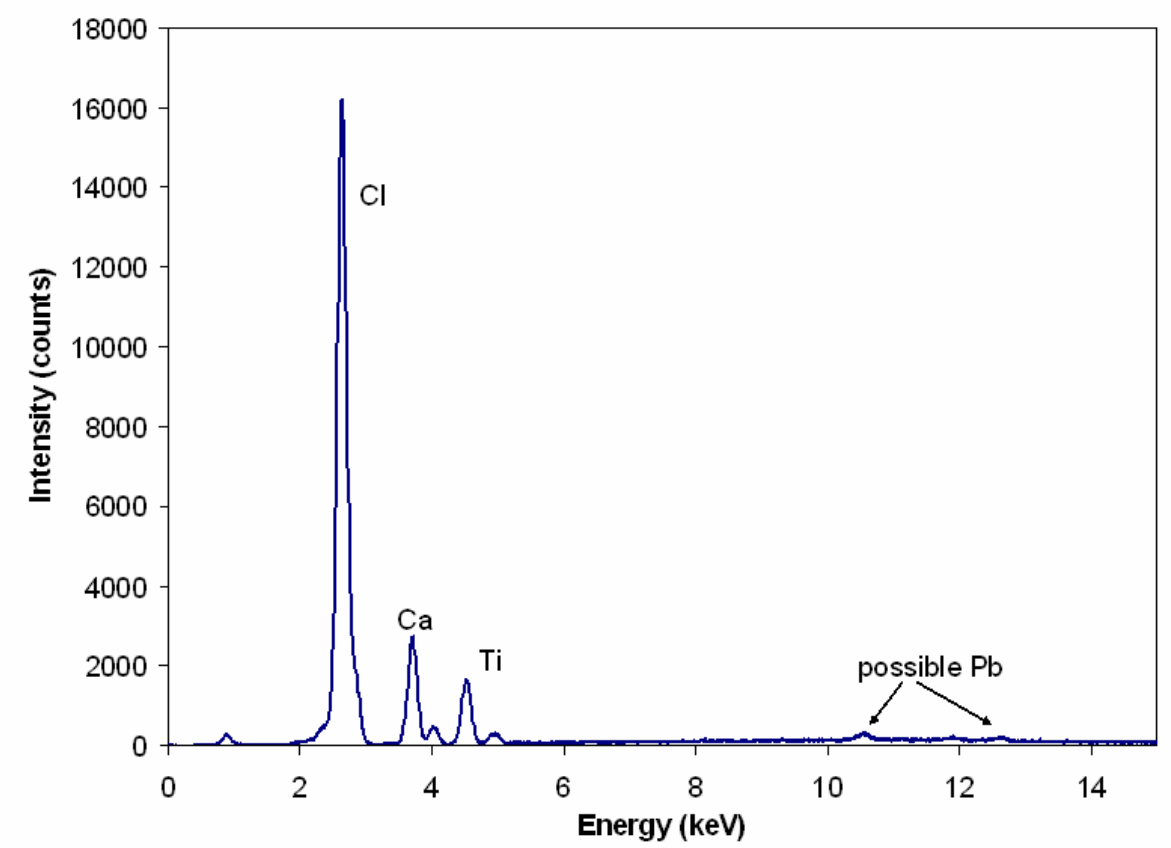

Particle analysis report Page 10

\section{Gold Coated Copper Contact}

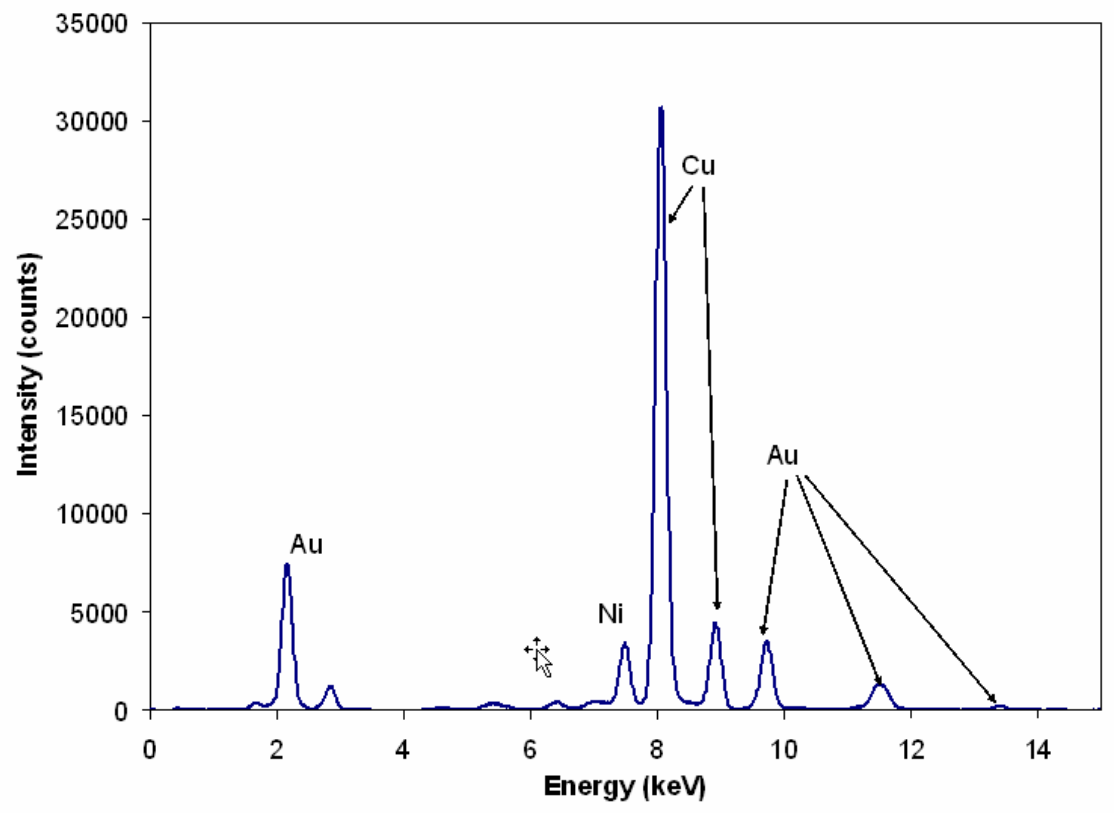

Particle analysis report Page 11 


\section{Results}

- Most of the particles are OsM which is from the cathode.

- Cathode particles are mostly dark, flaky, flat, long needle like

- Some steel particles composed of $\mathrm{Cr}, \mathrm{Fe}$ and $\mathrm{Ni}$

- Steel particles are shiny, globular, chunky

- Tape is polyvinylchloride - large $\mathrm{Cl}$ peak, with $\mathrm{Ca}$ and $\mathrm{Ti}$ (white colorants), possible lead contamination, peaks around $10.6 \mathrm{keV}$

- Broken gold coated contact was discovered in the bag - specimen was analyzed - unknown if this was part of the material collected in the vacuum tank

Particle analysis report Page 12

\section{$311 X$ Cathode Experience at LANL}

Experience at LLNL and early button testing at LBNL indicated potential performance improvements by switching from a $612-\mathrm{M}$ cathode to at 311-X cathode. The 311-X cathode did not have the Osmium Ruthenium or M coating of the 612, but a 311-X cathode was ordered to the LLNL specifications. It was also ordered with a "true bifilar" wound heater for superior magnetic performance. The "true bifilar" design resulted in $3 \%$ less total cathode, because of a greater required turn-to-turn spacing. This cathode was mounted on DARHT II but never made it to beam testing. The reason for its failure was its higher surface emissivity as compared to units with the M coating. With higher emissivity, more power is required to achieve operating temperature, and the needed power could not be supplied within the current limits of the heater filament. In fact the 311-X was heated to filament failure without ever reaching full operating temperature. The difference between the heating performance and that of the $M$ coated cathodes is 
shown in Figure 8.3 below. The $311-\mathrm{X}$ required more than $0.5 \mathrm{~kW}$ of additional power to reach the same temperature as the $\mathrm{M}$ coated 612-M and 311X-M

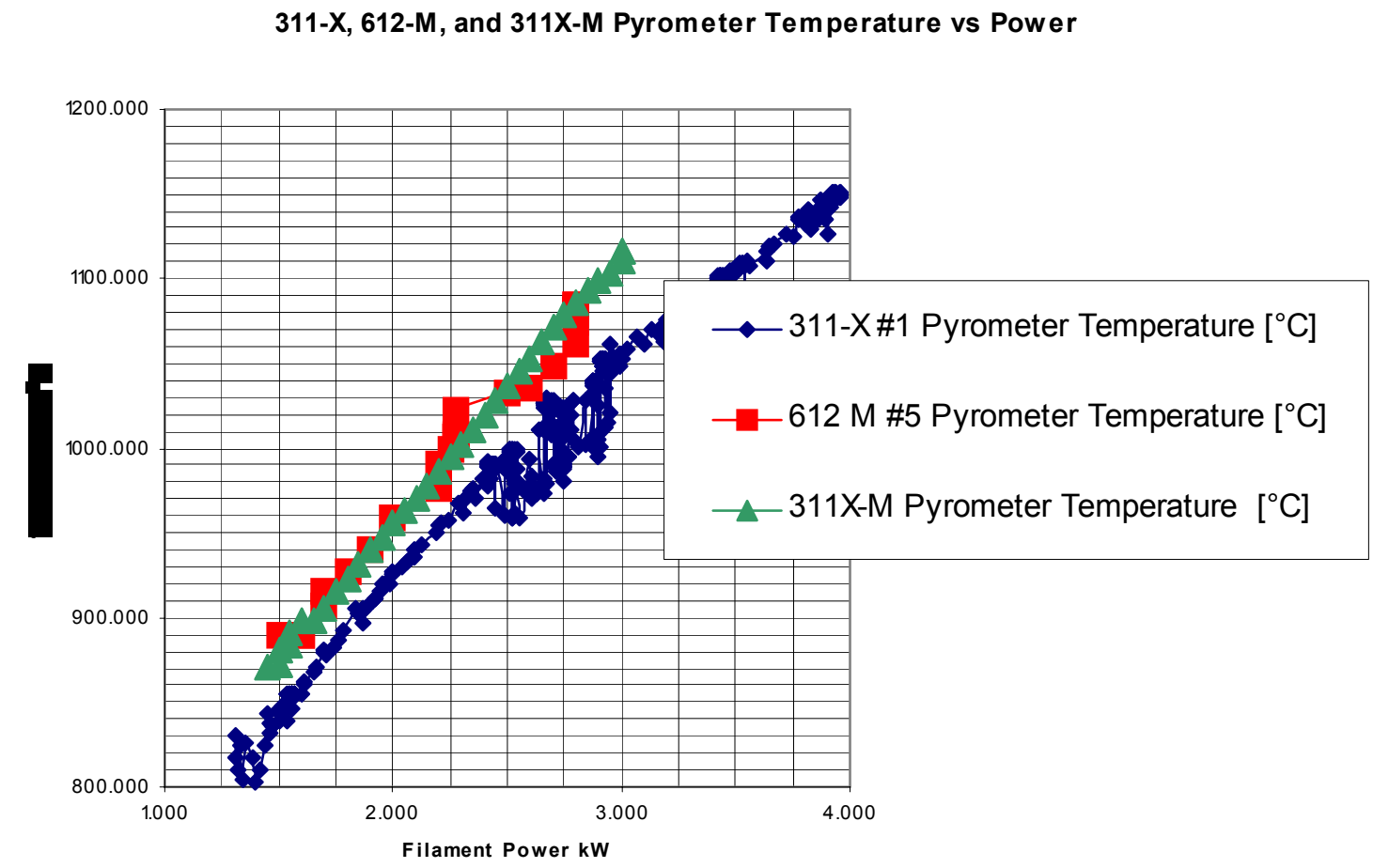

Figure 8.3: Heating performance of the $311-\mathrm{X}$ cathode as compare to the $612-\mathrm{M}$ and 311X-M cathodes.

The 311-X cathode heater failed preventing full activation and therefore preventing any beam testing with this unit. Therefore the decision was made to order a 311-X cathode with the M coating.

\section{X-M Cathode Experience at LANL}

After the inability to head the 311-X cathode, two new cathodes were order, a 612-M\#6 and a 311X-M \#1. The reason for ordering two types was that if the emissivity of a $311 \mathrm{X}-\mathrm{M}$ cathode also prevented successful heating to operating temperatures, another 612 would be available to work on the water vapor problem. Fortunately, the heating performance of the 311X-M turned out to be identical to that of a $612-\mathrm{M}$ and was therefore viable for use. Both of the units ordered after the 311-X (the 612-M\#6 and the 311X-M\#1) were order with a "true bifilar" filament. The second 311X-M unit ordered 
was returned to the original "quasi bifilar" heater. This return was to get to a more robust heater design when it was determined that the magnetic improvement of the "true bifilar" design was inconsequential.

\section{$\underline{311 \mathrm{X}-\mathrm{M} \# 1}$}

The311X-M\#1 was initially subjected to a heating test immediately following completion of installation. That test determined that the thermal performance of the $311 \mathrm{X}-\mathrm{M} \# 1$ was identical to that of a $612-\mathrm{M}$. The activation process followed for the $311 \mathrm{X}-\mathrm{M}$ is summarized in the table below:

\begin{tabular}{|l|l|}
\hline Step & Action \\
\hline 1 & $\begin{array}{l}\text { Slowly raise cathode heating power to } 400 \text { Watts }(\sim 400 \mathrm{C}) \text { keeping the } \\
\text { injector vacuum below } 2 \times 10^{-7} \text { Torr }\end{array}$ \\
\hline 2 & Hold cathode at 400 Watts for $12 \mathrm{hrs}$ \\
\hline 3 & $\begin{array}{l}\text { Slowly raise the temperature to } 875 \mathrm{C} \text { keeping pressure below } 2 \times 10^{-7} \\
\text { Torr }\end{array}$ \\
\hline 4 & Hold at $875 \mathrm{C}$ for 12 hrs. \\
\hline 5 & $\begin{array}{l}\text { Slowly raise the cathode to } 1100 \mathrm{C} \text { keeping the pressure below } 2 \times 10^{-7} \\
\text { Torr }\end{array}$ \\
\hline 6 & Hold at $1100 \mathrm{C}$ for $1 \mathrm{hr}$ \\
\hline 7 & Raise the cathode to $1185 \mathrm{C}$ \\
\hline 8 & Hold at $1185 \mathrm{C}$ for $2.5 \mathrm{hrs}$. \\
\hline 9 & Activation is considered complete \\
\hline
\end{tabular}

After completing this activation procedure and performing cold cathode testing, the cathode was beam tested. The operating temperature was set at $1120 \mathrm{C}$ and $1471 \mathrm{~A}$ of bean was achieved on the first pulse. The first pulse was intentionally taken at a voltage lower than the expected full voltage operating point. In six pulses the voltage was raised to full value and a full beam current of $2 \mathrm{kA}$ was achieved. The performance of $311 \mathrm{X}$ $\mathrm{M \# 1}$ is shown with the 612-M performance data in Figure 8.4 below: 

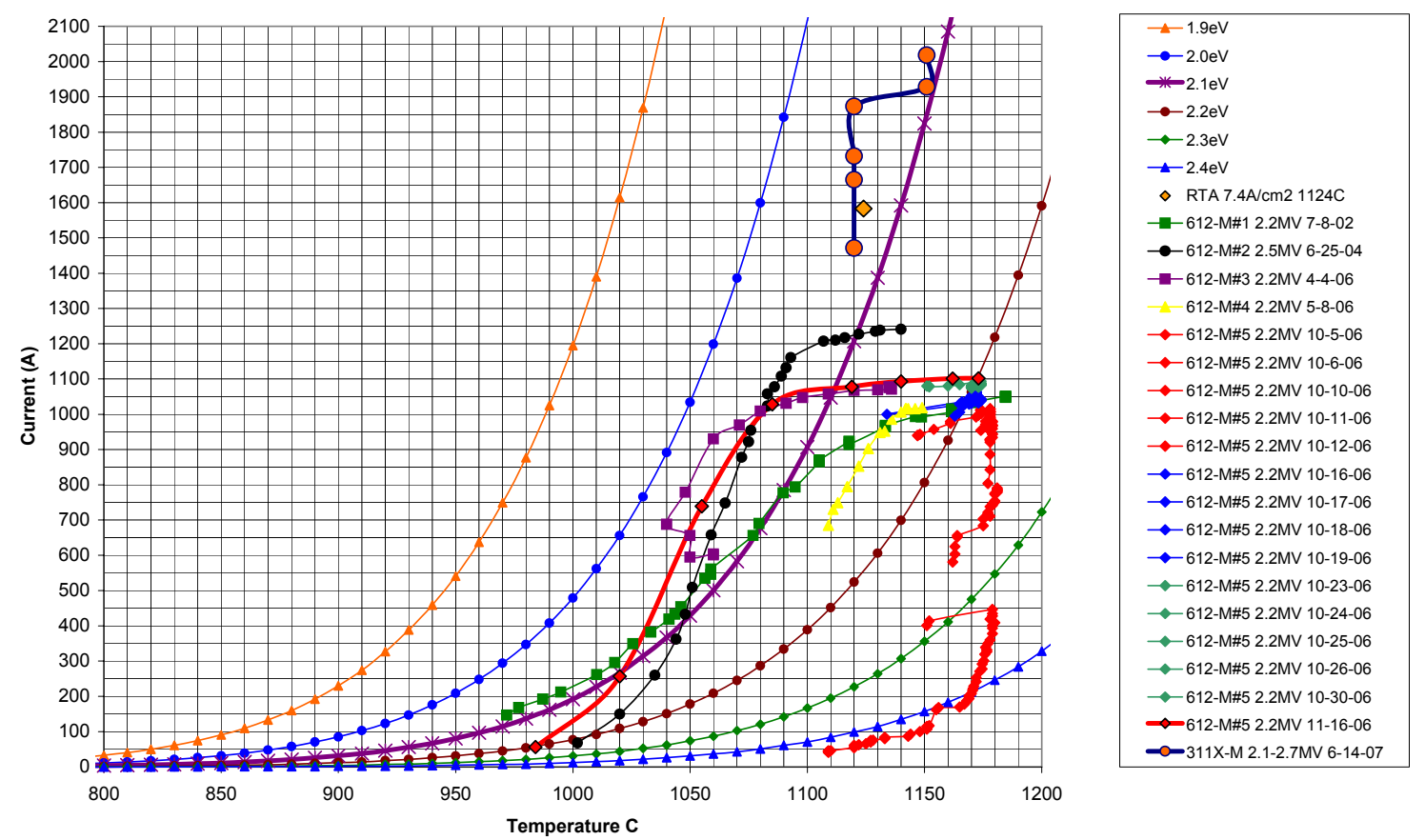

Figure 8.4: Performance of cathode 311X- cathode compared with the 612-M cathodes.

After the $4^{\text {th }}$ pulse the cathode temperature was raised to 1150 at the same time a small injector voltage step was made. It was clear that the temperature increase had no effect on the cathode current and that the only current increases were coming from voltage increases. In other words the cathode was operating in a space charge limited region at 1120C. Attempt to measure the cathode workfunction have not been undertaken for any of the $311 \mathrm{X}-\mathrm{M}$ cathodes. Therefore it is not known how much the cathode temperature can be reduced for $2 \mathrm{kA}$ operation. The $311 \mathrm{X}-\mathrm{M}$ cathode was operated for a number of days prior to a unscheduled vacuum venting due to the beam penetrating the downstream transport beam pipe. The thermal shock created by this venting damaged the cathode heater filament. The heater filament would operate at lower powers, but would shortout when raised to full operating levels. The cycle of operation at low power followed by shorting at full power was repeated several times. The inability to operate at full heater power prevented testing to see if the cathode surface survived the venting. The filament problems lead to the decision to return to the more robust "quasi bifilar" design on the next cathode order. 
Testing of cathode $612-\mathrm{M} \# 6$ followed the 2kA operation of $311 \mathrm{X}-\mathrm{M} \# 1$

\section{$\underline{311 \mathrm{X}-\mathrm{M} \# 2}$}

The 311X-M\#2 and \#3 cathode3 were both ordered with the "quasi bifilar" cathode heater design. $311 \mathrm{X}-\mathrm{M} \# 2$ was installed and activated in the same manner as $311 \mathrm{X}-\mathrm{M} \# 1$ with a single exception, the final hold temperature was reduced from $1185 \mathrm{C}$ to $1155 \mathrm{C}$. Also the cold cathode testing was eliminated following the cold cathode failure of 612M\#6. This cold cathode testing has resulted in additional conditioning during beam operation. Beam operation of $311 \mathrm{X}-\mathrm{M} \# 2$ has yielded identical beam current results to $311 \mathrm{X}-\mathrm{M} \# 1$. The balance between current and voltage in the heater circuit has shifted to slightly more voltage and less current for the same heating power. This is due to the filament design change back to the "quasi-bifilar" as compared with the "true bifilar" design. The thermal performance of temperature vs power is identical for both $311 \mathrm{X}-\mathrm{m}$ $\# 1$ and $\# 2$ and both are identical to the 612-Ms in thermal performance.

The effective work function of the 311X-M cathode has yet to be measured. The 311XMs have been operated in a range from $1120 \mathrm{C}$ to $1150 \mathrm{C}$ (true temperatures) with no change in their performance. $2 \mathrm{kA}$ operation is easily achieved with the $311 \mathrm{X}-\mathrm{M}$ cathodes. 


\title{
Appendix $A$
}

\section{Column High Voltage Design, Modeling, and Measurement}

\author{
William Waldron
}

\section{Column Electrical Design}

The history of the injector column design has been documented in Reference A. After oil was chosen as the dielectric around the high voltage stalk which houses cabling to the cathode, the dimensions of the stalk and column were chosen to limit the electric field on oil surfaces to a maximum of $190 \mathrm{kV} / \mathrm{cm}$ at $3.5 \mathrm{MV}$. The injector column consists of 6 Mycalex stacks (10 insulator rings per stack) and 3 alumina ceramic stacks ( 7 insulator rings per stack). Mycalex, which had previously been used on a LANL Van de Graaff generator, has a significantly higher impact strength than alumina ceramic, so the ceramic stacks are used at the top of the column where the electric fields in oil are the lowest. The concern was that a voltage breakdown in the oil could cause a shockwave which could impact and crack the insulator rings. There are shockwave diffuser rings to mitigate this hazard on the inner diameter of all Mycalex insulator rings. Purely capacitive grading of the column is non-uniform, so each insulator ring has parallel circuit boards which contain resistors and metal-oxide varistors (MOV's) to grade the column for both the risetime transient and the pulse flat top (Figure A.2). The final simulation of the column grading is described in Reference B (Figure A.1). In determining the final resistor and MOV configuration, there was no crowbar-induced transient analysis performed.

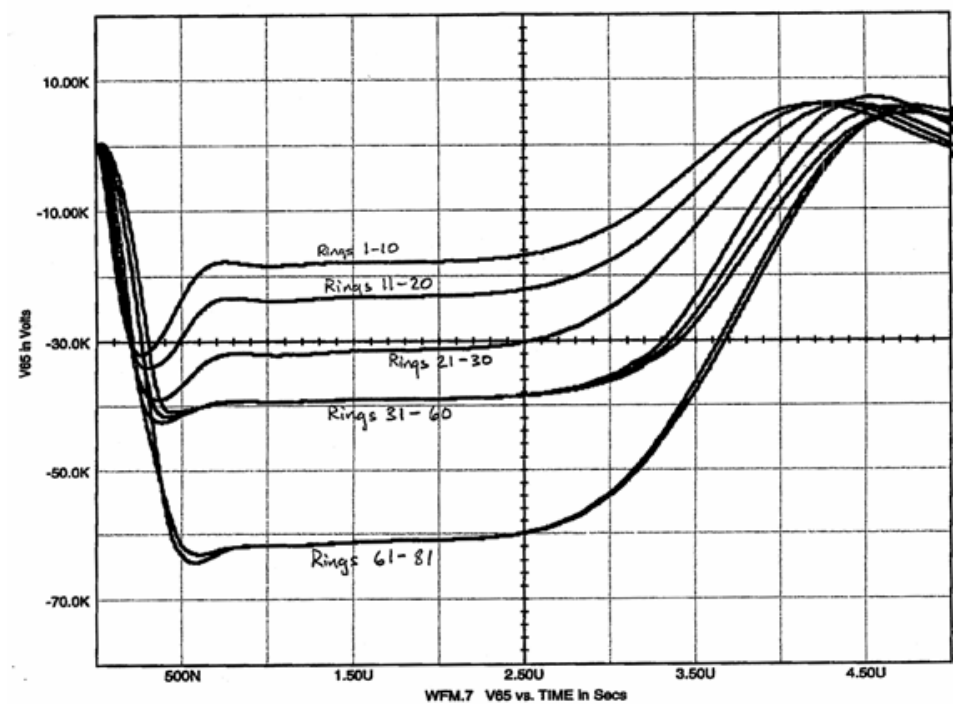

Fig. A.1: Column ring voltages including resistor voltage coefficients and MOV's at 3.13 MV from Reference B. Rings 1-60 are Mycalex and rings 61-81 are alumina ceramic. 


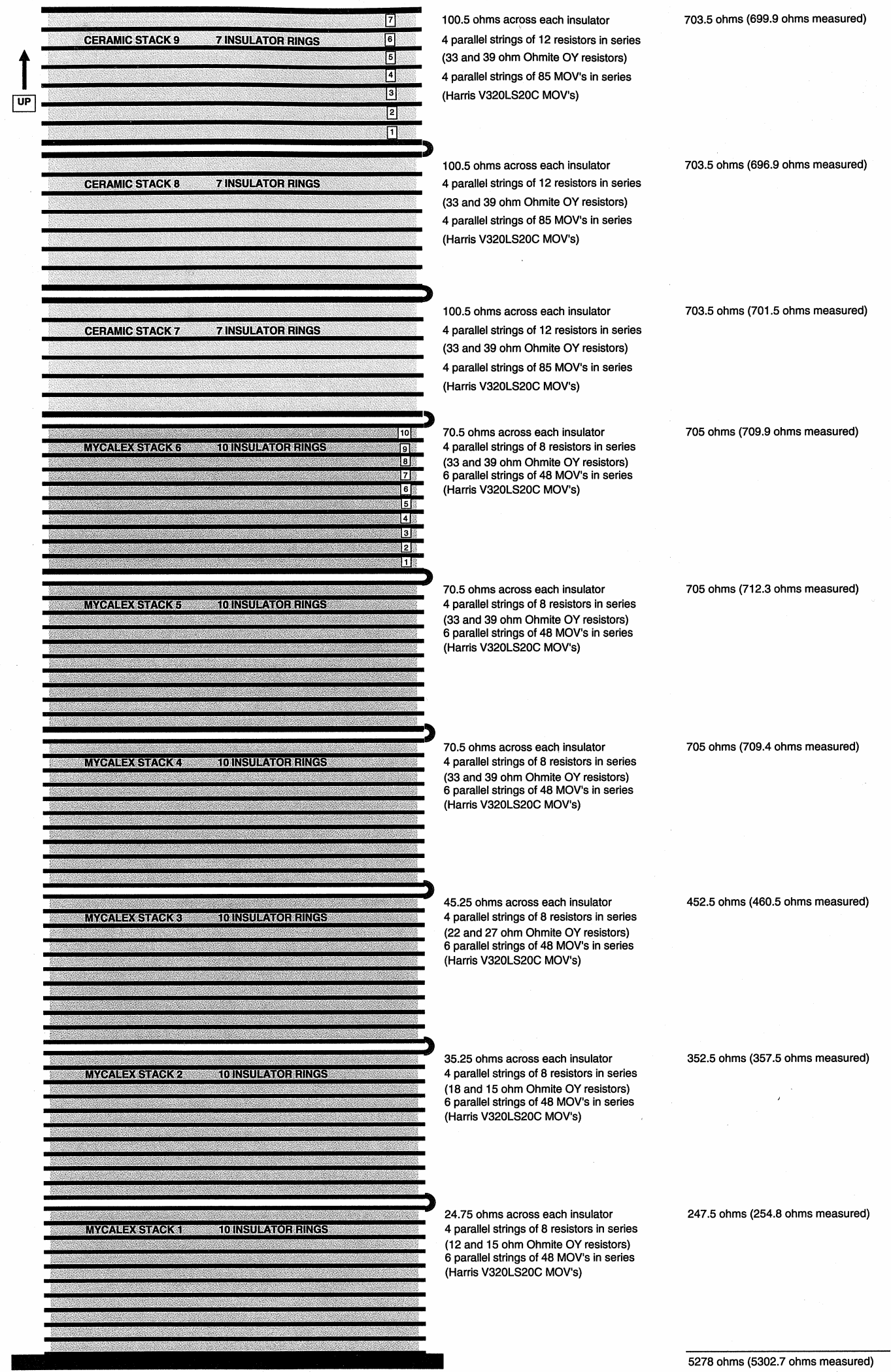

Figure A.2: Column configuration. Note that the resistor measurements were made at LNBL with a Fluke 177 multimeter and do not consider voltage coefficients. 
The column configuration was chosen so that the average axial gradient is $\sim 10 \mathrm{kV} / \mathrm{cm}$ for 3.5 MV operation. Peak electric fields were designed to be limited to $190 \mathrm{kV} / \mathrm{cm}$ on oil electrode surfaces, $70 \mathrm{kV} / \mathrm{cm}$ on vacuum electrode surfaces, and much less than 10 $\mathrm{kV} / \mathrm{cm}$ at triple points. A recent simulation at $3.2 \mathrm{MV}$ by Enrique Henestroza shows fields that are consistent with the design goals (Figures A.3 and A.4). Previous simulations at $3.5 \mathrm{MV}$ show an average axial gradient of $11.4 \mathrm{kV} / \mathrm{cm}, 190 \mathrm{kV} / \mathrm{cm}$ on the stalk in oil at the bottom of the column, and $70 \mathrm{kV} / \mathrm{cm}$ on the source dome in vacuum.

\section{BOTTOM OF COLUMN}

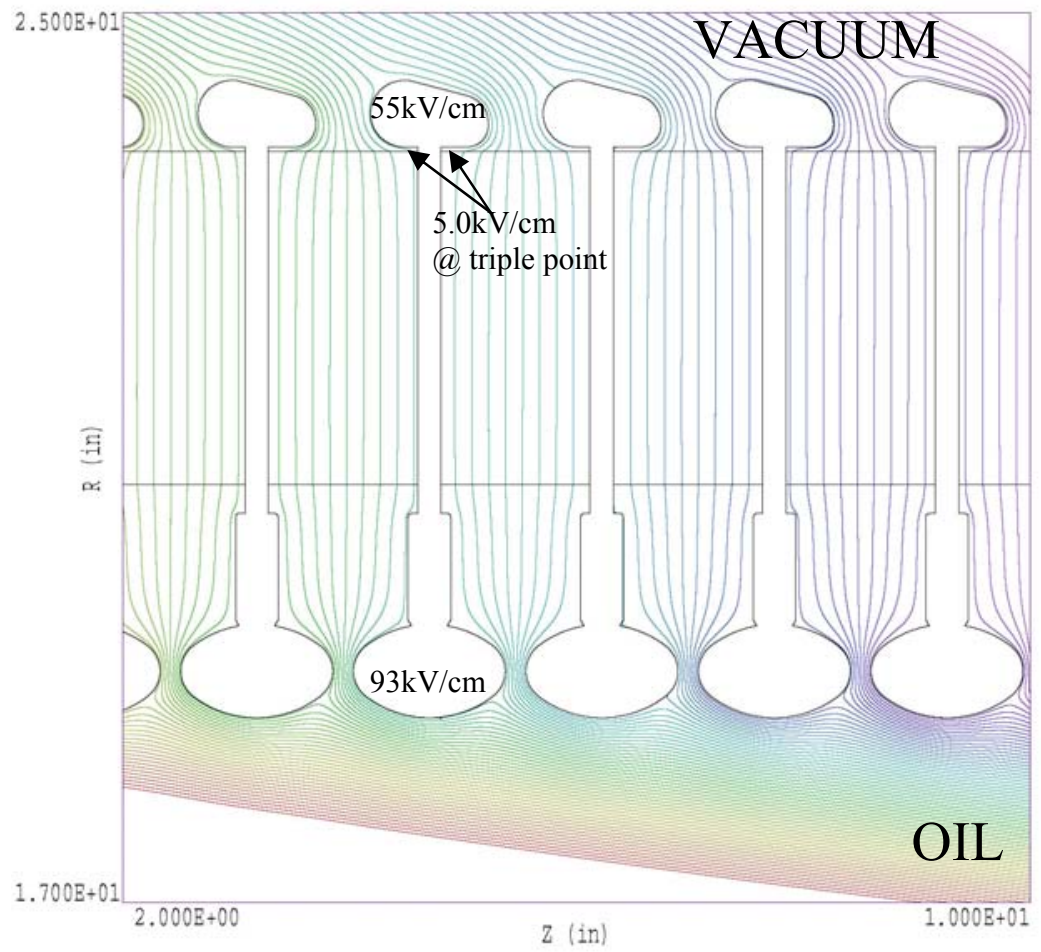

Figure A.3: Equipotentials at $5 \mathrm{kV}$ steps for a 3.2 MV injector voltage at the bottom of the column for $44 \mathrm{kV}$ peak across Mycalex rings. The average electric field across the $3.35 \mathrm{~cm}$ thick Mycalex rings is $13 \mathrm{kV} / \mathrm{cm}$. 


\section{TOP OF COLUMN}

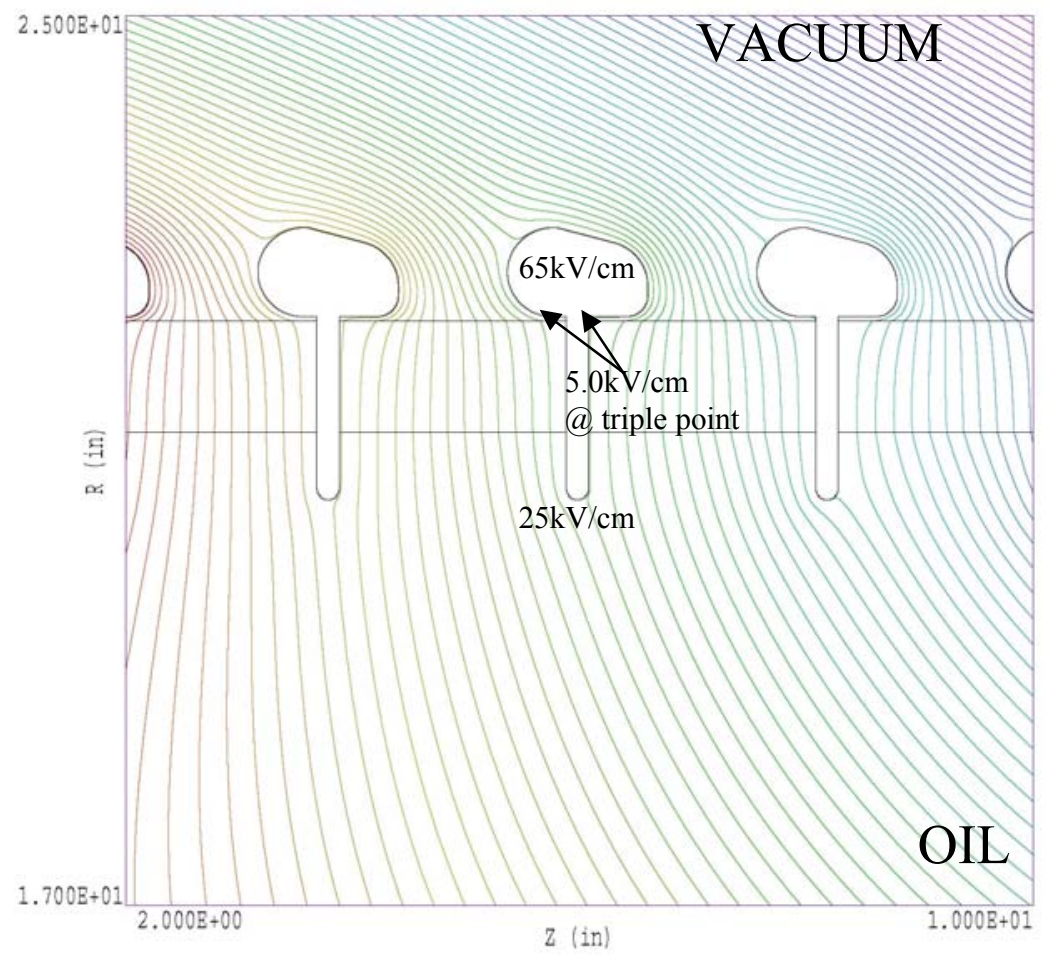

Figure A.4: Equipotentials at $5 \mathrm{kV}$ steps for a $3.2 \mathrm{MV}$ injector voltage at the top of the column for $65 \mathrm{kV}$ peak across alumina ceramic rings. The average electric field across the $5.08 \mathrm{~cm}$ thick ceramic rings is $13 \mathrm{kV} / \mathrm{cm}$.

\section{Column Mechanical Design and Testing}


A summary of the mechanical design and testing of the column are described in Reference C and D.

\section{$\underline{\text { MOV Component and Production Circuit Board Tests }}$}

Initial tests on the Harris V320LA20C MOV's used to grade the column during the rise time transient are described in Reference E. Device voltage and current characteristics were measured under pulsed conditions and parameter drift as a function of accumulated shots was characterized for 30 MOV's. Data was taken before and after 500k shots and after $1 \mathrm{M}$ shots. The results of these tests indicate that the probability of successful system operation after $210 \mathrm{k}$ shots is $90 \%$. The end of life was determined by a $20 \%$ drift in the clamping voltage which results in an increase from $14 \mathrm{kV} / \mathrm{cm}$ to $16 \mathrm{kV} / \mathrm{cm}$ peak electric fields across the Mycalex sections at the base of the column. It was also noted that because there are CVR current monitors on the boards at the base of the column, the MOV current can be monitored for drift and appropriate maintenance actions taken. This analysis assumed that there were 78 total insulating rings which make up 5 Mycalex stacks and 4 alumina ceramic stacks. The final configuration at DARHT-II is 81 total insulating rings which make up 6 Mycalex stacks and 3 alumina ceramic stacks.

The acceptance tests of a sample of the production MOV circuit boards are described in Reference F. Assembly voltage and current characteristics were measured under pulsed conditions and parameter drift as a function of accumulated shots was characterized for 80 circuit boards out of the total 360 boards in the Mycalex configuration. Data was taken before and after 10k shots. No analysis was done that specifically considered the alumina ceramic configuration. The results of these tests indicate that based on the measured distribution of measured currents at $35 \mathrm{kV}$ and the acceptable variation in clamping voltage, there is greater than or equal to a $95 \%$ chance that the column will perform as expected without any further testing. The tests also indicate that the rejection rate of MOV circuit boards is acceptable. 


\section{$\underline{\text { Resistor Component and Production Circuit Board Tests }}$}

The testing of various resistors for grading the column is described in Reference G. Resistance drift as a function of accumulated shots was evaluated for carbon composition and ceramic composition resistors from HVR, Cessiwid, and Ohmite. Ohmite OY series resistors were chosen after drifting an average of $-1.6 \%$ after $500 \mathrm{k}$ shots. A total of 47 resistors were tested. The mean time between failures for the entire column was estimated at $192 \mathrm{k}$ shots. This analysis assumed that there were 78 total insulating rings which make up 5 Mycalex stacks and 4 alumina ceramic stacks.

\section{Integrated Stack Acceptance Tests}

The details in this section have been put together from existing informal notes and spreadsheets from Bill Elliott, Jim Fockler, and Dave Anderson. Reasonable assumptions and corrections have been made, but there are uncertainties based on limited records and calibration questions.

Stack acceptance tests were performed on each assembled stack before they were shipped to LANL for installation. Prior to the installation of the resistor and MOV boards, several bare stacks with vacuum side triple point rings were tested to a factor of 1.5-2 times the operating voltage at $3.2 \mathrm{MV}$. However, the raw data is missing so quantitative results with appropriate correction factors can only be presented from the stack tests which included resistors and MOV's. The intention of the stack acceptance tests was to test to the equivalent resistor energy and action $\left(\mathrm{I}^{2} \mathrm{t}\right)$ corresponding to an injector voltage of 3.5 MV as defined by Dave Anderson and Jim Fockler. Although the voltage diagnostic used for these tests was likely the nonlinear LBNL cell voltage monitor, the voltage coefficients of the column resistors were derived using the same monitor. Therefore, the actual test action does not need a correction factor applied (Table 1). 


\begin{tabular}{|c|c|c|}
\hline stack & resistor action at 3.5 MV & tested resistor action \\
\hline 1 & 0.31 & 0.37 \\
\hline 2 & 0.24 & 0.28 \\
\hline 3 & 0.23 & N/A \\
\hline $4,5,6$ & 0.15 & 0.14 \\
\hline $7,8,9$ & 0.19 & 0.19 \\
\hline
\end{tabular}

Table 1: Stack acceptance test resistor action from Reference $H$.

Because the effective pulsewidth of the test was 3.75 us and resistor action is not linear with voltage, an action corresponding to $3.5 \mathrm{MV}$ does not correspond to ring voltages and electric fields at 3.5 MV (Table 2).

\begin{tabular}{|c|c|c|c|}
\hline stack & $\begin{array}{c}\text { peak ring voltage at 3.2 } \\
\text { MV }\end{array}$ & flat top ring voltage at 3.2 MV & tested ring voltage (kV) \\
\hline 1 & 33 & 18 & 21 \\
\hline 2 & 35 & 24 & 24 \\
\hline 3 & 40 & 33 & N/A \\
\hline $4,5,6$ & 44 & 40 & 40 \\
\hline $7,8,9$ & 65 & 62 & 62 \\
\hline
\end{tabular}

Table 2: Stack acceptance test ring voltages from Reference H.

Mycalex stack 1 was tested to $43 \mathrm{kV} /$ ring for $1 \mathrm{k}$ shots with many resistor failures. These resistor failures (chipping) were a result of operator error by testing above the intended test voltage and the fact that there was a significant resistor voltage coefficient. Because it is likely that the voltage monitor used with this test was the nonlinear LBNL cell voltage monitor, the $43 \mathrm{kV} /$ ring becomes $36 \mathrm{kV} /$ ring after a $19.5 \%$ correction. The correction factor for this monitor is described in Reference I (Figure A.6). At this point, the components were replaced and the voltage was lowered to the intended test voltage of $23 \mathrm{kV} /$ ring and $1 \mathrm{k}$ shots were taken with no breakdowns or damage to the components. Applying a $12.5 \%$ correction factor results in $21 \mathrm{kV} /$ ring. This number is not directly 
scalable with Dave Anderson's simulation in Reference B because of the difference in waveshape.

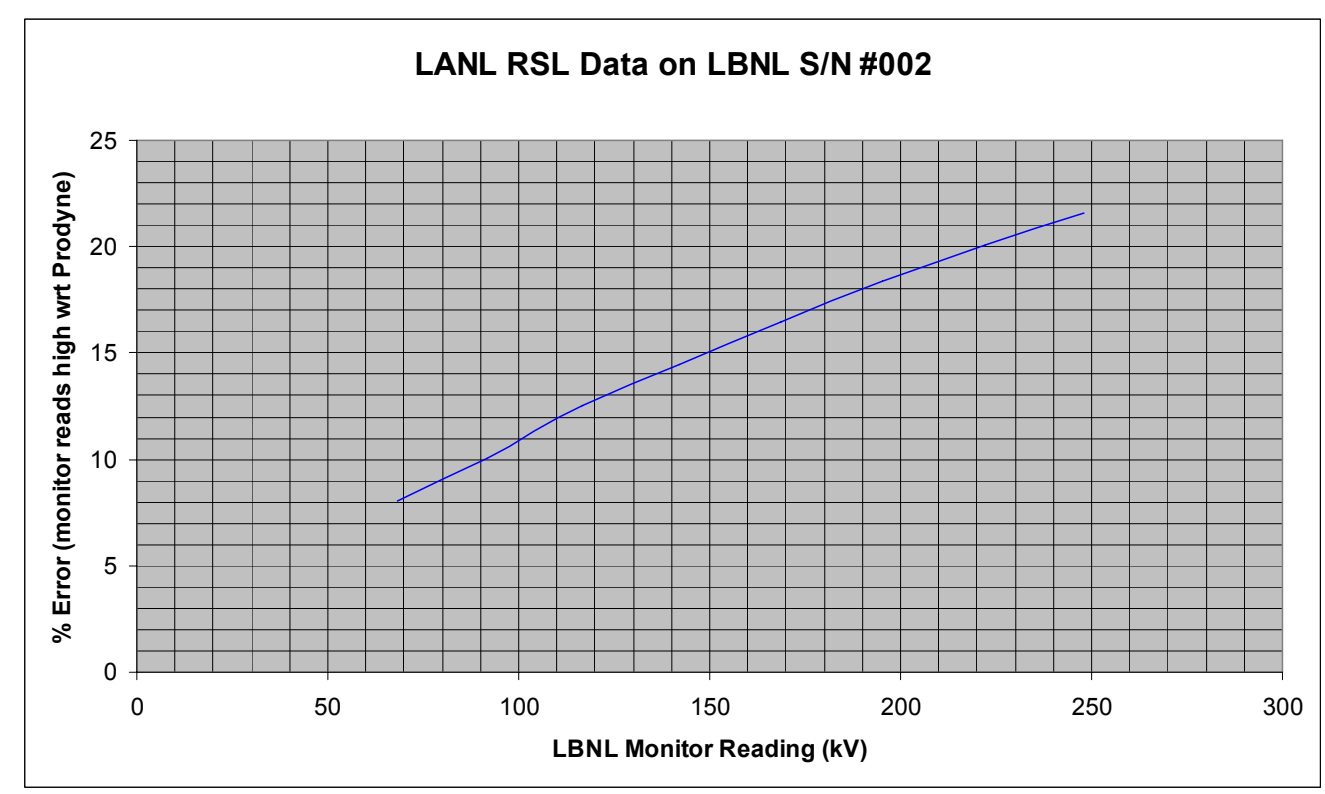

Figure A.6: Correction to LBNL cell voltage monitor for voltage coefficient.

Mycalex stack 2 was tested to $31 \mathrm{kV} /$ ring for $1 \mathrm{k}$ shots with some resistor failures. After applying a $15 \%$ correction factor which results in $27 \mathrm{kV} /$ ring. At this point, the components were replaced and the voltage was lowered to the intended test voltage of 28 $\mathrm{kV} /$ ring and $1 \mathrm{k}$ shots were taken with no breakdowns or damage to the components. Applying a $14 \%$ correction factor results in $24 \mathrm{kV} / \mathrm{ring}$. This number is not directly scalable with Dave Anderson's simulation because of the difference in waveshape.

Although Mycalex stack 3 was tested, there are no records of the test conditions.

Mycalex stacks 4, 5, and 6 were tested to $45 \mathrm{kV} /$ ring for $1 \mathrm{k}$ shots with no breakdowns or damage to the components. After applying a 20\% correction factor which results in 38 $\mathrm{kV} /$ ring and scaling this Mycalex ring voltage to an injector operating voltage yields a 3 MV injector voltage. During this test, the dummy load resistors increased in temperature and decreased the loading on the PFN output waveform. At the end of the test, the 
voltage per ring had increased to $52 \mathrm{kV}$. After applying a $22.5 \%$ correction factor which results in $42 \mathrm{kV} /$ ring and scaling this Mycalex ring voltage to an injector operating voltage yields a 3.4 MV injector voltage. The average of the two extreme injector voltages tested during the $1 \mathrm{k}$ shots is $3.2 \mathrm{MV}$.

Ceramic stacks 7,8 , and 9 were tested to $74 \mathrm{kV} /$ ring for $1 \mathrm{k}$ shots with no breakdowns or damage to the components. After applying a 20\% correction factor which results in 62 $\mathrm{kV} /$ ring and scaling these ceramic ring voltages to an injector operating voltage yields a 3.2 MV injector voltage.

In summary, it appears that from the integrated stack tests, there is a sufficient safety factor when considering the resistor action to safely run at 3.2 MV. When considering the voltage on the rings, there is insufficient test data to conclude what safety factor exists above 3.2 MV. An evaluation of the column grading design is probably a worthwhile exercise to eliminate the uncertainties in the existing data and gain confidence in the design at 3.2 $\mathrm{MV}$. 


\section{$\underline{\text { References }}$}

A. "Historical Guide of the DARHT-II Injector Column Design", DARHT Technical Note No. 246, May 8, 2002.

B. “Informal Notes on DARHT-II Injector Insulator Column”, LBNL Engineering Note M8075, January 25, 2002.

C. "Design and Construction of the 3.2 MeV High Voltage Column for DARHT II", LBNL Report 45483, August 20, 2000 (same as LINAC 2000 paper).

D. "High Voltage Column - Shock Analysis", DARHT Technical Note No. 316, March $5,2003$.

E. "Results of Initial Varistor Testing \& Implications to DARHT-2", DARHT Technical Note No. 358, March 10, 2003.

F. "MOV Assemblies Test Report for $2^{\text {nd }}$ Axis of DARHT Injector Insulator Column", DARHT Technical Note No. 117, October 20, 1999.

G. "Results from High Voltage Resistor Testing Effort Performed at LBNL", DARHT Technical Note No. 359, March 10, 2003.

H. "DARHT_stack test config_may01” Excel spreadsheet from Bill Elliott and modified by Will Waldron.

I. "Comparison of LBNL and Prodyne Cell Voltage Monitors", DARHT Technical Note No. 415, April 11, 2003. 
J. “DARHT-II Beam Position Monitor B-dot Owner's Manual”, LANL document, September 12, 2002. 


\section{Appendix B. Injected Beam Production - Summary of Early Experience}

\section{Tim Houck}

\section{Injector Diode Design - Historical Perspective}

The initial specifications called for a diode that could produce a $4 \mathrm{kA}$, low emittance beam. Depending on the pulsed power system, the beam pulse width (flat top) needed to be greater than two microseconds or the diode needed to be capable of producing four pulses of about $100 \mathrm{~ns}$ width within a two microsecond window. To achieve the spot size specification, the total normalized, edge emittance of the beam at the target needs to be no more than 1,500 mm-mr. The goal for the emittance at the injector including the diode and 8 induction cells was set at $500 \mathrm{~mm}-\mathrm{mr}$.

The low emittance requirement eventually led to the choice of a thermionic, (dispenser, Type M) cathode. Tests on the ATA injector [1] had shown that multiple pulse operation with a cold cathode was feasible, but emittance measurements on ITS [2] indicated that emittance could be an issue. To maintain a uniform current density across the cathode and a lower emittance, a Pierce type shroud was incorporated into the design. Photocathodes were also considered for the multipulse system.

The size of the cathode was set by the current density. While current densities greater than $20 \mathrm{~A} / \mathrm{cm}^{2}$ are possible for a dispenser cathode, ETA-II had the highest current density of any operational accelerator at about $16 \mathrm{~A} / \mathrm{cm}^{2}$ ( $2 \mathrm{kA}, 5$ " diameter cathode). Thus initial designs considered 7 to 8 inch diameter cathodes. Larger cathodes challenged the capability of the manufacturer and increased the difficulty of thermal uniformity.

Diode voltage was driven by a number of different considerations. Higher voltages, lower perveance designs generally have lower field stresses on the shrouds. Using ITS as a model and scaling for pulse length led to an initial goal of no more than $200 \mathrm{kV} / \mathrm{cm}$ peak field on the cathode shroud. Discussions with the Klystron Group at the Stanford Linear Accelerator Center (SLAC) eventually led to a more conservative $120 \mathrm{kV} / \mathrm{cm}$ goal. 
Maximum voltage was determined by stress on the insulating column. Initial designs considered the range of 3.5 to $4 \mathrm{MV}$ [3] [4]. These designs had theoretical emittances as low as $\sim 190 \mathrm{~mm}$-mr for the diode.

Improvements in radiographic diagnostics allowed dose requirements to be relaxed and the current specification was reduced to $2 \mathrm{kA}$ in 1999. This gave the option of lowering the current density, reducing the cathode size, or a combination of the two. A 6.5 inch diameter cathode was eventually selected with a modest $9.4 \mathrm{~A} / \mathrm{cm} 2$ current density [5]. This design had a theoretical emittance of $\sim 250 \mathrm{~mm}-\mathrm{mr}$ for the diode.

Two test stands were used to support the design of the diode. At LANL the Cathode Test Stand (CTS) [6] was an instrumented vacuum chamber used for measuring thermal, mechanical, vacuum, and emission characteristics of full size cathodes considered for the injector. Cathode temperature was measured and emissivity determined using a combination of multispectral imaging pyrometry and spot pyrometry. A $\sim 450 \mathrm{kV}, 1.5$ microsecond pulser extracted $0.5 \mathrm{kA}$ in fully space charge limited emission $\left(2.3 \mathrm{~A} / \mathrm{cm}^{2}\right)$. Peak current density from a close anode arrangement was $11 \mathrm{~A} / \mathrm{cm}^{2}$. In a close anode arrangement it is possible that barium will return to the cathode resulting in better performance than with an open anode arrangement.

RTA [7] was a nominal 1-MV, 1.2-kA, 200-ns pulse width, induction injector constructed at Berkeley. The cathode shroud, A-K gap and shroud material were designed to allow the study of vacuum breakdown issues in the presence of a beam. This was successfully accomplished. However, the 3.5 inch diameter dispenser cathode was also intended to demonstrate high $\left(20 \mathrm{~A} / \mathrm{cm}^{2}\right)$ current density and achieved only $13 \mathrm{~A} / \mathrm{cm}^{2}$. Beam dynamic experiments performed on RTA were performed at a current density of $9.6 \mathrm{~A} / \mathrm{cm}^{2}$.

It was not obvious why a higher current density was not achieved at either test facility for an open anode arrangement. For RTA there was some suspicion that the vacuum may have been insufficient to avoid poisoning, but this was not confirmed. 
A few comments should be made about the first cathode installed in the DARHT II injector. The edge of the cathode was chipped and damaged during shipping between LANL and LBNL. The axial length of this cathode was also too short resulting in a 100mil recess from the designed position relative to cathode shroud. A programmatic decision was made to install this cathode and use it for installation, equipment, diagnostic, and heating checks while awaiting a replacement cathode. This was beneficial in that an issue with the heat shields was discovered and subsequently corrected at the time of the installation of the second cathode. Delayed receipt of the replacement cathode led to this cathode being used not only for the commissioning of the injector, but also for accomplishing the accelerator commissioning (CD4d). However, the highest current density realized with this cathode was $6 \mathrm{~A} / \mathrm{cm}^{2}$ for a perveance of 0.25 micropervs. The poor performance was blamed on poisoning due to the greater than normal length of time between fabrication and installation, installation errors (a section of the cathode surface was wiped with a swipe), and delay between the initial activation cycle and first beam experiment. As will be described below, the poor performance may have been a problem with the osmium-ruthenium coating.

\section{ISSUES THAT AFFECT BEAM PRODUCTION QUALITY}

\section{CATHODE-SHROUD ALIGNMENT}

The position of the emitting surface with respect to the shroud has a significant effect on the quality of the emission. The desired alignment is for the shroud to meet the cathode at an angle of $67^{\circ}$ from the vertical. Refer to Figure B.1. Simulations [8] indicate that the emittance could increase by a factor of three for a 1-mm axial error in position. A 1-mm gap between the cathode and the shroud, i.e. a difference between the cathode outer radius and the shroud inner radius, leads to a $20 \%$ increase in emittance. The cathode is fabricated with a 100-mil (2.5-mm) shoulder [9] over which the inner radius of the shroud extends. Actual contact of the cathode with the shroud would result in a thermal leak and damage to the components. 
Mechanical tolerances of a few tens of microns are readily achievable. The issue for cathode-shroud alignment is thermal movement. Thermal analysis [10] of the cathode structure found that the shroud knife edge (inner radius) increased by 13 mils while the cathode expanded radially by 14.5 mils. Axially the shroud knife edge moved forward 29 mils while the cathode surface moved 27 mils. Thus the relative motion of the cathode with respect to the shroud was approximately 2 mils in both dimensions. The desired dimensions for proper cathode-shroud alignment under both cold and hot conditions are given with Figure B.1. The radial expansion of the shroud knife edge was measured on the CTS during heating and found to be 11 mils in reasonably good agreement with the thermal analysis. Accurate measurements of the cathode-shroud alignment have not been performed in situ with a hot cathode.

\section{Anode-cathode alignment}

Anode-cathode alignment does not impact the quality of emission from the cathode except in extreme instances of misalignment. The issue is related to whether the emitted beam is introduced to the focusing channel in a matter that will allow it to be transported without adversely effecting the current distribution. The ideal situation is for perfect alignment of the longitudinal axis of the cathode and cathode shroud with the anode shroud and the focusing solenoids. Even with this ideal alignment, the DARHT-II beam will be deflected from the mechanical axis by the magnetic field produced by the stalk current [11]. In addition to deflecting the beam, this magnetic field also introduces a small quadrupole-like field which effectively "squeezes" the beam in the vertical plane. Dipole and quadrupole corrector coils were installed in the anode to compensate for the effect of the stalk induced fields.

In a realistic system misalignments will occur. Simulations [12] were performed to determine the sensitivity of the beam transport to nominal alignment errors. Initial beam centroid displacements and tilts of $0.1 \mathrm{~mm}$ and $0.2 \mathrm{mr}$ were examined in a focusing channel comprised of the bucking coil, anode coil and eight transport solenoids. 
Simulations involving a thousand random solenoidal configurations with an RMS offset of $\pm 0.1 \mathrm{~mm}$ or RMS tilt of $\pm 0.4 \mathrm{mr}$, with an energy variation of $\pm 0.5 \%$ were performed. The results indicated that initial beam centroid tilt did not lead to increased offset. An initial offset was retained through the simulated focusing channel, but did not increase.

These results were expected. The initial beam tilt would be quickly corrected by the quasi-electrostatic fields of the diode while the large bore solenoids have uniform fields over a significant fraction of the anode radius. It should also be mentioned that solenoid tilt increased the final beam centroid offset by a factor of seven over solenoid offset. This is an important consideration as the bucking coil is mechanically linked to the cathode housing. In addition to any misalignments in positioning this solenoid, it will also reflect the misalignments of the cathode. Considering only beam centroid offset, the anodecathode alignment tolerance for tilt should be the same as for solenoids and the offset should be determined by acceptable centroid offset at the accelerator exit.

\section{CATHODE TEMPERATURE UNIFORMITY}

The uniformity of the cathode's surface temperature impacts the useful lifetime and possibly the emitted beam quality. Due to the strong dependence of current density on temperature, we desire to operate at a temperature where emission is fully space charge limited to minimize variations in current density. This means that the temperature of the coldest area of the cathode surface must be increased to a level where emission is limited by space charge for the applied voltage. The other areas of the cathode are emitting at the same space charge limited current density, but at temperatures greater than required. This is not an unusual condition but the temperature variations should be minimized as the life time of the cathode is strongly dependent on the operating temperature. A temperature increase of 50 degrees centigrade will reduce the cathode lifetime by a factor of four [13]. 
The standard specification for thermal uniformity for an M-type dispenser cathode is $\pm 5^{\circ} \mathrm{C}$. Due to the size of the cathode, the manufacturer (Spectra-Mat) was unwilling to accept specific temperature uniformity and the final cathode specification [14] did not include temperature uniformity. Factory testing by Spectra-Mat on the first three production 6.5 inch cathodes found a temperature variation on the face of the cathode from the edge to the center varied from $20^{\circ} \mathrm{C}$ to $42^{\circ} \mathrm{C}$ in brightness. The test bed for these measurements did not insure uniform reflection back to the cathode and may have contributed to this large variation.

Measurements [15] [16] made at the LANL Cathode Test Stand (CTS) found variations in temperature of $26^{\circ} \mathrm{C}$ for a 6.5 inch cathode (pre production) and $38^{\circ} \mathrm{C}$ for the 8 inch cathode. During initial heating of the first installed cathode, a temperature variation of $13^{\circ} \mathrm{C}$ was measured [17]. This in situ measurement was taken using a hot wire pyrometer visually pointed at the coolest/hottest areas with a peak temperature of $925^{\circ} \mathrm{C}_{\mathrm{T}}$ (emissivity of 0.44$)$.

A new cathode heater design may be required to reduce the observe temperature variation. Locating the heating coil at a larger radius, using a different coil radius, varying the thickness of the cathode, and/or using a bombarder technique are all possible changes that could increase the temperature of the outer radius of the cathode with respect to the center and improve thermal uniformity.

\section{CATHODE POISONING}

Cathode poisoning refers to the chemical reaction between the cathode and background gas and/or metal vapors causing a degrading (increase) in the surface work function. To avoid poisoning, dispenser cathodes require a clean vacuum. The large size of the DARHT-II Injector and its application results in a number of challenges related to achieving a sufficient vacuum. Commercial guns, e.g. klystrons, can have all components baked out in situ at temperatures $>400^{\circ} \mathrm{C}$ and then have the vacuum system hard sealed 
(pinched off) for the life of the gun. In some cases electron bombardment of electrodes is used to remove subsurface containments. These techniques produce ultra high vacuum environments essentially devoid of water and other adverse background gases. In contrast, the DARHT-II vacuum system can not be a closed system as entry to replace consumable components and maintenance is required. The size of the components, e.g. the 4-m tall insulating column, and installed electronic components make in situ bake out impractical. Also, the benefits of bake out and other cleaning techniques on individual components are unfortunately compromised during the installation.

Information previous to this work on dispenser cathode poisoning in the environment associated with induction accelerators is limited. A study [18] by W. Turner of osmiumcoated, dispenser cathode poisoning in support of the ETA-II accelerator [19] is the most pertinent to the DARHT-II Injector. A summary of his results that are applicable to DARHT-II are given in the following table. It should be noted that Turner used a close anode configuration for the measurements and achieved relative high current densities. In the table, the partial pressures are maximum values to achieve high current density $(\sim 50$ $\mathrm{A} / \mathrm{cm}^{2}$ ). These partial pressures could be relaxed for lower current densities, but it was not obvious how to correlate the current densities to an open anode configuration. For the CTS, a close anode configuration produced 5 times the density as an open anode. Also note that the temperature is brightness instead of true temperature.

Table. Partial pressures for high current density operation.

\begin{tabular}{|c|c|c|}
\hline Gas Constituent & Temperature $\left({ }^{\circ} \mathrm{C}_{\mathrm{B}}\right)$ & Partial Pressure (nTorr) \\
\hline $\mathrm{H}_{2} 0$ & 1,111 & $<70$ \\
\hline $\mathrm{H}_{2} 0$ & 1,157 & $<100$ \\
\hline $\mathrm{CO}$ & 1,111 & $<100$ \\
\hline $\mathrm{CO}$ & 1,157 & $<300$ \\
\hline $\mathrm{N}_{2}$ & 1,112 & $<100$ \\
\hline $\mathrm{N}_{2}$ & 1,155 & $<1,000$ \\
\hline $\mathrm{O}_{2}$ & 1,113 & few \\
\hline $\mathrm{O}_{2}$ & 1,150 & $<10$ \\
\hline Shield Diala Oil & 1,110 & $<500$ \\
\hline Shield Diala Oil & 1,150 & $<700$ \\
\hline
\end{tabular}


A description of the DARHT-II Vacuum System, partial pressure specifications, and total system pressures are given in the "DARHT-II Injector \&Accelerator Vacuum Systems Design \& Analysis Report" [20]. The majority of the gas load under vacuum for the injector was calculated and confirmed to be water. The specification for the water partial pressure was set at less than 50 nTorr, consistent with Turner's study. The only constituent with a lower specified partial pressure was Oxygen at less than $9 \mathrm{nTorr}$. The adopted average total pressure limit in the injector is $\leq 50 \mathrm{nTorr}$ with the cathode at operational temperature. Recent measurements of the total average pressure during operation have been less than $30 \mathrm{nTorr}$ with the partial pressure of $\mathrm{O}_{2}$ less than $3 \mathrm{nTorr}$. However pressures are measured on ion gauges some distance from the cathode and localized virtual leaks in the immediate vicinity of the cathode would be difficult to detect.

Metals in the vicinity of the cathode are limited to molybdenum, copper, and stainless steels. Of the three, only the steel is a source for poisoning. The anode and cathode shrouds are fabricated primarily of stainless steel because of its ability to support high electric field stress and low emission characteristics. The knife edge and extension spool of the cathode shroud are fabricated of copper to provide about a one-inch buffer between the cathode and the stainless steel portion of the shroud. It is possible that beam interception with the anode shroud or beam line could produce ions that would return to the cathode. To avoid this problem, considerable effort was expended in designing a transport system that minimized beam interception within the first several meters of the cathode. The injector has no diagnostics that could monitor ion bombardment during the pulse. Testing of the cathode after removal may be able to identify degradation due to ion bombardment.

A Miram plot and practical work function distribution [21] (PWFD) was constructed from measurements made on the first cathode installed in the injector. Although the shape of the PWFD did not indicate poisoning, the large thermal variation across the cathode would reduce the width of the PWFD and mask the effects of poisoning. 
Two additional techniques could be employed to improve the vacuum and lessen the possibility of cathode poisoning. A getter material could be introduced in the vacuum vessel at one or more of the available ports. This should essentially eliminate $\mathrm{H}_{2} \mathrm{O}$ from the background gas constituents. Second, electron-beam cleaning could be use in the diode region. A molybdenum or tungsten filament could be inserted into the diode region, heated, and biased to spray electrons over the metallic surfaces. This would dislodge both surface contaminants and contaminants just below the surface.

\section{BARIUM MIGRATION}

A dispenser cathode emits electrons when heated to high temperature. These emitted electrons constitute the tail of a Maxwell distribution with enough energy to overcome the surface potential (work function) barrier of the material. The body of the cathode consists of a high-temperature metal substrate, e.g. tungsten, with a surface impregnation of a material with a low work function, e.g. barium. Barium on the tungsten surface evaporates rapidly at high temperature and is replenished by the barium originally located below the surface.

The evaporated barium will eventually condense on cooler surfaces usually within lineof-sight of the cathode. This can be very dangerous for insulating surfaces as barium is conducting and would cause the insulator to fail. The DARHT-II design protects the column by distance from the cathode, hiding the insulating surfaces behind the cathode shroud, and further hiding the insulators behind grading rings.

Barium condensing on the cathode shroud presents a different issue. Shrouds are fabricated from materials with relative high work functions and their surfaces may be treated, e.g. greening, to further increase the work function. The condensed barium lowers the work function and increases emission. The shroud emission per unit area may be orders of magnitude smaller than the heated cathode surface, but the very large surface area of the shroud can lead to a total emission that can effect the beam current distribution and emittance. 
Operating with the cathode shroud at an elevated temperature will prevent the barium from condensing. However, too high of a shroud temperature will increase emissions from the original surface. Discussions with the Klystron Group at the Stanford Linear Accelerator Center and others indicated that temperatures between $200^{\circ} \mathrm{C}$ and $250^{\circ} \mathrm{C}$ would be sufficient to prevent barium condensation and not noticeably change the emission characteristics of the shroud.

Shroud temperature can be controlled through heat flow based on the cross sectional area of material and cooled mounting plates. Thermal analysis [22] of the cathode assembly indicated that temperatures should be $240^{\circ} \mathrm{C}$ and $250^{\circ} \mathrm{C}$ along the shroud surface from the inner diameter out to the high field stress region for a hot cathode. Thermal couples on the back surface of the shroud register temperatures of $200^{\circ} \mathrm{C}$ and $210^{\circ} \mathrm{C}$ during normal operations.

A less serious issue is accumulation of barium on the port windows used for the pyrometers. In time, the barium deposits will darken the windows leading to erroneously low temperature measurements. Regular in situ calibration of the pyrometers through the windows and/or window replacement will alleviate the problem. Cross checks between cathode heater power and measured temperature are an easy method to catch irregularities in temperature measurements.

\section{PERFORMANCE DATA}

\section{CATHODE TEMPERATURE PROFILES}

Figure B.2 shows a thermal image of the second cathode with the improved heat shields. The absolute scale of the image is suspect, but the relative temperature variation across the cathode is believed accurate. The readout of the FAR pyrometer that looks at the center of the cathode indicated a temperature of $1129^{\circ} \mathrm{C}_{\mathrm{T}}$. A recent recalibration of this 
pyrometer indicated that it was reading $20^{\circ} \mathrm{C}_{\mathrm{T}}$ low, i.e. the indicated temperature was actually $1149^{\circ} \mathrm{C}_{\mathrm{T}}$. The image indicates that the edge of the cathode is $25^{\circ} \mathrm{C}$ cooler than the center. During removal of the second cathode, there were indications of possible interference between the heat shields, cathode housing, and shroud that could have effected temperature uniformity.

\section{Perveance - voltage and current waveforms}

Figure B.3 plots the diode (source dome) voltage and the beam current measured at the first BPM (about $65 \mathrm{~cm}$ from the cathode) as a function of time for Shot \#2264. The perveance, defined as $I / \mathrm{V}^{3 / 2}$, is shown in Figure B.4 for this shot. Due to relativistic effects, the perveance of the diode is expected to be greater at lower voltages, e.g. the rise time, than during the flat top portion of the pulse. Immediately after installation, the cathode was capable of producing a perveance of $0.32 \mu$ pervs. Figure B. 5 shows the declining perveance with shot number.

\begin{tabular}{|c|c|c|}
\hline Gap $\backslash$ Temperature & Cold Cathode & Hot Cathode \\
\hline Radial & 20 mils & 18 mils \\
\hline Axial & 5.5 mils & 7.5 mils \\
\hline
\end{tabular}

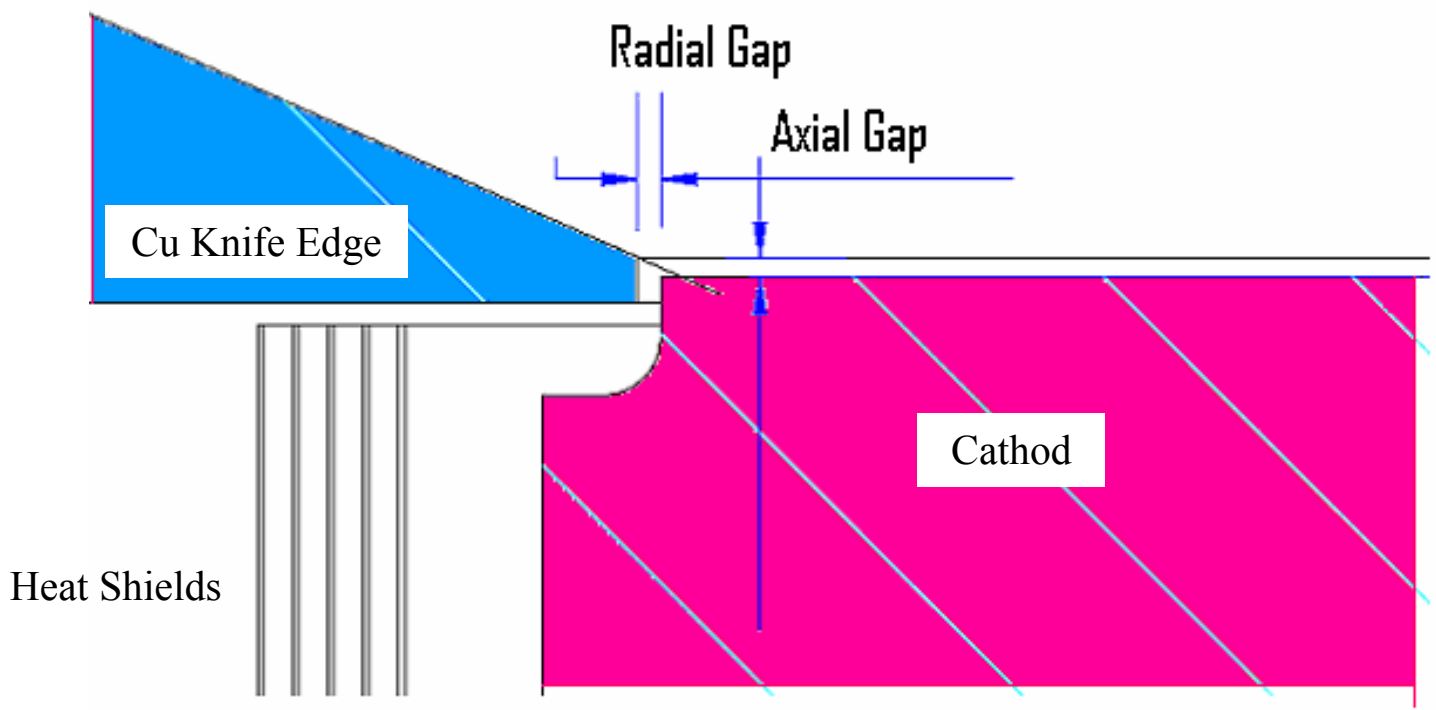

Figure B.1. Sketch of the relative position of the cathode shroud knife edge to the cathode. 
DARHT 2 CATHODE TEMPERATURE (DEG. C) FOR EMIS. $=0.66$

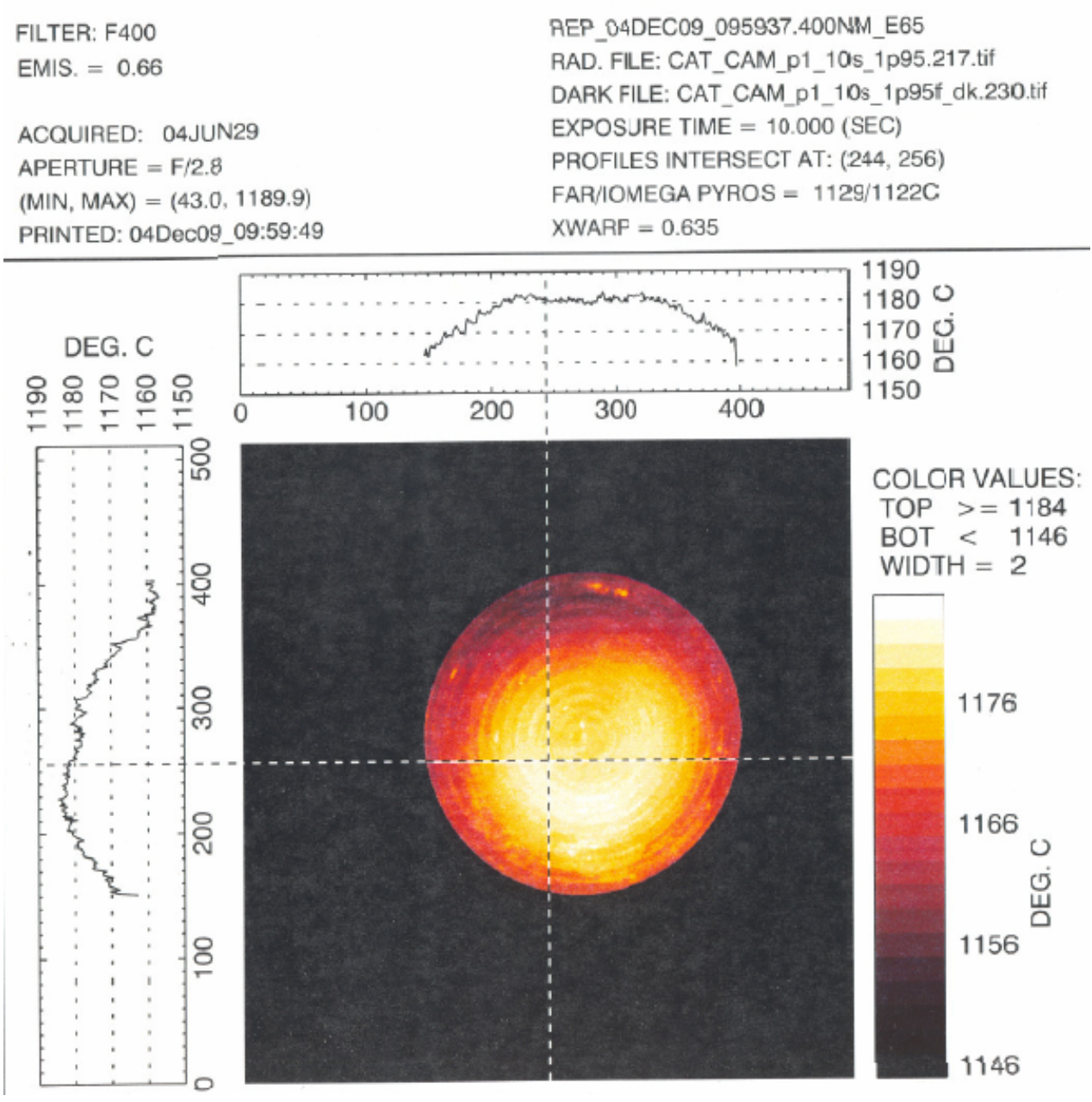

Figure B.2. Thermal imagery of the second cathode installed in the DARHT-II Injector at nominal operating temperatures. 


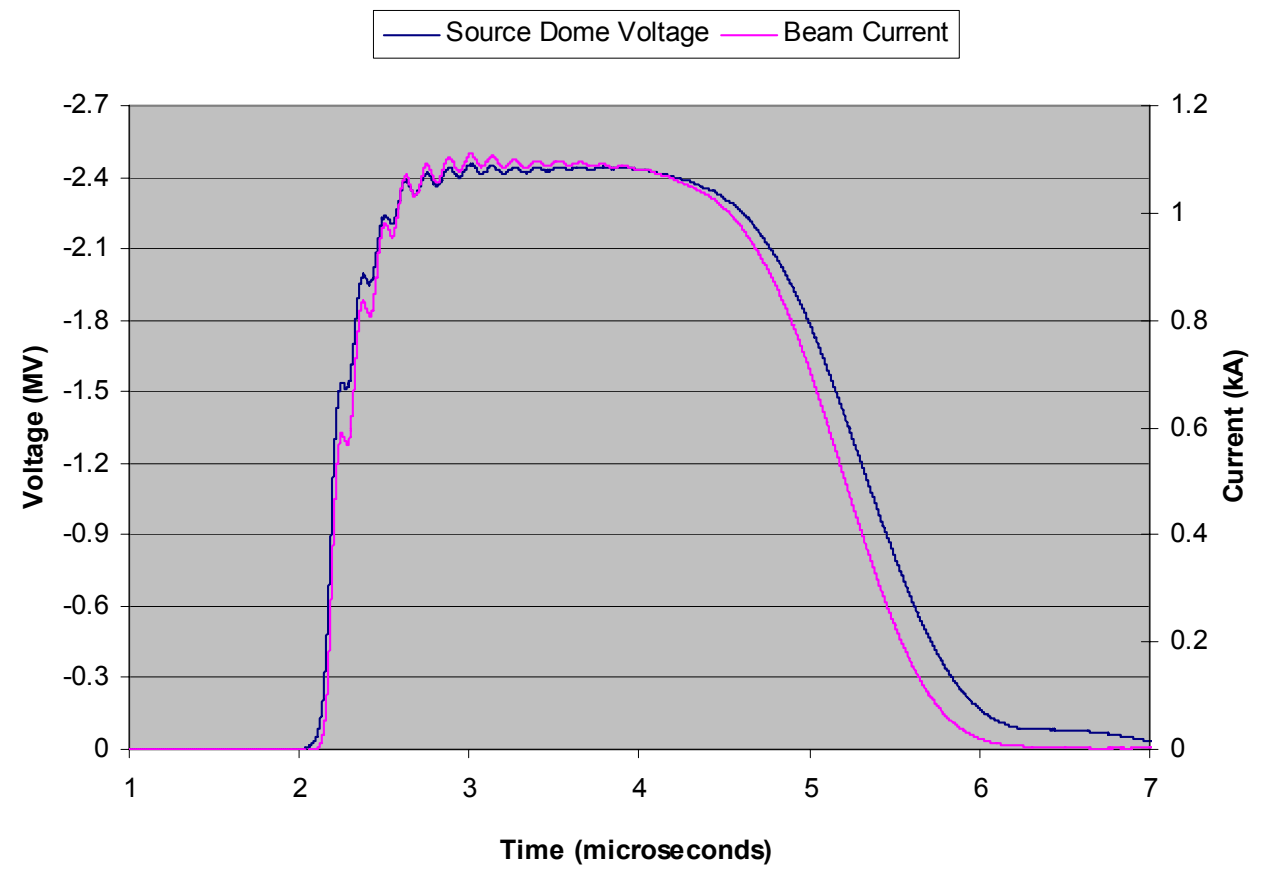

Figure B.3. Plots of the source dome voltage and the beam current as a function of time.

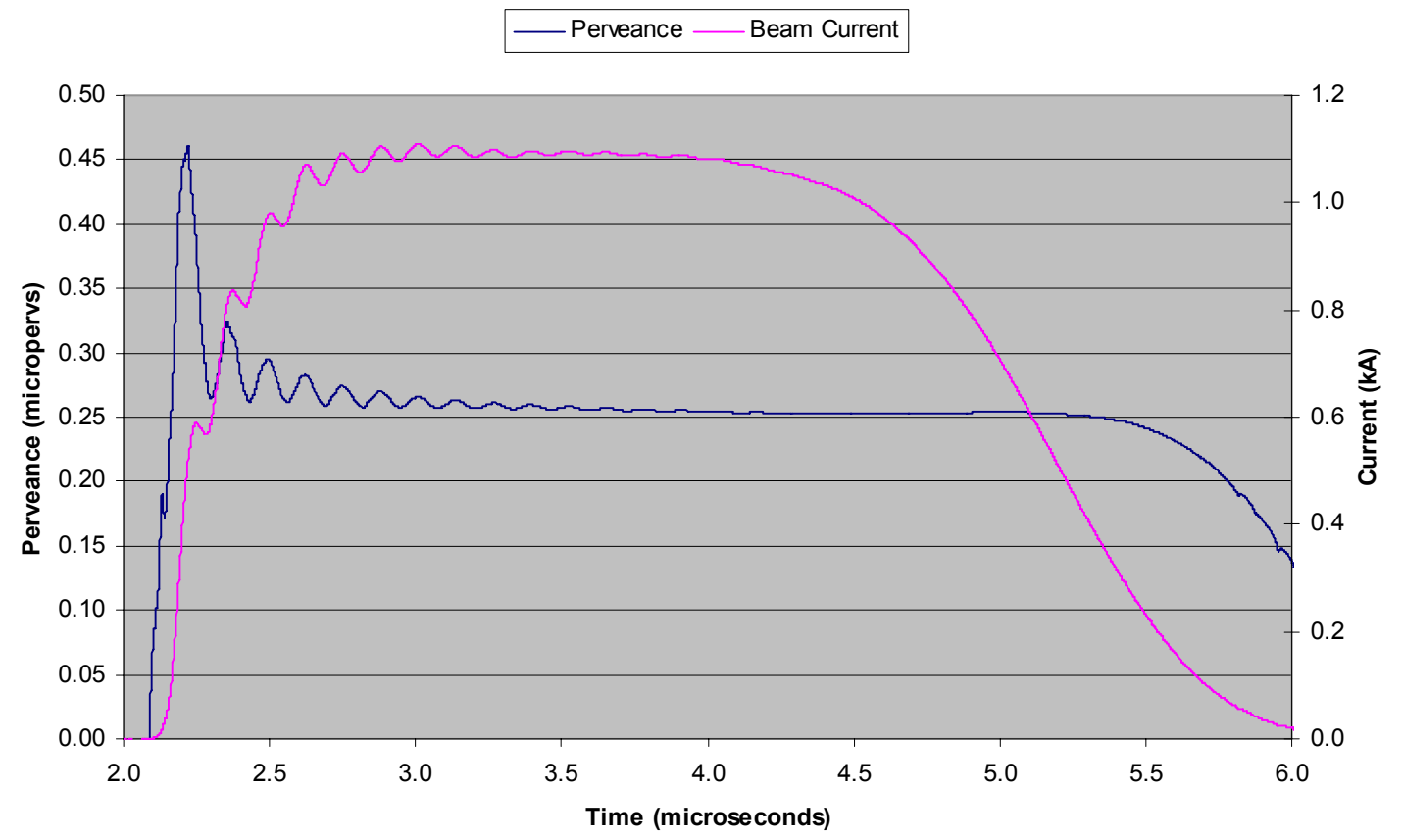

Figure B.4. Plots of the perveance $\left(\mathrm{I} / \mathrm{V}^{3 / 2}\right)$ and beam current as a function of time. 


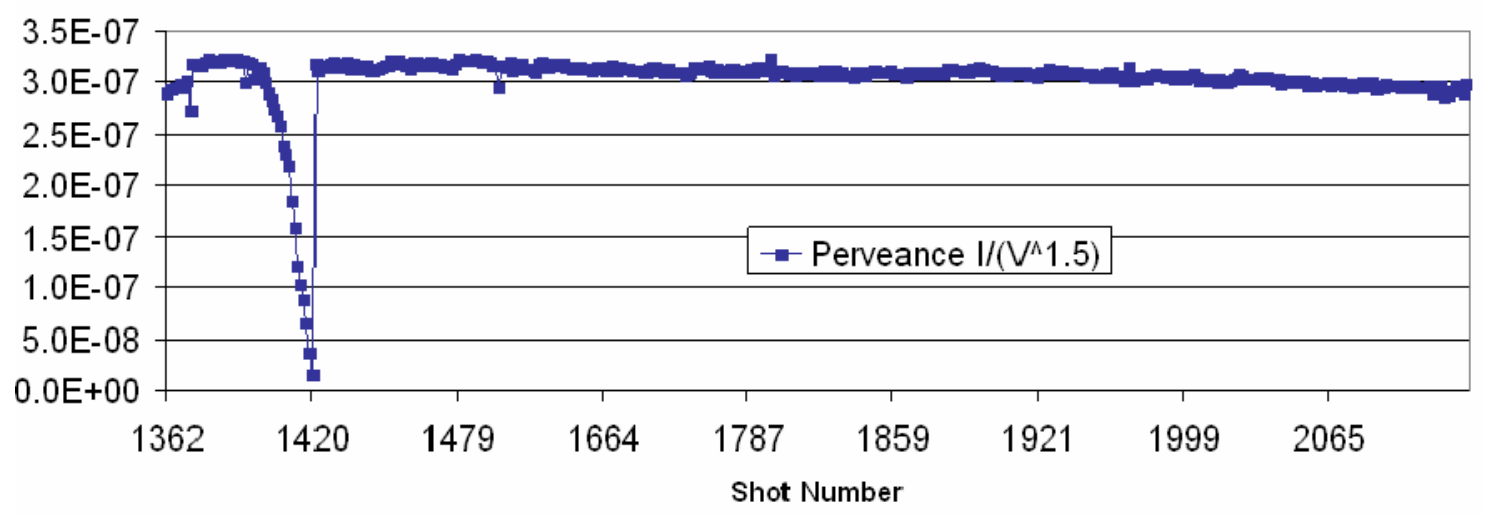

Figure B.5. Plot of perveance as a function of Shot number. Vertical axis is perveance in units of pervs.

\section{MIRAM CURVE}

Miram Curves for the first two installed DARHT-II cathodes are shown in Figure B.6. The associated Practical Work Function Distribution (PWFD) curves are plotted in Figure B.7. The diode voltage was greater by about $10 \%$ for the lower current measurements than for the higher current measurements due to the different beam loading. This would tend to make the PWFD curves look "wider", but should not be significant.

The PWFD for the first cathode, indicated uniform emission, but had a work function greater than a "B-type" cathode. The second cathode had a slightly lower work function, but still abnormally high. At lower temperatures, the emission drops off faster than expected and the resulting PWFD is very unusual. Possible causes [23] for this behavior would be a changing temperature variation across the cathode, rapidly changing osmiumruthenium emissive enhancement, or a combination of the two with cathode heater power. 


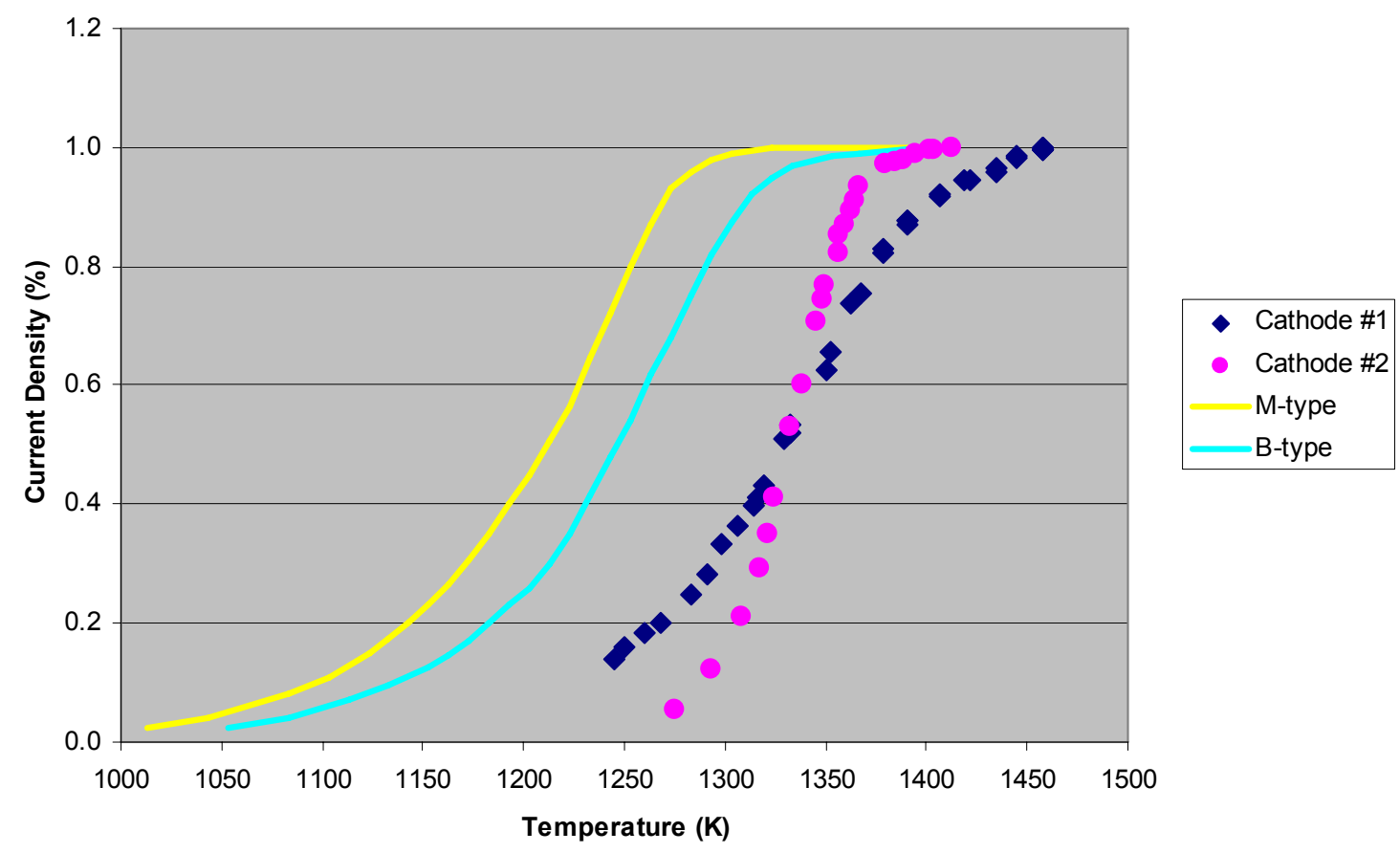

Figure B.6. Miram Curves for the DARHT-II cathodes compared to "Best of Class" Mtype $\left(8 \mathrm{~A} / \mathrm{cm}^{2}\right)$ and B-type cathodes $\left(4 \mathrm{~A} / \mathrm{cm}^{2}\right)$.

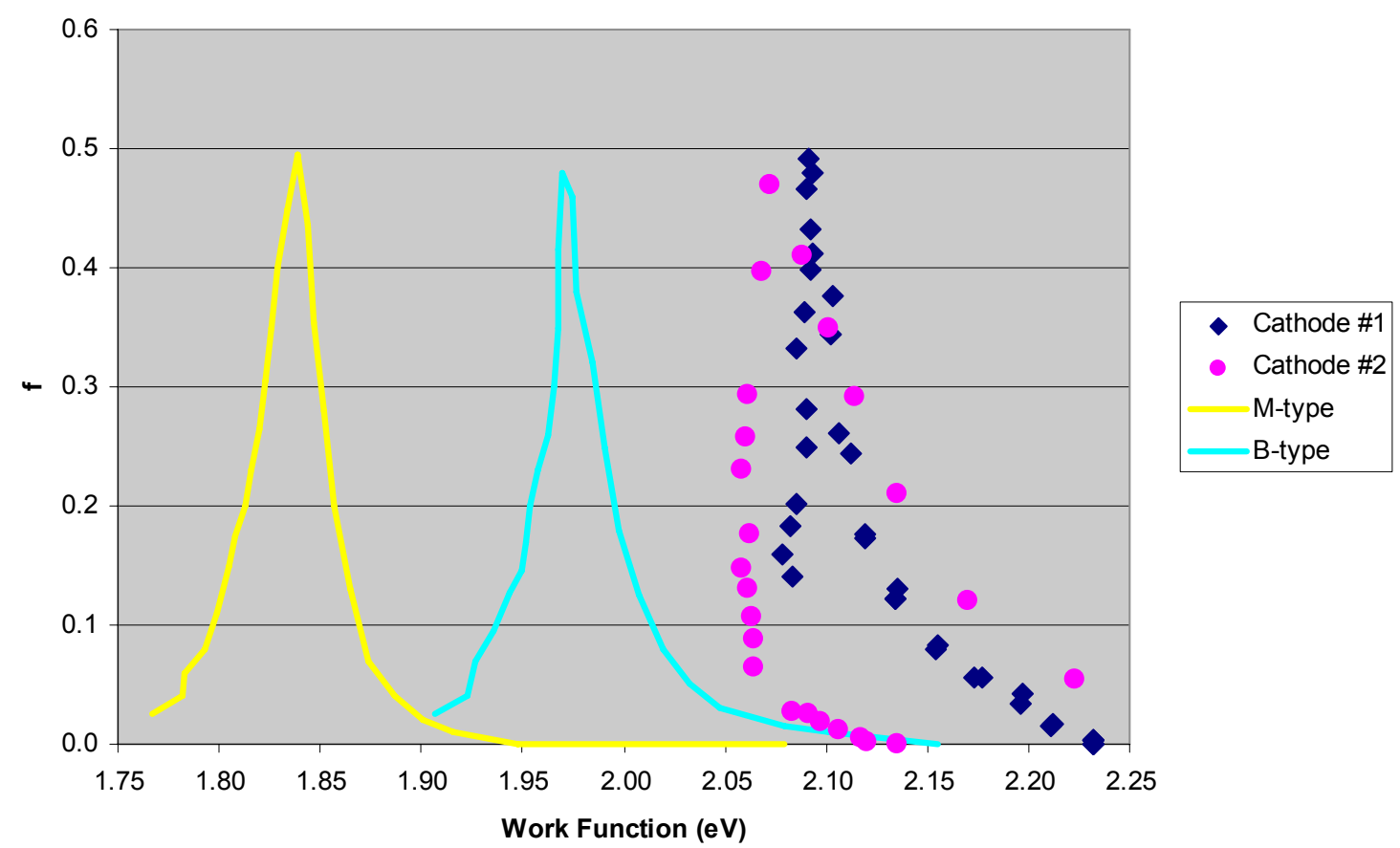

Figure B.7. Practical Work Function Distributions (PWFD) Curves for the DARHT-II cathodes compared to "Best of Class" M-type $\left(8 \mathrm{~A} / \mathrm{cm}^{2}\right)$ and B-type cathodes $\left(4 \mathrm{~A} / \mathrm{cm}^{2}\right)$. 


\section{References:}

[1] G. Westenskow, et al., "Double Pulse Experiment with a Velvet Cathode on the ATA Injector", Proceedings of the 1995 Particle Accelerator Conference, pp. 1027-1029, 1995

[2] M.J. Burns, et al., "Status of the Dual Axis Radiographic Hydrotest Facility", Proceeding of the $18^{\text {th }}$ International Linear Accelerator Conference, Geneva, Switzerland, August 1996

$\left.{ }^{[3}\right] \quad$ T.P. Hughes, D.R. Welch, and R.L. Carlson, "Diode and Final-Focus Simulations for DARHT”, Proc. 1997 PAC, Vancouver, B.C., Canada, 1997 (DARHT Technical Note 069)

[4] T.P. Hughes, R.E. Clark, and S.S. Yu, "3-D Calculations for a 4 kA, 3.5 MV, 2.5 Microsecond Injector”, Proc. 1999 PAC, New York, pp. 2748-2748, 1999 (DARHT Technical Note 110)

[5] S. Eylon, E. Henestroza, W. Fawley, and S. Yu, "Time Dependent Beam Focusing at the DARHT-II Injector Diode”, Proc. 1999 PAC, New York, pp. 1934-1936, 1999

[6] C. Fortgang, C. Hudson, D. Macy, M. Monroe, K. Moy, and D. Prono, "The Cathode Test Stand for the DARHT Second-Axis", Proc. $19^{\text {th }}$ Linear Accelerator Conf., Chicago, Il, pp. 171-173, 1998

[7] S.M. Lidia, et. al., " Initial Commissioning Results of the RTA Injector”, Proc. 1999 PAC, New York, pp. 3390-3392, 1999

[8] E. Henestroza, "Injector Physics Design", DARHT $2^{\text {nd }}$ Axis Injector Workshop, LANL, Slides 8-10, 15 April 2003

[10] C. Peters, "Injector - Cathode - Thermal Analysis of Cathode Structure", LBNL Mechanical Memo 8022, 9 November 2001, and DARHT Technical Note 339 
[11] W.M. Fawley and M.E. Stuart, "Physics Design for the DARHT-II Anode Solenoid, Dipole Corrector and Quadrupole Corrector Magnets", DARHT Technical Note 236

[12] E. Henestroza, "Injector Physics Design", DARHT 2 ${ }^{\text {nd }}$ Axis Injector Workshop, LANL, Slides 17-19, 15 April 2003

[13] J.L. Cronin, "Modern Dispenser Cathodes", IEE Proc. Vol. 128, No.1, p.19, 1981

[14] C. Peters, "Injector-Dispenser Cathode Performance Specification”, DARHT Technical Note 351

[15] D.F. Simmons and C.M. Fortgang, "Using Multispectral Imaging to Measure Temperature Profiles \& Emissivity of Large Thermionic Dispenser Cathodes", DARHT Technical Note 192

[16] C.M. Fortgang, "Thermal Imaging and Current Emission Measurements on a Large Thermionic Dispenser Cathode", presented at the DARHT II Risk Reduction Workshop, LLNL, 29 August 2001

[17] T. Houck, "Cathode Heating and Related Diagnostic Testing in support of the DARHT-II Injector Commissioning", DARHT Technical Notes 258

[18] W.E. Nexsen and W.C. Turner, "Poisoning Studies of an Osmium-Coated Dispenser Cathode", Journal of Applied Physics, Vol. 68 (1), pp. 298-303, 1 July 1990

[19] J.C. Clark, et al., "Design and Initial Operation of the ETA-II Induction Accelerator", Proc. 1988 LINAC Conference, Williamsburg, VA, Oct 1988 (UCLR-99042, Lawrence Livermore National Laboratory)

[20] P. Shoaff Jr. and K. Kishiyama, "DARHT-II Injector \& Accelerator Vacuum Systems Design \& Analysis Report”, DARHT Technical Note 249

[21] M. Cattelino and G. Miram, "Predicting cathode life expectancy and emission quality from PWFD measurements", Applied Surface Science, Vol. 111, pp. 9095, 1997

[22] C. Peters, "Injector - Cathode - Thermal Analysis of Cathode Structure", LBNL Mechanical Memo 8022, 9 November 2001, and DARHT Technical Note 339

[23] Private conversations with George Miram, September 2005 


\section{Appendix C \\ Activation Process for the DARHT 311-X type cathode}

- Before starting, make sure that the vacuum is good. Lower vacuum is always better and it should be at least in the low $10^{-7}$ Torr range.

- Increase the Cathode Heater Power in small increments (typically $0.05 \mathrm{~kW}$ per step) while keeping the injector vacuum stabilized below $3 \times 10^{-7}$ Torr.

- When the Cathode Heater Power set point reaches $0.4 \mathrm{~kW}$, hold this Power setting for 12 hours (overnight). The vacuum must be stabilized before resuming Heater Power ramp and pressure control.

- Ensure the FAR Pyrometer is on when Heater Power reaches $1 \mathrm{~kW}$.

- When the Far Pyrometer reads a stable temperature of $875 \pm 25^{\circ} \mathrm{C}$, hold the Cathode Heater Power constant for 8 hours. The vacuum must be stabilized before resuming Heater Power ramp and pressure control.

- When Far Pyrometer temperature reaches $1025^{\circ} \mathrm{C}$ (nominal operating temperature) hold this power setting and temperature for 8 hours (overnight). The vacuum must be stabilized before resuming Heater Power ramp and pressure control.

- When Far Pyrometer temperature reaches $1050^{\circ} \mathrm{C}$ hold this power setting and temperature for 2-4 hours or more until the temperature stabilized.

- The activation is done when the vacuum is also stabilized.

- Either lower temperature to nominal operating temperature for beam extraction, or turn down to standby mode at $875 \pm 25^{\circ} \mathrm{C}$.

Notes:

1. If at any time it is felt there is a need to vary from this process, check first with Trent McCuistian and Ray Scarpetti before instituting changes.

2. This process assumes around the clock activation without planned interruption.

3. A time-stamped printout of the RGA spectrum will be taken every half hour and collected in a binder for the entire duration of the cathode \#4 activation.

4. The purpose of the hold at $0.40 \mathrm{~kW}\left(\sim 400^{\circ} \mathrm{C}\right)$ is to break down the hydrates formed with the barium-calcium-aluminates in order to out-gas the hydrated water.

5. $0.40 \mathrm{~kW}$ is an approximate value determined by LBNL on their Cathode Test Stand, and a more refined value may be available at the start of activation.

6. If the pressure goes above $3 \times 10^{-7}$ torr, back off on the heater power to the cathode until the pressure recovers.

7. The purpose of the hold between $850^{\circ} \mathrm{C}$ and $900^{\circ} \mathrm{C}$ is to allow $\mathrm{W}_{2} \mathrm{O}_{5}$ to break down and combine with any available hydrogen, reducing the tungstate to clean tungsten as well as reducing any residual carbonates found in the impregnant. Care must be taken to assure the temperature approaches but does not exceed $900^{\circ} \mathrm{C}$.

8. Temperature reading from the pyrometer indicates "brightness" temperature, the true temperature can be 50 deg higher depending on the surface emissivity. 
9. Steve Eversole will request Jim Harrison to produce an activation summary spread sheet which will collect the following data every half hour plus every time the cathode heater power is changed: Pyrometer Temp 2. Heater PS Power, Heater PS Filament I, Mounting Plate Temp, Shroud Temp 2, Shroud Temp 4, Injector Tank Ion Gauge Press 1, Injector Tank Ion Gauge Press 2, Injector Tank Ion Gauge Press 3, Injector Tank Ion Gauge Press 4,

10. Since we are not bringing the cathode to the $1200^{\circ} \mathrm{C}$ level, the activation is considered a slow one and the cathode may continue to improve it emission characteristic over time. It is recommended, as soon as is practicable, to characterize the emission by plotting beam current density vs. cathode temperature at the lowest possible beam voltage (around $2 \mathrm{MV}$ for DARHT). The administrative limit is $1100^{\circ} \mathrm{C}$. The "Miram Plot" and the practical work function distribution (PWFD) thus produced will characterize the cathode and can be used to predict it performance at higher beam voltage. 


\section{Appendix D \\ Activation Process for the DARHT cathode \#4 April 27, 2006}

Approved

Ray Scarpetti

Date

Approved

Trent McCuistian

Date 
Activation Process for the DARHT cathode \#4:

- Increase the Cathode Heater Power in small increments (typically $0.05 \mathrm{~kW}$ per step) keeping the injector Vacuum at or below $3 \times 10^{-7}$ Torr.

- When the Cathode Heater Power set point reaches $0.40 \mathrm{~kW}$, hold this Power setting for 12-16 hours before resuming Heater Power ramp and pressure control.

- Ensure the FAR Pyrometer is on when Heater Power reaches $1 \mathrm{~kW}$.

- When the Far Pyrometer reads a stable temperature of $875 \pm 25^{\circ} \mathrm{C}$, hold the Cathode Heater Power constant for 12-16 hours before resuming Heater Power ramp and pressure control.

- When Far Pyrometer temperature reaches $1000^{\circ} \mathrm{C}$ hold this power setting and temperature for 2 hours before resuming Heater Power ramp.

- When Far Pyrometer temperature reaches $1100^{\circ} \mathrm{C}$ hold this power setting and temperature for 2 hours

- The activation is considered finished at this point.

Notes:

1. If at any time it is felt there is a need to vary from this process, check first with Trent McCuistian and Ray Scarpetti before instituting changes.

2. This process assumes around the clock activation without planned interruption.

3. A time-stamped printout of the RGA spectrum will be taken every half hour and collected in a binder for the entire duration of the cathode \#4 activation.

4. The purpose of the hold at $0.40 \mathrm{~kW}\left(\sim 400^{\circ} \mathrm{C}\right)$ is to break down the hydrates formed with the barium-calcium-aluminates in order to out-gas the hydrated water.

5. $0.40 \mathrm{~kW}$ is an approximate value determined by LBNL on their Cathode Test Stand, and a more refined value may be available at the start of activation.

6. If the pressure goes above $3 \times 10^{-7}$ torr, back off on the heater power to the cathode until the pressure recovers.

7. The purpose of the hold between $850^{\circ} \mathrm{C}$ and $900^{\circ} \mathrm{C}$ is to allow $\mathrm{W}_{2} \mathrm{O}_{5}$ to break down and combine with any available hydrogen, reducing the tungstate to clean tungsten as well as reducing any residual carbonates found in the impregnant. Care must be taken to assure the temperature approaches but does not exceed $900^{\circ} \mathrm{C}$.

8. Steve Eversole will request Jim Harrison to produce an activation summary spread sheet which will collect the following data every half hour plus every time the cathode heater power is changed: Pyrometer Temp 2. Heater PS Power, Heater PS Filament I, Mounting Plate Temp, Shroud Temp 2, Shroud Temp 4, Injector Tank Ion Gauge Press 1, Injector Tank Ion Gauge Press 2, Injector Tank Ion Gauge Press 3, Injector Tank Ion Gauge Press 4,

9. Since we are not bringing the cathode to the $1200^{\circ} \mathrm{C}$ level, the activation is considered a slow one and the cathode may continue to improve it emission characteristic over time. It is recommended, as soon as is practicable, to characterize the emission by plotting beam current density vs. cathode temperature at the lowest possible beam voltage (around $2 \mathrm{MV}$ for DARHT). The administrative limit is $1100^{\circ} \mathrm{C}$. The "Miram Plot" and the practical work function distribution (PWFD) thus produced will characterize the cathode and can be used to predict it performance at higher beam voltage. 


\section{Appendix E}

\section{Cathode handling and record keeping}

The cathode contains $\mathrm{BaO}$ which can be easily poisoned by moisture and other contaminants. To insure optimum performance, the cathode should not be exposed to atmospheric conditions for too long. There is no sharp threshold for this, and to be accurate, one would have to specify the moisture and particulates content in the air, flow rate, etc. Therefore the basic principle is to minimize exposure. The most recent bulletin from SpectraMat suggested limiting the exposure to less than 48 hours, but their earlier version indicated 8 hours.

For storage, the cathode should be kept in inert gas such as nitrogen or argon, or alternatively in a partial vacuum of $10^{-3}$ torr or better. Since this level of vacuum is difficult to verify from the gauge on the shipping container, the inert gas method is preferred.

All direct handling should be done with reasonable clean room processes, e.g., wear clean gloves (use the type without powder) and a lab coat, and if possible work in a room with filtered air. Avoid touching the cathode surface. In case if any debris is found on the surface, use a pair of tweezers to remove it or use dry nitrogen to gently blow it off. A vacuum cleaner with a clean tip may also work well. Do not try to "clean" or wipe the surface. For protection, use UHV grade aluminum foil instead of lint free paper. The UHV foil shall be essentially free from contamination and residual rolling oils (certified to ASTM B479 (3.1.4 \& 10.3.1).

Apply the principle of 5P's (Prior Planning Prevent Poor Performance) to minimize the exposure time and reduce risk of damage. This often means using a dummy for a trial run to practice beforehand, or make a special fixture to hold the cathode in place. In some case, setting up a staging area with inert gas purge will help to reduce the exposure to moisture.

We want to keep detail records on the history of each cathode, starting from the beginning when it was made in the factory, to the end of its useful life. Perhaps the best way is to write things down on a log book that follows the cathode wherever it goes. Of course any potential damage must be recorded and no entry is too trivial to be included. As a guide, enter the date, time, the worker's name, what was done to it, how much was the estimated time of exposure, and the work environment. Also write down the condition of the cathode (visual description) before and after working on it, and how and where it was stored afterward.

After the cathode is installed on a test stand for operation, the record keeping should continue. We would like to know what kind of base pressure is in the vacuum system, the main components that show up in the RGA, the number of hours while the cathode is hot, and typical emission current and pulse length. Obviously, any vacuum leak incident, 
or frequent high voltage breakdowns (inside the injector region) must be recorded in the $\log$ book. 


\section{Handling and usage records of the DARHT cathode \#4}

Entry made by: Matthaeus Leitner

$4 / 10 / 2006$

The cathode vacuum shipment container had been opened by Ken Chow and Dave Anderson briefly (15 minutes) when it arrived the first time. I was not present at that time.

Entry made by: Matthaeus Leitner

$4 / 10 / 2006$

9:57 am up to air

10:25 am under vacuum

total exposure time: 28 minutes

handling according to UHV practice, cathode surface never got touched

Notes: put cathode on source mounting flange, measured alignment on CMM

Entry made by: Matthaeus Leitner

$4 / 11 / 2006$

$12: 10 \mathrm{pm}$ up to air

1:05 pm under vacuum

$1: 10 \mathrm{pm}$ up to air

$1: 45 \mathrm{pm}$ under vacuum

total exposure time: 90 minutes

handling according to UHV practices, cathode surface never got touched

Notes: put cathode on source mounting flange, measured alignment on CMM, brought cathode within alignment specs, after alignment: installed heater lead feedthroughs, put briefly under vacuum during heater lead installation since we had to look for installation hardware, installed finished cathode in larger shipping container, mounted UHV cleaned heatshield, sent to Los Alamos 